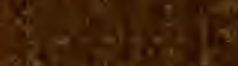

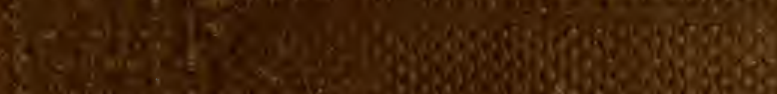

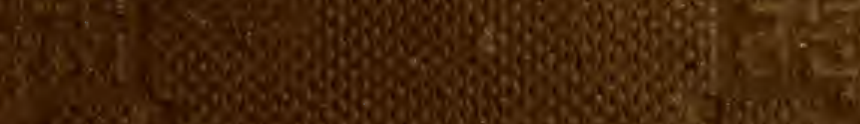

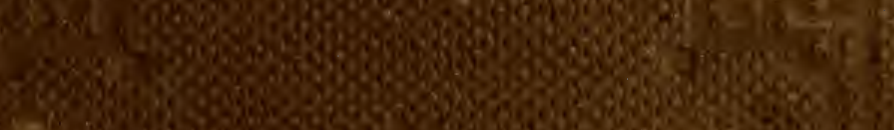

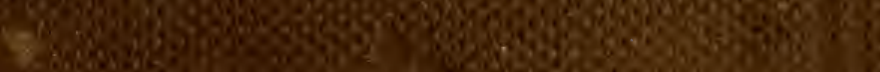

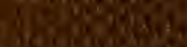

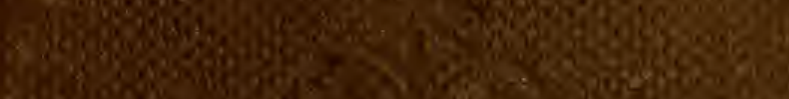
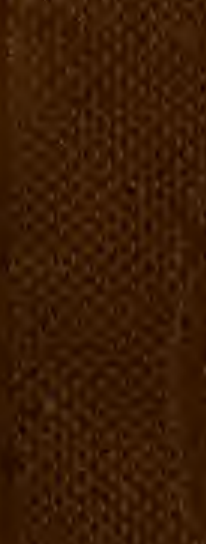

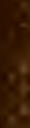

37

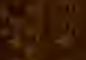

8

$\frac{8}{9}$

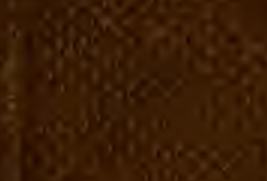

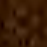

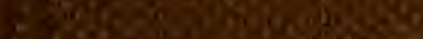

8

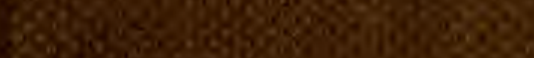

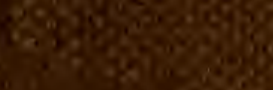

C.

$x$

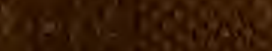

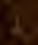

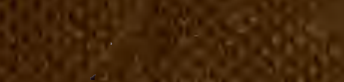

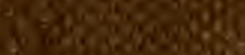

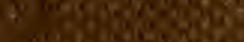

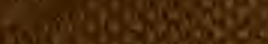

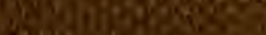

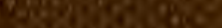

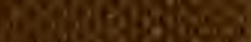

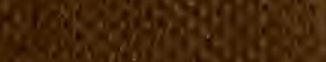

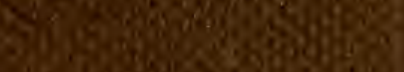

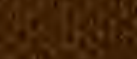

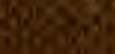

$$
\text { 183 }
$$





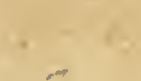

$-$

$\sqrt{2}$

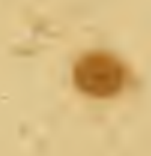

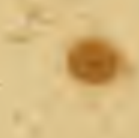

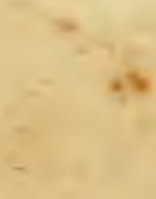

$+2$

*

*s

s

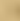

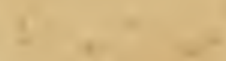

s.

t
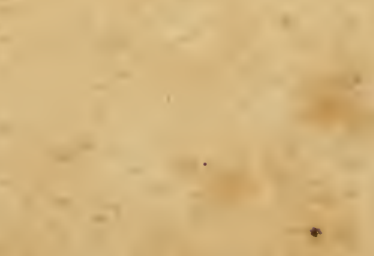

$+$
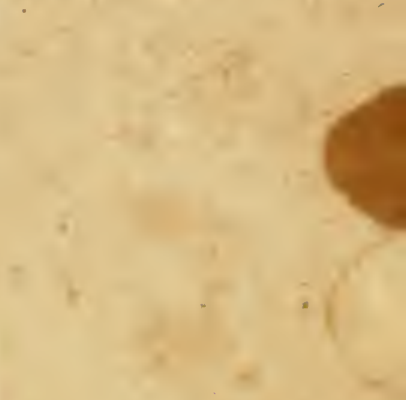

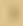

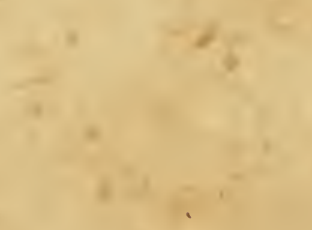

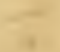

s
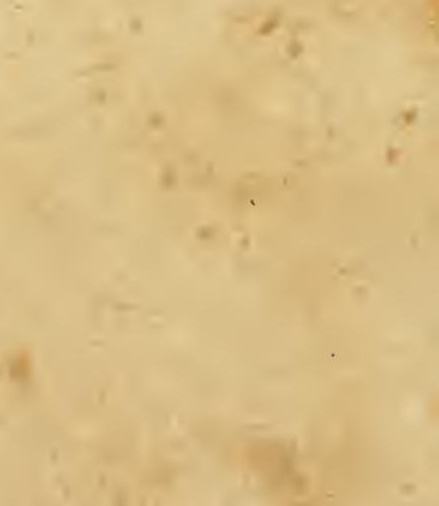

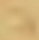

$*$
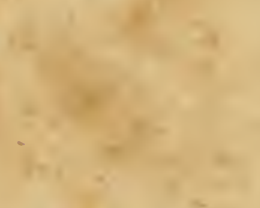

$\bullet$

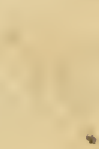

b

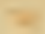

$\checkmark$

$+$
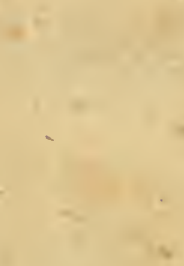

-

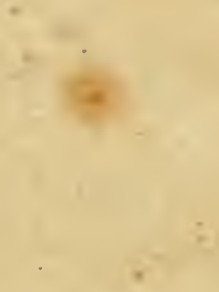

4
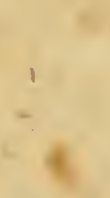

a
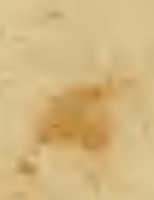

12
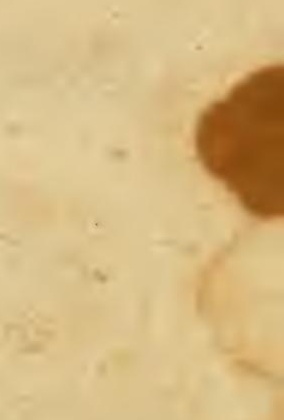



\section{THE}

\section{FARUER'S OWN BOOK:}

A TREATISE ON THE

Numerous Diseases of the Horse,

IVITH $\triangle N$

EXPIANATION OF THEIR SYMPTOMS,

AND THE

COURSE OF TREATMENT TO BE PURSUED;

ALSO -A TREATISE ON THE DISEASES

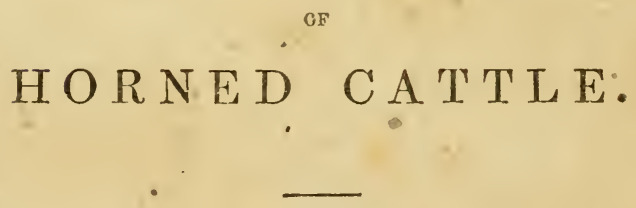

-

PUBLISHED BY

$$
\text { J. D. KOOGLE, }
$$

Middletown, Maryland. 
ENTERED according to the Act of Congress in the year 1857, BY J. D. KOOGLE, In the Clerk's Office of the District Court of Maryland. 


\section{P R E F A C E.}

The object of this work is to give a thorough explanation of the numerous diseases to which the horse is subject, and point out in a clear and distinct manner the symptoms by which the diseases may be known, so that the Farmer and others having the care of horses may be enabled to detect any disease in its first stages, - thereby rendering it an easy case to cure; also, giving a regular course of medicine to be pursued in the treatment of the different diseases, by which almost any one, with a little study, can treat the most difficult cases. The great objection to other works that have been issued is that they do not point out the symptoms of the diseases in horses; and their treatment is so badly arranged that it is very difficult for the Farmer and persons generally to understand it. The advantages this work possesses over others, is its plainness in pointing out the diffculties attending the treatment of diseases in horses and the manner in which they may be surmounted. And it is hoped that those interested will give this book their careful attention, as the author is satisfied that it will save them a vast amount of time and trouble in times of need.

THE AUTHOR. 


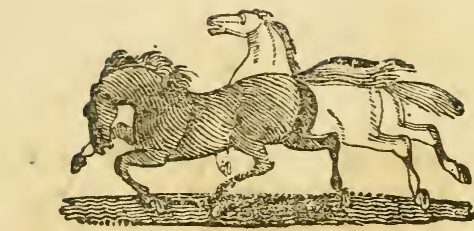

\section{DISEASES OF HORSES.}

The diseases of the horse are very numerous, and many of them so complicated as to defy detection; except by those who are thoroughly acquainted with the nature of the animal, and his mode of living. This is the reason that horses which have been under the care of the farrier are often returned to the owner in a worse condition than when they received them. It is to prevent this practice as much as possible that has induced me to bring this work before the public, in the hope of alleviating the condition of that noble animal-the Horse. 


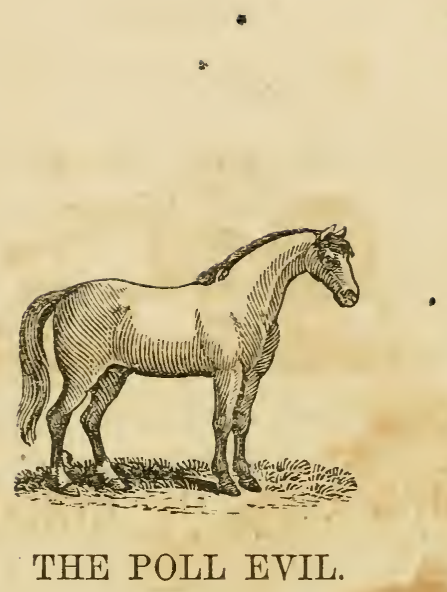

This disease may arise from accident, but is commonly the result of blows or bruises carelessly inflicted by those having charge of the horses. It is a tumor or swelling in the sinews, found between the noll bone and the uppermost joint of the neck, immediately on the nap of the neck.

Nearly all farriers tell you to sell your horse for anything he will bring, or give him away; but I would advise you to keep your horse and cure him, which can be done quickly and surely with the following remedies: 


\section{REMEDY No. 1.}

First wash the sore well with strong warm soap suds, then drop 8 or 10 drops of muriatic acid in it twice a day, until it has the appearance of a fresh wound, after which it should be washed clean with soap suds from castile soap and then left to heal, which it will quickly do if the acid has been used long enough in a proper manner; but it it does not get well, wash as before, and apply the acid until a cure is effected. It is a sure remedy, and will not fail if applied properly until the disease is burnt out or killed.

In case you should drop any of the acid on the part that is not affected, apply a little oil, which will neutralize the power of the acid and prevent it from becoming sore.

\section{REMEdy No. 2.}

When the disease first makes its appearance, take a quantity of asmart and put it to soak, letting it remain all night. In the morning take as much as you can hold in your hand and apply it to the swollen part, holding it there some 20 or $30^{\circ}$ minutes, pressing on it as hard as 
you conveniently can, which must be repeated several times. This remedy generally scatters the disease, but if it should fail you will be obliged to use applications of a more astringent nature.

\section{REMEDY No. 3.}

After the disease has fully shown itself, wash as directed in Remedy No. 1; then take Arsenic and apply it until the foul flesh has all disappeared, and let it heal. This is a certain reme$\mathrm{dy}$, and has cured several cases within my own knowledge.

\section{Revedy No. 4.}

Take 1 quart of strong ley and boil it into a salve, then apply a portion of the salve every 2 hours until the core comes out, and heal with elder ointment. If this remedy does not effect a cure on the first application, try it again, as it is a certain cure. Should the ley after being boiled down leave a hard substance, it must be worked into a salve. 


\section{REMEDY No. 5.}

First wash the ulcer well with warm soap suds; then take air-slacked lime and put as much into the sore as will lay on, which must be repeated 2 or 3 times a day, and the affected part cleaned and swabbed out as often. This, though very simple, is an excellent remedy, which I have never known to fail.

The foregoing remedies are very plain and simple, and cannot fail if properly applied. In washing the ulcers, use none other than castile soap, which is far superior to any other for cleansing and healing wounds and eruptions of any kind, and can be had.from any of the drug stores at $2 \check{5}$ cents per pound. It is also an excellent article for domestic purposes, such as shaving, \&c. and will be found cheaper than any other fine or toilet soaps. 
FLATULENT OR WIND COLIC.

\section{FLATULENT OR WIND COLIC.}

This is an entirely different disease from the Spasmodic Colic. It often originates with something that the horse has eaten and then drinking large quantities of water, by which the food becomes fermented and creates a gastric gas, which enlarges to a greater or less extent, sometimes to twenty or thirty times the bulk of the food. It generally takes place in the stomach, but at times in the small or large intestines.

\section{STMPTOMs.}

The horse suddenly slacks his pace, perhaps lays or falls down as if he were shot. In the stable he paws the floor with his fore feet, lays down and rolls, starts up instantly and throws himself down again with greater violence, looks wistfully at his flanks, and makes many fruitless efforts to void his urine. Here the symptoms are similar to other colics, but the true character of the disease soon develops itself.- 
It is in one of the large intestines, and the belly swells all round, but mostly on the right flanks and as the disease progresses the pain becomes more intense, and the horse more violent. The treatment is quite different from other colics.

\section{Remedy No. 1.}

Take 1 ounce of the chlorate of lime and $\frac{1}{2}$ pint of warm water, put it into a bottle and shake well, so as to dissolve, then give it as a drench which will derour the gas, and cause the swelling to subside. If in fifteen minutes after this has been given, the pain does not seem to have been alleviated, take 4 ounces of spirits of Pimento, and 1 ounce of Laudanum, mix it with $\frac{1}{2}$ pint of warm water and give it also as a drench. If you have no pimento and it is not convenient to get. it, take $2 \frac{1}{2}$ ounces of peppermint, and 1 ounce of Jaudanum, and should you not have laudanum, take a larger quantity of peppermint with $\frac{1}{2}$ pint of warm water, and give it as a drench. In this disease no time should be lost, as it very often runs its course in from 1 to 2 hours. If the first should not give 
relief in 15 or 20 minutes, repeat it until it does. Rubbing the belly with a smooth rail or pole will greatly facilitate the action of the medicine. Should you not have any of the above remedies on hand or convenient, use from 1 to 2 ounces of golden tincture as the case may require.

\section{REMEDY No. 2.}

In the first place take 2 ounces of the essence of peppermint, mixed with $\frac{1}{2}$ pint of warm water and give it to him as a drench, then take a bat of common raw cotton and set fire to it, holding it close to the nostrils of the horse, so that he can freely inhale the smoke arising therefrom; continue this until you see that the horse is relieved. The quantity of cotton used is from 4 to 5 bats, as the necessity of the case may require.

This is a simple and safe remedy, and numbers who have tried it say that they have never known it to fail. I saw a horse that had suffered from the colic for nearly three hours, being puffed up almost to bursting, and in half an hour after this operation had been performel on him, he was completely cured. 


\section{SPASMODIC COLIC.}

This is a disease to which horses generally are subject, and in consequence of improper treatment, it often proves fatal. It is produced by improper riding, feeding, watering, and may arise from a want of proper action in the bowels, which occasions constriction of the intestines and a confinement of the air.

\section{SYMPTOMS.}

The horse begins to shift his position, looks around at his flanks, paws violently, strikes his belly with his feet, and crouches in a peculiar manner, advancing his hind legs under him, he then suddenly lies or rather falls down, and balances himself on his back with his feet resting on his belly. The pain seems to have ceased for a while, and he gets up and shakes himself; he begins to feed, but in a short time the pain returns, and is more violent than before; he heaves at the flanks, breaks out in a profused 
perspiration, and throws himself more recklessly. The pulse is little affected in the commencement, but as the disease progresses, it becomes full. Legs and ears of a natural temperature. The affection of the strength scarcely perceivable.

\section{REMEDY.}

Relief may be obtained from motion in this disease. Take
1 ounce of turpentine,
1 ounce of laudanum,
$\frac{1}{2}$ pint of gin or good whiskey,
$\frac{1}{2}$ pint of warm water.

Mix and give it as a drench. Bleed, and if not relieved in half an hour, repeat the dose, rubbing the belly with a stout brush or a smooth rail. If not relieved in 15 or 20 minutes, repeat the dose and continue it until relief is obtained. If the horse be walked about or trotted moderately, it will relieve the spasms. A glyster with warm soap suds should be injected, which may be done by burning the peth out of elder, and filling a bladder with the suds, then tie the 
bladder on the elder tight and force it into the fundament, occasionally throwing the warm suds in until it operates; if a reasonable portion of it remains, it will do no harm if it does not operate, but will help to relieve the spasms. This should be done immediately, as in most cases no time is to be lost. A glyster of tobacco smoke may be thrown in as a last resort. Keep the horse in a warm stable and give bran mash and plenty of warm or thin gruel for two or three days.

The turpentine, laudanum, gin and warm water were never known to fail if given at the proper time. Should you not have these medicines at hand, give $2 \frac{1}{2}$ or 3 ounces of peppermint every 15 or 20 minutes until the horse is relieved; or if you have no peppermint, give same quantity of golden tincture.

The gruel for feeding is made by putting auy quantity of bran into a bucket or tub, then pour boiling water over it, so as to scald it thorough$1 y$, and cover it with a cloth until it is cooi enough for him to eat. 


\section{INFLAMMATION OF THE BLADDER.}

In this disease and inflammation of the kidneys, the symptoms are nearly similar; therefore, in order to ascertain whether the disease is inflammation of the bladder or inflammation of the kidneys, it is necessary to introduce the hand into the rectum, where you will find the bladder immediately under the hand, if it feels hard and full, accompanied by more than natural heat and tenderness, it is a sure case of inflammation of the bladder, but if the bladder is empty and no increased heat is apparent, then it must be a case of inflammation of the kidneys.

In treating these two diseases-though the symptoms are so much alike-be very careful to observe that the course of treatment recommended in each is entirely lifferent, and should you give the medicine prescribed for inflammation of the bladder for that of the kidneys, it will greatly endanger the life of the horse. 


\section{Srmptoirs.}

The early symptoms in this disease are generally those of fever, but the seat of the disease soon becomes apparent. The horse occasionally looks round at lif flanks, stands with his hind legs wide apart, is unwilling to lie down, straddles as he walks, evinces great pain in turning shrinks when his loins are pressed; the loins feel hot, the urine is roided in small quantities, which is often highly colored and sometimes bloody; he tries to urinate very often and strains painfully, but the discharge is nearly or quite suppressed; the pulse is quick, hard and full at first, but rapidly becomes small, indicating a disease of the urinary organs, yet not distinguishing inflammation of the bladder from inflammation of the kidneys.

\section{Treatment-Remedy.}

When you feel satisfied that it is a case of inflammation of the bladder, blister the loins with the blister ointment and give 1 ounce of turpentine with 1 ounce of laudanum. 
INFLAMMATION OF THE KIDNEYS.

\section{$-4$ \\ INFLAMMATION OF THE KIDNEYS.}

The symptoms of this disease are similar to those of inflammation of the bladder, but are to be treated in quite a different manner. Inflammation of the kidneys is brought on by over-riding, heavy loads, improper feeding, and sometimes by being poled on the haunches, or across the kidneys and loins.

\section{Treatment-Remedy.}

Place a mustard plaster made with vinegar across the loins and bleed. After this give an active purge, and when it begins to abate give of white helebore from $\frac{1}{2}$ to $\frac{3}{4}$ of a drachm, and $1 \frac{1}{2}$ drachms of tartar emetic, with $\frac{1}{2}$ a pint of warm water, this should be repeated 2 or 3 times a day, according to the nature of the disease. For drink, give him warm water or gruel as much as he will drink, and keep the back and loins warm and comfortable. 


\section{$*$ \\ INFLAMMATION OF THE LUNGS.}

This disease is generally brought on by sudden cold, hard driving, high feeding, \&c.

\section{SyMPTOMS.}

The first appearance of this disease is generally marked by fits of shivering, accompanied with a coldness throughout the entire body, which, however, gradually wears off; and he becomes warm, except the ears and feet; but it sometimes commences slowly, with a hard, dry cough, which appears to give the horse great pain; he appears dull, and refuses to eat his food; the pulse is obscure and oppressed-he heares at the flanks, the nostrils are extended, the eye-lids and linings of the nose are inflamed with a disagreeable running at the nose, experiences great difficulty in breathing, seems very stiff, is unwilling to lie down or move, and often stands until completely exhausted. 
INFLAMMATION OF THE LUNGS.

\section{TTEatMent-ReMedy.}

Bleed until the pulse becomes round and full, and then the heart will be able to accomplish its object; next hand rub the legs well, rap them up with flannel bandages as high as the knees, put a blanket on the horse to keep him warm, but let the stable have a sufficient opening to admit the fresh air, not so much as to make it cold or chilly. In warm weather the horse cannot have too much fresh air. The following prescription will be found very beneficial:

1 drachm powdered fox-glove,

$1 \frac{1}{2}$ " tartar emetic,

3 " nitre,

4 " tincture of aloes,

$\frac{1}{2}$ pint of warm. water.

Mix well, give it as a drench and clystèr with soap and warm water; when the focus has become softened a little, leave off using the tincture of aloes, but continue to administer the remaining portion of the above prescription, and blister the sides and brisket with the blister ointment erery 6 hours. If the ointment should act well 
on the first application, there is no further need for it, but should it not act properly continue the blistering until it does, or until the parts become very sore, and in two or three days after dress with lard.

In the latter stages of the disease it will be found very difficult to get the blister to act properly on account of the exhaustion of the natural powers of the animal, but it must be continued, and the sinking energies aroused, or the horse is lost. The blister is often prevented from acting by the gig being up.

In this disease the treatment should be prompt and decisive, as not a moment of time is to be lost. The first object should be to subdue the inflammation, and if the mouth continues hot, the extremities cold, and the nose red, the horse must be bled again and again in rapid succession, the good that we can do must be done immediately or not at all.

The first step to be taken in this disease is to bleed profusely-let the lancet used be a large, broad shouldered one, in order that the blood may be extracted as quick as possible and the disease destroyed without impairing the strength 
of the animal. (If the blood be allowed to flow slowly in a small stream, the strength of the animal will be sapped, while the disease remains untouched.) Let the blood flow until the pulse falters and the horse begins to tremble; no harm will be done however if he should fall by bleering in this disease. As soon as possible after the bleeding, give the medicine prescribed; then hand rub and bandage, and cover with warm blankets; feed him on bran mash and let him run to grass for a month. 


\section{INFLAMMATION OF THE BOWELS.}

This discase arises from various causes, and is frequently brought on by long standing costiveness, neglected gripes, or hard riding, over heating and immediately drinking of cold water.

\section{Symptoms.}

In many cases of this disease fits of shivering or restlessness are the first indications of its approach; the mouth becomes hot, the nose red, the horse begins to evince the most intense pain by pawing, striking at his belly with his feet, looking wildly at his flanks, groaning and rolling. The pulse is quick but small, the ears and feet cold, the belly tender to the touch and sometimes hot, the breathing is quickened, the bowels costive, and the horse rapidly becoming fearfully weak. He paws and stamps as in the colic, but the pulse is much quicker than in that disease, and the pain becomes constant without any intermissions, as occur in colic. 


\section{Treatument-Remedy.}

Commence by bleeding profusely, taking at least 7 or 8 quarts of blood, or as much as the horse can bear, which must be done immediately, or a fatal termination may be looked for. If the horse does not seem to have been relieved or the pulse become round and full, the bleeding must be repeated as the only means of subduing the inflammation, which is the immediate cause of the weakness. If the inflammation is subdued by the extraction of the blood the weakness will soon disappear. After the bleeding, make a strong decoction of aloes and opium or laudanum, say 1 ounce of laudanum with the same quantity of the tincture of aloes, and give it to the horse; this must be quickly followed by back-raking and an injection of soxp and warm water or thin gruel, in which epsom salts or aloes may be dissolved in moderate quantities; repeat this until the bowels are completely cleaned out. He should be given as much warm water or thin gruel as he will drink, and half the quantity of tincture of aloes and laudanum should be administered every two or three hours until the bowels are freely opened. Blister the sides 
24 INFLAMMATION OF THE BOWELS.

and belly with common blistering ointment and

- bandage the legs up to the knees with flannel, cover him with blankets as directed in inflammation of the lungs, and give him a comfortable stable, but not too hot, with plenty of fresh air. No corn or hay should be allowed in this disease-bran mash will answer very well for feed, but green meat is preferable if it can be had. Turn him out for two or three hours in the middle of the day if not too cold; give the legs good hand-rubbing every day; continue to clyster with thin gruel for two or three days. 


\section{BOTS OR GRUBS.}

The Bots or Grubs are small worms of a red or brownish color, found in the stomach, and it is considered almost impossible for them to do any harm, but a horse that has the bots, grubs or worms, loses flesh, becomes hide bound and dull.

\section{SYMptoMs.}

In this disease a yellowish matter is often found under the horse's tail; he has pain, stamps and rolls, switches his tail between his legs, turns up his upper lip, and frequently looks round' to his flanks, and often tries to rúb his fundament against the wall, or any other place that he can.

\section{Treatment-Remedy No. 1.}

First give an active purge, and if that is not sufficient to expel them, take 2 drachms of tartar emetic, with a small quantity of tin or pew- 
ter filings, or a little ground glass, make into balls or pills, and give one every morning for two weeks; if it is necessary, the balls can be made with a little tar, which will also improve the condition of the horse.

\section{REMedy No. 2.}

Take 1 pint of common honey and give it as a drench; in two hours after give an active purge:-1 pint of molasses added to 1 pint of soft suap and a handful of salt will answer rery well. Repeat the dose if it does not operate in four or five hours. 


\section{MEMBRANES. OF THE NOSE.}

Showing the Stmptoms that Mark the Diffrer- ent Stages of the Disease.

1st.-The pale pink hue, when the horse is in perfect health.

2d.-An increased tinge of red, and the gradual uniform painting of the membrane, indicating some excitement of the general system.

3d.-The streaked appearance when inflammation is threatening or commencing.

4th. - The intense florid red, of inflammation being acute.

5th.-The starting of the vessels from their gossamer coat, and their seeming to run bare over the membranes, when inflammation has attained its highest point.

6th.-The pale ground, with patches of vivid red, showing the half subdued but still existing fever. 
7th.-The uniform color, but of a deeper red than natural, indicating the return of a healthy state of the circulation.

8th.-A paleness approaching to white, with a slight radiation of crimson, showing that there is still considerable irritability, and that mischief may be in the wind.

9th.-The pale, livid color, warning you that the disease is assuming a typhoid character.

10th.-The deep livid, announcing that the typhus is establishing, and that the vital current is stagnating.

11th.-The brown or dirty painting, intermingling with and subduing the lividness, denoting that the game is up.

12th.-These appearancês will be guides to our opinions and treatment, which can never be too highly appreciated. 


\section{THE EYES.}

From the eye of the horse we form an idea of - his age. There is, at the back of the eye a considerable quantity of fatty substance, on which it may revolve easily without friction. In aged horses much of this disappears, the eye becomes sunken, and the pit above it deepens: The eye is a very important organ of the horse, and should be large, clear, shining, lively, dark colored, round and full, so that you maylook deep into them; when moving but a small portion of the white should show, and the purchaser who notices this should pause ere he completes his bargain for a horse that shows too much of the whites of his eyes. 


\section{THE EARS.}

Those who are acquainted with the nature of the horse pay much attention to the size and motion of the ear. Ears rather small than large, placed not too far apart, erect and quick in motion, indicate both breeding and spirit. If a horse is frequently in the habit of carrying one ear forward and the other backward, and especially when on a journey, he generally possesses both spirit and continuance; and if attentive to what is taking place about him, he cannot be 'much fatigued or likely soon to become so. 
THE STAGGERS.

\section{STAGGERS.}

A number of opinions have been advanced in relation to the origin and seat of this disease. Some think that it is confined entirely to the head, while others say that the lungs are also affected; that it originates in the stomach, from which it is removed by the action of the lympatic vessels, and being thrown into the circulation is diffused throughout the entire system, and carried by the arteries into the lungs, through which all the blood in a horse's body passes many times during an hour, where it undergoes a change, thus depositing a portion of the poisonous matter that had been received into the stomach in.the lungs. It is common to horses of all ages and conditions, and is a very rare case where it does not prove fatal.

\section{SyMPTOMS.}

The symptoms in this disease are feebleness, drowsiness, loss of appetite, a constant hanging 
of the head, with inflamed eyes, nearly closed; he kicks, rears and plunges, seemingly unconscious of what he is doing; it is dangerous for any one to approach him in this state; the ears and forehead hot, accompanied by a burning ferer.

\section{Treatuent-Remedy.}

The first step to be taken in this disease is to relieve the overloaded organs of the brain, which shoild be done by opening the neck or jugular vein with a large lancet, that the blood may flow freely. No definite quantity of blood need be taken, but let it run until the horse begins to falter and blow; or, perhaps, with more assurance of success, until he falls. Immediately after inject freely with warm water, and give as a drench $\frac{1}{2}$ ounce of aloes, $\frac{1}{2}$ ounce of ginger, and $\frac{1}{2}$ pint of warm water; feed on bran mash and green meal. 


\section{RABIES OR MIADNESS.}

If a horse be bitten by a dog or horse that is affected with rabios or madness, the wound should be well burned ont with causec, (nitriate of silver, ) and on the third day after remove the scab and repeat the operation. The caustic should reach every part of the wound.

The following remedy has often been administered, and found effectual in nine cases out of every ten. Talke

2 ounces of fresh leaves of tree-box,

2 " " of rue,

$\frac{1}{2}$ "sage,

Chop these very fine and boil in a pint of water down to half a pint; strain carefully, and press out the liquor, put back the ingredients into a pint of milk, and boil again to half a pint; strain as before, mix both liquors, which forms three doses for a human subject. Double this quantity for a horse or cow. Two-thirds of the quantity is sufficient for a large dog, half for a middling sized, and one-third for a small dog. Three doses are sufficient each subsequent morning fasting, giving the quantity directed, being that which forms these three doses. 


\section{INJURY OF THE EYE.}

The eye itself of the horse is rarely injured by blows and bruises carelessly inflicted by passionate persons, but the substance that surrounds it may be seriously wounded, and considerable inflammation ensue-this may be abated by the application of poultices, bleeding and physicing. Sometimes the eye-lids become inflamed from the same cause-fomentations of warm water will be serviceable in this case. The horse occasionally has a scaly eruption on the edges of the eye-lids, attended with much itching, in the effort to allay which the eye is often blemished by being rubbed against some hard substancethe nitriated ointment of quicksilver, mixed with an equal quantity of lard may be slightly rubbed on the edges of the lids, with good effect. Warts are sometimes attached to the edges of the lids, and are a source of great irritationthey should be removed with a pair of sharp sicssors, and their roots. touched with lunar caustic. In common inflammation of the eye, free bleeding, cooling applications, physic and mash diet will usually allay the evil; the tincture of opium is a good lotion. 
LAMPASS.

\section{LAMPASS.}

The lampass is a.swelling of the gums on the innerside of the upper jaw, to which young horses are mostly subject, and sometimes suffer considerably before it is discovered.

In some cases the swelling will subside without further medical treatment than administering a few alteratives, and feeding on bran mashes, but should this fail it will have to be cured by cutting across the bars with a lancet or pen-knife. If, however, it returns in three or four months after this operation, which it sometimes dðes, take a sharp, flat piece of iron, a little crooked at one end, heat it and burn out the disease a little below the level of the teeth, being very careful not to let the iron rest or bear against the teeth. After this operation give the horse a little meal, mixed with a small quantity of salt, and feed on mashes. 


\section{THE PROCESS OF TEETHING.}

At $1 \frac{1}{2}$ years of age the mark in the central nippers will be much shorter and feinter; that in the other pairs will have undergone an evident change, and all the nippers become flat.

At 2 years this will be nore manifest, and about this period a fifth will appear. Now, likewise, another process is commencing: the first teeth are adapted to the size and wants of the young animal, and are sufficiently large to - fill the colt's jaws.

At 3 jears old the horse should have the central permanent nippers growing, the other two pairs wasting away; six grinders in each jaw above and below, the first and fifth level with the others, and the sixth protruding; the sharp edge of the new incisors, which will be very evident when compared to the neighboring teeth. 
At 4 years the central nippers will be fully developed, with the edge somewhat worn off, and the mark in them shorter, wider and feinter; the next pair will have made their appearance with the mark deep, and extending entirely across them. The corner nippers will be larger than the inside ones, yet smaller than they were and flat, with the mark nearly effaced. The sixth grinder will have become level with the others, and the tushes beginning to make their appearance.

At 5 years the horse's month is almost perfect. The corner nippers are quite up with the long, deep mark, irregular on the inside, and the other nippers bearing evident tokens of increasing wearing. The tush is much grown, the grooves have almost or quite disappeared, and the outer surface is regularly convex:

At 6 years the mark on the central nippers is worn out, though there is still a difference in the color of the centre of the teeth. The cement filling the hole, made by the dipping in of enamel, will present a browner hue than the other part of the teeth. 
At 7 years the mark in the manner which we have described it, has worn out in the four central nippers, and is fast disappearing in the corner teeth; the tush also is beginning to alter -it is rounding. at the point, the edges, and without, and beginning to get round inside.

At 8 years old the tush is rounded in every way, the mark has disappeared from all the bottom nippers, and it may almost be said to be out of the mouth. There is nothing remaining in the bottom nippers afterward that can clearly show the age of the horse. 
OHEST FOUNDER.

\section{CHEST FUUNDER.}

I believe this disease to be nothing more than the rheumatism, produced by suffering the horse to remain too long tied up and exposed to the cold, or riding him against a very bleak wind.

\section{Sriptoms.}

The horse has considerable stiffness in moving, evidently not arising from the feet; there is a tenderness about the muscles of the breast and occasional swelling; it is sometimes accompanied with a considerable degree of fever.

\section{TreatMent-Remedy.}

Bleeding, physic, and a rowel in the chest, warm stabling and warm clothing, with occasional doses of antimonial powder, will soon subdue the complaint. 
INFLAMMATION.

\section{INFLAMMATION.}

Inflammation consists of an increased flow of the blood to and through the parts. The proper mode of abating which is to lessen the quantity of blood-if we take away the fuel, the fire will go out-all other means are comparatively unimportant contrasted with bleeding. Blood is generally extracted from the jugular vein, so that the general quantity may be lessened, but if it can be taken from the neighborhood of the diseased part, it will be productive of tenfold benefit: one quart of blood extracted from the foot in acute founder, will do more good than five quarts taken from the general circulation; an ounce of blood obtained by scarifying the swollen vessels of the inflamed eye, will give as much relief to that organ as a copious bleeding from the jugular. This is a principle in the animal's nature which should never be lost sight of; hence the necessity for bleeding early and largely in inflammation of the lungs, or of the bowels, or of the brain, or of any important organ. Many horses are lost for want of, or in- 
sufficiency in bleeding, but we never knew of one being materially injured by the most copious extraction of blood.

It is very difficult to decide when a cold or hot application is to be used, and no general rule can be laid down, except that in cases of inflammation in the early stages, cold will be preferable, but when the inflammation is deeper seated or fully established, warm fomentations will be found most serviceable. Stimulating applications are frequently used in local inflammation. When the disease is deeply seated, a stimulating application to the skin will cause some irritation and inflammation there, and lessen or remove the malady; hence the use of rowels and blisters in inflammation of the chest. If we excite it in one, we shall abate it in the other,-and also, by the discharge which we establish from the one, we shall lessen the determination of the other. Stimulating and blistering applications should never be applied to a part that is already inflamed. A fire will not go out by heaping more fuel upon it; hence the mischief which is often done by rubbing those ahominable oils on a recent sprain, 
hot and tender. Many a horse has been ruined by this absurd treatment, when the heat and tenderness have disappeared by the use of cold lotions or fomentations. When the leg or sprained part remains enlarged long or matter threatens to be deposited, it may be right to excite inflammation of the skin by a blister, in order to rouse the deeper seated absorbants to action and enable them to take up this deposit; but, except to hasten the natural process and effects of inflammation, a blister or stimulating application should never be applied to a part already inflamed. 


\section{INFLAMMATION OF THE LARYNX.}

$\mathrm{He}$ who is desirous of ascertaining whether there is any disease in the larynx of a horse, should apply his ear to the lower part of the windpipe. If he finds that the air passes in and out without interruption, there is no disease of any consequence, either in the windpipe or the chest, for it would be immediately detected by the loudness or the interruption of the murmur. Then let him gradually proceed up the neck with his ear still upon the windpipe; perhaps he soon begins to recognize a little gurgling sound. He can have no surer proof that there is the seat of the disease.

\section{Treatment-Remedy.}

The treatment here is very plain: Blood must be copiously extracted from the jugular vein, which must be done quickly, letting it run until 
44 INFLAMMATION OF THE LARYNX.

the pulse begins to flutter, then administer the fever medicine:

$$
\begin{aligned}
& 1 \text { drachm digitalis, } \\
& 1 \frac{1}{2} \text { " } \text { " emetic tartar, } \\
& 3 \text { nitre, } \\
& \frac{1}{2} \text { ounce aloes, }
\end{aligned}
$$

Which must be repeated twice or thrice in the day. Aloes may be safely given at this stage of the disease, because the chest is not yet implicated. To this must be added immediately a blister, and a sharp one.

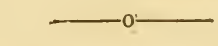

\section{EPIDEMICS.}

In epidemics all offensive matter should be immediately and carefully cleared away, and no small portion of the chloride of lime used in washing the stables, troughs, \&c., and particularly his ulcers, \&c. 
CHRONIC COUGH.

\section{CHRONIC COUGH.}

If a harsh hollow cough is accompanied by a staring coat; it proceeds from irritability of the air passages, which will be discovered by the horse coughing after drinking, or when he first goes out of the stable in the morning, or by occasionally snorting out thick mucus from the nose, medicine may be given with advantage to diminish the irritation; generally small doses of digitalis, emetic tartar and nitre administered at night. Take
Digitalis $\frac{1}{2}$ drachm,
Emetic tartar 1 drachm,
Nitre 1 drachm.

This should be mixed into a ball with tar and given every night regularly for a considerable length of time. A blister extending from the root of one ear to that of the other, taking in the whole of the channel and reaching six or eight inches down the windpipe has been tried with good effect. Feeding has much influence on this complaint: too much dry meat, and especially chaff increases it; carrots afford decided relief. 


\section{THICK OR BROKEN WIND.}

There is no remedy for the cure of this but it may be improved. The horse should have full proportions of solid food, but very little hay, and no chaff; he should not be worked immediately after a heavy meal; water should be given in moderate quantities, but the horse should not be suffered to drink as much as he likes until the day's work is over; green meat will always be serviceable, and carrots are particularly useful. 


\section{PHYSICING.}

A horse should be carefully prepared for the action of physic. Two or three bran mashes given on that or the preceding day, which should be continued until the dung becomes softened, as a less quantity of physic will then suffice. On the day which the physic is given, the horse should have walking exercise, or may be genitly trotted for a quarter of an hour twice in the day; but after the physic begins to work, he should not be moved from his stall. A little hay may be put in the rack, and as much mash given as the horse will eat, and as much water as he will drink with the coldness off. Aloes is the best purgative, for there is no other that is at once so sure and safe-the dose is from $\frac{1}{2}$ to 1 ounce, if the horse is properly prepared. The only other purgative on which dependence can be -placed is the croton; the dose varies from 1 scruple to $\frac{1}{2}$ a drachm. Linseed oil is an uncertain but safe purgative, in doses from a pint to a pint and a half. Epsom salts are an ineficacious remedy except in the immense dose of a pound and a half, and then they are not always safe. 


\section{SPRAINS OF THE BACK SINEWS.}

Should there remain the slightest lameness or enlargement, the leg must be blistered; and it would seldom be a bad practice to blister after every case of severe sprain. The inflammation may lay deep, and the part once sprained may long remain weak, and subject to renewed injury, not from unusual but ordinary exertion. The horse should be afterwarls turned out for one or two months.

We must here again repeats that a blister should never be used while any hoat remains.

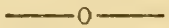

\section{ENLARGEMENT OF THE HOCK.}

A horse with an enlarged hock must always be regarded with suspicion: in truth he is unsound. The animal may discharge his usual work during a long period, without return of lameness, but when all his energies are required, the weakened part will fail. The treatment is plain enough: fomentations, blistering, \&c. may remedy the evil. 
SPRAIN OF THE COFFIN JOINT.

\section{SPRAIN OF THE COFFIN JOINT.}

The proof of this is when the lameness is sudden, and the heat and tenderness are principally felt around the cornet. Bleeding at the toe, physic, fomentations and blisters are the usual means adopted. This lameness is not easily removed even by a blister, and if removed. like sprains of the fetlock and of the back sinews, it is apt to return again. Sprains of the coffin joint sometimes become a very serious affair; not being attended by any swelling, and being detected only by heat around the coronet. First reduce the heat by fomentations: say bathe the foot with water as warm as the hand will bear, fomentate with this for 15 or 20 minutes - the long continuance of fomentations has been found very efficacious in reducing inflammation; next apply a clay poultice made with vinegar, and when getting dry moisten by pouring vinegar on the foot and clay. After the heat has left the parts, then blister. The horse should not be used for a month or two. 
GREASE:

\section{GREASE.}

Grease consists of swollen legs, although swelled legs occur frequently, yet there is no grease. Friction and bandaging will generally remove this. Grease is a specific inflammation of the skin of the heels, sometimes of the forefeet, but oftener of the hinder ones. It is not a contagious disease, as some have asserted although when it once appears in a stable, it frequently attacks almost every horse in it. Bad stable management is the true cause of it. The first appearance of grease is usually a dry and scurfy state of the skin of the heel, with redness, heat and itching. The heel should be well but gently washed with soap and water, and as much of the scurf detached as is easily removed. If the cracks are deep, with an ichorous discharge and considerable lameness, it will be necessary to poultice. A poultice made of carrots boiled soft and mashed will answer the purpose. The efficacy of a carrot poultice is seldom sufficiently appreciated in cases like this. The poultice just referred to should be 
diligently applied at night, to insure success, and when the heat and tenderness and stiffness of motion have diminished, astringent lotions should be applied. Either the alum lotion or a strong decoction of oak bark-perhaps the alum dissolved in whiskey will do better than water, or the alum dissolved in a decoction of bark will answer better than either. This disease requires perseverance-the decoctions should. be made very strong. After washing several times should there be watery matter on the heels or leg, wash it off with water and soap. Moderate physicing, bran mashes, \&c. will be found very beneficial. The above decoctions will never fail to cure the scratches. 


\section{INFLAMMATION OF THE FEET, ACUTE FOUNDER.}

This is a disease that was less understood than any other until very recently. It often arises by allowing a horse that is very much heated to stand in the snow or cold water for any length of time, or where he is apt to become chilled, which produces a general stiffness throughout the entire system; but it will soon be observed that the seat of the disease is in the feet, by the disinclination of the horse to remain upon them.

\section{SyMptous.}

The earliest symptoms of ferer in the feet are restiveness, frequent shifting of the fore legs, but no pawing. The pulse is quickened, the Alanks heaving, the nostrils red, and his moaning indicating great pain. He looks about his litter, as if preparing to lie down; he continues to shift his weight from foot to foot; he is afraid to draw his feet sufficiently under him for the purpose of lying down, but at length he drops. 
His lying down will distinguish inflammation of the feet from that of the lungs, in which the horse obstinately persists in standing until he drops. His quietness when down will distinguish it from colic or inflammation of the bowels. He will point out the seat of the disease by looking at the part; his muzzle will often rest on the feet or affected foot.

\section{Treatuent-Remedy No. 1.}

The treatment in this disease resembles that of other inflammations. Bleeding is indispensable and that to its fullest extent. Four quarts of blood should be taken from the toe of the foot, which may be put into warm water to quicken the flow of blood. Poultices of linseed meal, made very soft, should cover the whole of the foot and pastern, and be frequently renewed. This will relieve its painful pressure on the swelled and tender parts beneath. The shoo should be removed, the sole pared as thin as possible, the crust and quarters well washed-all this should be done gently. Sedatives and cooling medicines should be diligently administered, consisting of digitalis, nitre and tartar emetic, 
1 drachm digitales, 2 drachms tartar emetic, 3 drachm saltpetre. If no amendment is apparent after this, blood should again be extracted on the following day. In extreme cases, a third bleeding may be justifiable, and instead of the poultice, cloths kept wet with water in which nitre has been dissolved, in the proportion of an ounce of nitre to a pint of water. The cloths should be wrapped around the feet.

\section{Treatuent-Remedy No. 2.}

Take 1 quart sweet milk, 1 quart molasses, $\frac{1}{2}$ oz. pulverized saltpetre, mix and dissolve all together, give in 2 drenches about 5 minutes apart: this is highly recommended by those who have tried it. 
RESTIVENESS, OR TAMING HORSES.

\section{RESTIVENESS, OR TAMING HORSES.}

Mr. Catlin has published an account, the veracity of which is unimpeached, of his travels among the North American Indians. "Ho coils his lasso on his arm and gallops fearlessly into the herd of wild horses. He soon gets it over the neck of one of the number, when he instantly dismounts, loaving his own horse, letting the lasso pass out gradually and carefully through his hands until the horse falls for want of breath. The Indian advances, keeping the lasso tight upon his neck until he fastens a pair of hobbles on the animals two fore feet, - then passing a noose round the under jaw by which he obtains great power over the affrighted animal, that is rearing and plunging when it gets breath. By this means he gradually advances until he is able to place his hand on the animal's nose and over its eyes, and at length to breathe into its nostrils, when it soon becomes docile and conquered; so that he has little else to do than remove the hobbles from its feet, and lead or ride it to the camp." 
56

BESTIVENESS, OR TAMING HORSES,

Mr. A. B. Moss happened to read this account, and he felt a natural desire to ascertain how far this mode of horse training might be employed among the American horses. $\mathrm{He}$ soon had an opportunity of putting the veracity of the story to the test. A man on a neighboring farm was attempting to break a very restive colt, which had foiled him in every possible way. After several attempts, he succeeded in breathing into one of the horse's nostrils, and from that moment all became easy. The horse was completely subdued. He suffered himself to be led quietly away with a loose halter, and was perfectly at command. 
BROOD MARES.

\section{BROOD MARES.}

Great care and attention should be paid to brood mares, particularly three or four weeks before foaling. She should be worked up to the day of foaling, being very careful not to overwork or exert her too much; light and moderate work is an advantage to the animal with foal. She should be fed on a little flax seed meal, or the whole seed if the meal cannot be obtained, twice a week at least six or eight weeks before foaling, and should never fail to to turn out to grass of a night for several weeks previous to foaling. Should be fed on bran mash through the winter, and up to the time of foaling, which will be found very advantageous to both mare and colt. There is nothing so refreshing as a bran mash with a little salt in it, adling a reasouable quantity of corn and oats. If this course and caution is taken you will not loose one mare out of a hundred, and perhaps not one out of a thousand. 


\section{WARTS.}

Warts are found on the eye-lids, the muzzel, the ears, the belly, the neck, the penis, and the prepuce. There are some caustics available, but frequently they must be removed by an operation.

If the root is a very small it may be snapped asunder close to the skin with a pair of scissors, and touched with lunar caustic.

If the pedicle or stem is somewhat larger, a ligature of waxed silk should be passed firmly round it and tightened every day. The source of nutriment being thus removed the tumor will in a short time die and drop off.

If the warts are large or in considerable clusters, it will be necessary to cast the horse in order to cut them off close to the skin. The root should then be seared with a red hot iron; unless these precautions are used the warts will speedily sprout out again. 


\section{A COMPLETE LIST}

\section{$\mathrm{OF}$}

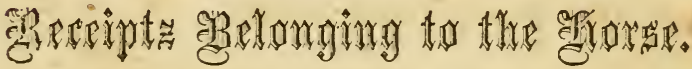
AND THEIR USES. 
60 CELEBRATED HOISE POWDERS.

\section{CELEBRATED HORSE POWDERS.}

For the cure of Yellow Water, Hide Bound, Grub Worms, Bots, \&c.

These powders will cleanse the blood and give new life and vigor to the animal, its effects will soon be made apparent. They are harmless and can be fed with safety. Take

$\frac{1}{2}$ pound gentian root.

1 " flour of brimstone,

1 " fenugreek,

$\frac{1}{2}$ "6 alum,

$\frac{1}{4} \quad$ 6 gum assafotida,

1 "rosin,

$\frac{1}{4}$ " angelica root;

$\frac{1}{2}$ " rhubarb,

$\frac{1}{2}$ "columbo,

1 " copperas,

1 "cut and dried tobacco,

$\frac{1}{2}$ " cream of tartar,

$\frac{1}{4}$ " red tartar,

1 " epsom salts,

1 " juniper berries,

$\frac{1}{2}$ "garden benedict, 


\section{CELEBRATED HORSE POWDERS:

$$
\begin{aligned}
& \frac{1}{2} \text { pound salts of nitre, } \\
& 1 \text { " spice berries, } \\
& \text { * } 1 \text { " antimony" } \\
& 1 \text { " ginger, }
\end{aligned}
$$

Mix and pulverize well. The glass should be ground through a fine mill two or three times. If the benedict and spice berries cannot be obtained it will do well without them.

\section{DIRECTIONS FOR USE.}

The dose is 1 table spoonful night and morning, with bran mash or oats, which can be increased or diminished to suit the case. By leaving out tobacco it will make an excellent powder for cows, hogs, sheep, \&c.

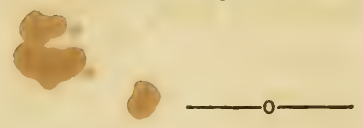

\section{* TO CURE GALDS ON HORSES.}

Take dry white lead and sprinkle it on the gald twice a day, which will dry it up and cure it in a short time. 
.62

ARABLAN OIL FOR HORSES.

\section{ARABIAN OIL FOR HORSES.}

,

This oil is an excellent mixture for sprains, swellings, galds, \&c. either for a human subject or a horse. Take.
1 quart of linseed oil,
1 pint of turpentine,
4 ounces oil of origanum
6 " oil of spike,
6 " spirits of camphor,
1 " oil of sassafras.

Mix and shake well before using; and keep the vessel that contains it well corked. The spirits of camphor is made by taking 95 per cent. alcohol, adding as much gum camphor as it will dissolve.

\section{$\longrightarrow$ \\ FOR THE BOTS.}

Dissolve in a pint of milk warm water $\frac{1}{4} \mathrm{lb}$. of alum and give it as a drench; in ten minutes after give 1 pint of linseed oil. 
AN INFALLIBLE LOTION.

\section{AN INFALLIBLE LOTION.}

FOR BLOWS, BRUISES, SWELLINGS, SPRAINS, \&C.

This lotion is truly astonishing in its effects, and cannot be surpassed for the purposes for which it is intended. Dissolve 2 ounces of gum camphor in 1 pint of 95 per cent. alcohol, and when dissolved add

2 ounces oil of turpentine,

2 " spirits sal amoniac,

1 " . oil origanum,

2 tablespoonsful laudanum.

This lotion must be well rubbed in with the hand for a full quarter of an hour every time it is used, which should be four times a day.

\section{FOR THE BLACK TONGUE.}

Take a handful of fine salt and rub well upon the tongue of the horse that has this disease, which will effect a cure in two applications. It is an infallible, simple and cheap remedy. 
64 LOTION FOR SCRATCHES OR GREASE.

\section{LOTION FOR SCRATCHES OR GREASE.}

Take white oak bark and make a strong deroction of it by boiling; then dissolve a portion of pulverized alum in the decoction, say $\frac{1}{2}$ pound of alum to a quart of decoction, and it is ready for use. Before applying the lotion, wash the parts with warm soap suds two or three times a day. This lotion has never been known to fail when properly applied. A lotion made of alum and water is said to be good.

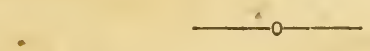 \\ TO QUIET OR TAME HORSES.}

Take of the oil of roses 4 drops, oil of cummin 4 drops, and a portion of the wart or horney substance that forms on the leg, "powder it fine; then drop the oil in and mix it in your hand, put some up the horse's nostrils, and give him some in his feed. This is said to be a certain remedy for taming horses, so that you may handle them as you please. 


\section{TREATIENT OF FOUNDER.}

As soon as it is ascertained that the horse is foundered, take from the neck vein from 1 to 2 gallons of blood; then give 1 ounce of pulverized alum, mixed with damp oats; place the horse in a dry stall, ground floor is best, wrap the legs ip as high as the knees and hock joints, with woollen cloths, saturate them with cold water for seven or eight hours; give him no food for twenty-four hours, and then let it be a light feed of oats and bran mash mixed. In two or three days turn him ou for exercise. It the ankles continue feverish, bathe them at night with equal parts of vinegar, alcohol and sweet oil.

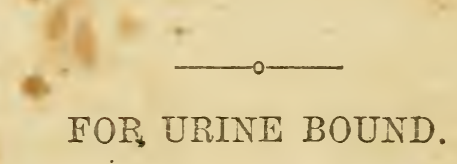

Take dandeline leaves, make a strong decoction and drench freely. A decoction made of water-melon seeds will answer the same purpose. Whiskey will generally accomplish the object. 


\section{FOR THE DISTEMPER.}

Give the horse indigo water to drink: feed on bran mash mixed with a small quantity of sulphor or brimstone; or you may use some good horse powders, adding thereto a little of the brimstone. The easiest mode to tincture the water with the indigo is to put it into a common muslin bag; then dip the bag into the water, letting it remain until the water becomes blueish, or until you think it contains a sufficient quantity of the indigo. Give no other water to drink. This is a safe remedy.

\section{$\longrightarrow$ \\ - HOOF OINTMENT.}

Take 1 pound of tar and 1 pound of tallow, mix them vith $\frac{1}{2}$ pound of common turpentine in a stone ware dish; stir them until they are thoroughly mixed together. This is an excellent dressing for sore hoof's, for horses and oxen. 
EMBROCATION FOR THE THROAT.

\section{EMBROCATION FOR THE THROAT.}

This embrocation may be used without taking the hair off. Take
2 ounces spirits of hartshorn,
2 " oil of turpentine,
2 "spirits of camphor,
1 "laudanum.

Mix well and put into a bottle; keep it well corked.

\section{$-0-$ \\ TO MAKE ELDER OINTMENT.}

Take the green leaves of elder, if they can be had; if not, take of the inside bark any quantity and lard in proportion to the elder, then fry to a crisp, which will be found very efficacious in healing sores, scalds, burns, sprains, or any humorous swelling. The elder alone fried in the same manner and strained, makes a much better ointment. This is worth making and keeping on hand, as its cost is a mere trifle. 
68 FOR BLOOD OR BOG SPAVIN.

\section{FOR BLOOD OR BOG SPAVIN.}

For curing the above disease dress with mercurial ointment two or three times, and then with iodinepinitment. To make mercurial ointment, take 1 ounce of quicksilver to 3 ounces of lard, beat both together until thoroughly mixed. Iodine ointment is made by mixing equal quantities of iodine and mercurial ointment well together.

\section{A GOOD HORSE POWDER.}

The following prescription will make an excellent powder for ordinary purposes. Take

2 pounds sulphor of brimstone,

2 " cream of tartar,

1 " antimonia,

1 " saltpetre.

The dose of this mixture is 1 table spoonful morning and evening. 


\section{ON BLISTERING.}

The spanish fly in its action is intense, yet superficial. It plentifully raises the cuticle, yet rarely injures the true skin and therefore seldom blemishes. The application of other acrid substances is occasionally followed by deeply seated ulceration; but a blister composed of the spanish fly alone, while it does its duty leaves, after a few weeks have passed, scarcely a trace behind. The art of blistering consists in cutting or rather shaving the hair close, then rubbing on the ointment at least ten minutes. As soon as the vesicles have risen, which will be in something like 20 hours, you may relieve the enimal by the application of olive or neatsfoot oil. In inflammation of the lungs, \&c., it should be made to act sooner. The principle of the blister is, that no intense inflammation can exist in the neighboring parts at the same time. An infusion of 2 ounces of the flies in 1 pint of oil of turpentine, for several days, is frequently used, and with good effect. This is a sure and safe remedy. If in the winter blanket the horse to keep him warm until he is over it; put a blanket over the head also if very cold. 


\section{TINCTURE OF ALOES AND MYRRH.}

This will answer well for dressing either fresh or old wounds. Take

$$
\begin{aligned}
& 8 \text { ounces of powdered aloes, } \\
& 1 \text { " " myrrh, } \\
& 1 \text { quart spirits of wine, } \\
& 1 \text { ounce water, }
\end{aligned}
$$

Put these into a bottle and shake every day for two weeks, when it will be ready for use. This is an excellent preparation, and can be relied on. Any person having horses should never be without this tincture, the cost being but a mere . trifle, and will often and in erery case save time, trouble and expense, where there is use for it.

\section{$\longrightarrow$ \\ TINCTURE OF OPIUM.}

To make the above take 2 ounces of powdered opium and 2 pints spirits of wine, put into a bottle and shake well every day for a week, when it will be ready for use. 


\section{COMMON BLISTERING OINTMENT. \\ COMMON BLISTERING OINTMENT.}

To make the above ointment which may be used for blistering in inflammation of the lurigs, bowels, \&c. Take

\section{$1 \frac{1}{2}$ pounds of lard, \\ 2 ounces renice turpentine, \\ 2 "rosin, \\ $2 \frac{1}{2}$ spanish flies, powdered,}

Melt the rosin, turpentine and lard in any common vessel, and when the mixture begins to cool put in the powdered flies; mix well by stirring. Before applying the blister clip or shave the hair off and grease, rub well for ten minutes. After it has acted, grease with lard or oil.

\section{FOR RING BONE OR SPAVIN.}

The following will be found very useful for removing ring bone or spavin, or any other bony substance. Take

8 ounces of spanish flies,

1 pound of lard,

1 "rosin,

6 ounces of venice turpentine, 
Melt the lard, rosin and turpentine over a slow fire, and when beginning to cool add the spanish flies. Apply three mornings in succession; and in twelve hours after the last application dress with lard; keep out of the water while blistering, which may be reduced with oil and used for the purpose of irritating and removing inflammation, lameness, \&c. The horse should not get wet while blistering.

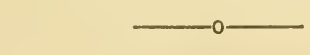

\section{SPIRITS OF PIMENTO.}

To make spirits of pimento take

$\frac{1}{2}$ pound of ground allspice,

1 quart of alcohol.

1 " of water,

Put these into a bottle and shake well before using. It is now ready for use though it is better to let it stand several days. This is a good lotion for the wind colic after the gas has been removed. 
To make this tincture take 1 ounce of iodine, 1 pint of spirits of wine, and mix well. It is very good fur enlarged glands of the neck, joints and muscles, and may be used twice a day without taking the hair off.

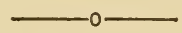

LNIMENT FOR SPRAINS, SWELLINGS, \&c.

To make this liniment, which will never fail in curing sprains, swellings, \&c. \&c. Take

2 ounces hartshorn,

2 " spirits camphor,

1 " oil of turpentine,

$\frac{1}{2}$ " laudanum.

Mix well together and put into a bottle, being careful to keep it well corked. 
74 COOLING LOTION FOR INFLAMMATION.

\section{COOLING LOTION FOR INFLAMMATION}

This is an excellent lotion for wounds of the eyes, \&c. to be used after bleeding freely. Take

2 drachms sugar of lead,

1 " white vitriol,

1 pint lime water.

Put them into a bottle and shake often, so as to dissolve the ingredients. Apply it as a wash, bathing the parts affected two or three times a day.

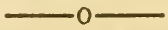

\section{FOR THE SWEANEY.}

This is a troublesome disease, and is very common amongst horses. It can easily be detected by examining the withers, which will be slightly sunk, and the skin becomes very tight to the muscles and flesh; and if suffered to run on, the horse will get very lame and the skin tight, and the withers much sunken. I have seen horses frequently have it on the rump or 
near the hip bone; it would cause the horse to become very lame. This disease should be attacked when first discovered, and never suffer it to run on until the horse becomes very lame and the parts much sunken.

\section{REMEDY.}

Take 1 pint strong vinegar,

"I gill spirits turpentine,

" $1 \mathrm{nz}$, pulverized saltpetre.

Put all into a bottle, shake, mix and dissolve well, and it is fit for use. Rub the liniment on the sunken parts with the hand as much as will soak in twice a day, until it becomes sore, and the skin gets loose; then apply once a day until all is used. This liniment will never fail in curing if applied properly, and is the only safe and sure remedy for sweaney. I have never known it to fail; you may grease with sweet oil 1 day after using the last time. This liniment will take off the hair, but it will do no harm, as the hair will come out in a short time as fine as ever, and will not leave the least blemish. The liniment must act on the skin, 
and if it does not make sore or act on the skin, add more spirits turpentine. If you have a horse that has the sweaney, do not put yourself to the trouble of getting any person to cure it for you, or purchase any quack medicine for it; but go to work and cure it yourself, which can be done for $12 \frac{1}{2}$ cents. The horse should not be worked while using it. I have known it to be cured whilst working the horse, but the animal should not be punished in that way. In case the first dose does not entirely relieve, use the second time: this you will have no need for if you do not work the horse. 
HOW TO THROW OR MAKE A HORSE LAY DOWN. 77

\section{HOW TO THROW OR MAKE A HORSE LAY DOWN.}

Whatever you may intend the horse to do, it is always necessary to give him some idea what you wish him to do, and repeat whatever it may be until the horse is sure to remember it. To make a horse lay down, bend the left fore leg until the hoof is nearly bottom upwards; then fasten a loop over his leg above the pastern joint firmly, so that he cannot get the foot down: next fasten one end of another strap around his right foot above his hoof; place the strap through the left leg where it is bent; keep the strap in your right hand; keep on the left side of the horse; let the bridle have a strap to it; bring this up over the opposite side of his .neck, grasp it with your left hand, drawing the strap steady, so as to draw his head to the right; pull steady with the right hand strap, bearing against the shoulder to cause him to move; when he does move, he will come on his knees; keep the strap tight, so that he cannot straighten his leg; keep him in this position, turning his head 
78 HOW TO TIIROW OR MAKE A HORSE LAY DOTW.

towards you; bear against his side slightly with your shoulder with an equal pressure; in ten minutes or so, he will be down. As soon as he is down, he will be conquered; and you can handle as you please; heep his head up, now you may take off the straps, straighten out his legs, rub him about the face, head and neck with your hand the way the hair lays; handle all his legs gently, and he will soon learn that you wont do him any harm. After he has laid some 15 or 20 minutes, let him get up again. Rest him a short time, and make him lay down again as before: repeat the operation three or four times which is sufficient for one lesson; give him 3 or 4 lessons, and he will lay down by taking hold of one foot, and tapping him on the other leg with a stick while you have hold of his footfinally he will lay down from the motion of the stick. Before you attempt to make a horse lay down, place a thick bed of hay on the floor or ground, so that he cannot hurt himself in the least. If your horse is very' scarry, fretful or skittish after you have given him one or two lessons, take something that will rattle or any thing that is calculated to frighten him, rattle 
HOW TO THROW OR MAKE A HORSE LAT DOWN. 79

it 'and pass over his head and about him; he may be much frightened at first, keep his head up, and he eannot get up, and by continuing with this, he will soon get used to it and not mind it. It will be the same with a kicking horse after you pass over him with harness, chains, \&c. he will soon become accustomed to it, so that you can hitch him up and work him with safety.In all cases where horses have been broke of bad habits, you should be cautious not to show him opportunities to learn his old tricks over. The most gentle horse can be spoiled and brought into bad habits; so you should be careful with the one that has just been broke from his bad habits.

The above is the only safe and sure course which you can pursue with a horse with bad habits. I would here again press upon you when you have him on his knees, to commence patting him under the belly-contiuue with gentle strokes upon the belly. You will in a few minutes bring him to his knees behind: continue the process and he will lay down and submit himself to your treatment. By proceeding gently you may handle his feet and 
SO HOW TO THROW OR MAKE A HORSE LAY DOWN.

legs any way you choose. By practising this process a few times, you will find him perfectly gentle and submissive, and will generally follow you, and is unwilling to leave you unless he be very wild; the first treament will answer.Should you have a very wild horse, and cannot manage him, take the button or horney substance which grows on the back part of the horse's leg; dry this, pulverize it fine, drop a few drops of oil of roses and a few drops oil cummin; put some of this up his nostrils: this is best done by putting it in a large quill and blowing it up the nostril; feed him with a small portion of it from off your hand, with a little oats; also breathe your breath into his nostrils; by doing this, he will permit you to handle his feet, legs, \&c. or permit you to get on his back, cr sufier you to handle as you please. By pursuing these courses, and handling occasionally, always letting him know what you want him to do, you will be able to quiet and tame a horse to become perfectly gentle. 
RULES FOR A HORSE THAT SHIES.

\section{RULES FOR A HORSE THAT SHYES.}

When you have a horse that shyes or scares at a stump, log or any object that may come in his way, never whip him for it, or attempt to force him up to it or by it. But be easy with him, try and get him up to the object by gentle handling; patting and rubbing him on the neck, shoulders, \&c. Finally you will get him up to the object, and he will smell or feel it with his nose. If you pursue this course he will finally forget and give up the halbit of scaring. If you wish to satisfy yourself about this course, take a buffalo robe or a red blanket, place your horse in a yard and hold up the robe, moving towards him; he will soon throw up his head, snort and run. Then throw the robe down in the centre of the yard; if frightened he will not rest until he has touched it with his nose; he will soon begin to walk toward the robe and snort, getting a little closer until he touches it with his nose, he will see that it will do him no harm, and finally he will pick it up with his teeth and care nothing about it. This will show you at once 
that if you can get him up to the object and let him feel it with his nose, he will care nothing about it, and soon forget his scaring, \&c.When you try the robe experiment step up to one side and watch his motions, and he will soon give you the principle upon which he acts. The same course must be pursued in breaking wild colts; go up to it cautiously and by degrees, never rush up to it all at once; be cautious, watch the colt, and if you see that he is frightened at your approach stop a little, and when he becomes quiet approach a little nearer, and so on until he will suffer you to touch his face, then rub him gently the way the hair lays; continue doing this until he will permit you to feel him pretty near all over; then place your halter on him, gently rubbing and feeling hin over the face and head. When you have the halter on lead him orer the yard cautiously; do not frighten him or whip him. Never whip unless he is rery stubborn and does not fear you, then you should give him a few sharp cuts with the whip about his hind legs so as it will crack sharp and cause him to fear you. After you have him started feel his face, fore legs, \&c. a good 
deal more than you have whipped him, then he will soon become fond of you again. After you have learned him to move off, you may put on the bridle and learn him by gentling him as you did with the halter; you may now put on the saddle, but do it cautiously, feeling him by degrees, then get yourself a block about eighteen inches high, place this by his side and when he gets used to this get up on the block, then put your foot in the stirrup, putting a little of your weight in it by degrees; as soon as you find he will bear it you can get on the saddle and make him move off, but do it all cautiously so as not to frighten him. When you have learned him all this you may next put on the harness, carefully feeling him first, and give him to understand what you want him to do; as soon as he finds out you will not hurt him he will suffer the harness to be put on; now you may hitch him to a light log, and learn him to pull this first; when he does this well use a heavier one, and when he does this all well you can hitch him up in a wagon or sulky, but do it all carefully, and do not frighten him or you may make a bad job of it. The above principle 
84 RULES FOR A HORSE THAT SHIES.

should always be carried out in every thing you wish the horse to learn. You cannot expect a man to do any piece of work for you unless he understands it, or has learned the principle of it, much less can you expect a horse to do something he knows nothing about. If you pursue this course you can soon get the horse to understand what you want him to do, and he will become very fond of you. I will here state that if you have a very stubborn colt or horse, you may use the oil of roses and oil of cummin with the powdered button, which should be blown into his nostrils. 
TO BREAK A KICKING HORSE.

\section{HOW TO DRIVE OR BREAK A KICKING HORSE.}

Or horses with bäd habits. First take up one fore foot, bend his leg till his hoof is bottom upward, then slip a loop over his knee above the pastern joint to keep it tight. This should be done with a leather strap, forming a loop around the one, and so fixed as to buckle around the other; be careful so as to fasten it so as it cannot slip down or come loose, or you may pass a loop over the leg, and with another strap tie the loop close together, between the leg, so as to prevent it from coming down. This will leave the horse on three legs. You can handle now as you wish, as it is impossible for him to kick whilst his leg is up. This will conquer the horse quicker than any other course which you can pursue, and especially a kicker or one that runs off when he has the chance so to do.

The surest plan for a horse that will attempt to run off as soon as you hitch him up, is to fasten $\mathrm{up}$ his leg as directed above or learn him to 
hop along on three legs awhile, which he will soon learn to do. Exercise him two or three times, in this way fifteen or twenty minutes at a time, or until conquered, allowing his leg to be loosed. When you have learned him to walk in this way, fasten up his leg and put the harness on him and hitch up to sulky. Now you may drive off and need not be fearful of the horse kicking or doing any damage while one foot is up, nor can he kick or run fast enough to do any harm. But you can now drive him as you please. Shoull he want to run let him have the lines and whip too, with perfect safety; by doing this two or three times you will cure him at once of running off. The horse will be frightened at first, but he will soon see that you do not want to hurt him and will not care anything more about it. You can finally let down the leg and drive off gently without any further trouble.

I will here give you another plan to break or prevent a horse from kicking whilst working him. Loop a strap or rope around the horse's hind leg, with one end and with the other end fasten around the fore leg, allowing it just,long 
enough for him to make a step, in ordér to keep the strap from dragging on the ground or being in his way while walking. Pass a strap around his back, letting it pass under his belly and fasten it up in this way; this properly done will soon conquer him, as it is impossible for him to kick whilst the strap is to his legs.

I will still give you another plan to prevent a horse from kicking. Loop a strap around the hind leg; let it pass through between the fore legs, thence through the ring of the bridle bit, allowing the strap just long enough for him to make the step, now fasten the strap. You can now drive off with safety, as it is utterly impossible for him to kick or to do any harm. You should pass a strap around, the horse's back and fasten up the strap or ropo to prevent it from dragging on the ground.

Another still to prevent a horse from kicking when hitched up in shafts, if he will stand quiet long enough to fasten in the shafts, when you have him hitched up, loop a strong strap around the shaft on the one side, let it pass over the hips and fasten it to the shaft on the opposite side; next fasten the strap to the harness at the 
top, so as to prevent it from slipping down; you can now drive off with safety, as far as the kicking is concerned; for he cannot kick to do any harm if the strap stays firmly at its place, and the vehicle heavy enough to prevent him from raising it. 


\section{FOR THE BLACKSMITH.}

If you have a horse which you cannot manage to shoe, take up his leg as directed in the kicking horse, and handle him awhile, patting and rubbing all his legs, \&c.; when he becomes quiet, let his leg down to rest; then take it up again and rub his legs as before, and let him know what you are about to do to him; then let his leg down and commence to shoe. Should he be very fretful yet, and will not suffer you to put on the shoe, you will meet with success by making him lay down and perform as directed in making the horse lay down. 


\section{CURE FOR BOTS.}

Iix 1 pint honey with 1 quart sweet milk; give as a drench; 1 hour after dissolve 1 oz. pulverized coppeas 1 pint of water, use as a drench; then give 1 quart linseed oil; this cure is said to be effectual. The principle of giving the horse the sweet drench is good; it will generally cause the bots to let loose and take a fill of the sweet drench; then you should not fail to give plenty of phrsic to carry them off. 


\section{HOW TO MAKE A HORSE FOLLOTV YOU.}

Put your horse into a large stable or small yard; commence to gentle him a little, take hold of the halter or bridle, turn him towards you, touching him with a long whip; at the same time lead him the length of the stable or yard, rubbing him on the neck, face and head; say to him gently as you lead, come along boy, or better to use his name: whenever you turn, touch him slightly with the whip, so as to make hirn step up close to you; then gentle him again with your hand as before; he will soon learn to escape the whip and to be gentled with the hand; he will soon learn to follow you around without taking hold of the halter or bridle. Should he stop or turn from you, give him a few cuts about the hind legs; he will soon turn his head towards you, when you must always gentle him with your hand. A few lessons will make him follow you or run after you if he sees the motion of the whip; in a half hour he will follow you about the stable or yard. After you have given him 3 or 4 lessons in this way, you can take into a lot and from thence into the road, and he will follow you any where and run after you. 


\section{HOW TO LEARN HIM TO STAND STILL.}

Commence to gentle him with your hand about the head, \&c. Should he move give him a cut with the whip and put him back in the same place if he stands; gentle him with the hand as before, and continue in this until you can get around him without making him more; continue walking around him, increasing your walk, touching him occasionally; enlarging your circle as you walk around, and if he should move, give him a cut with the whip and put him again in his place; if he stands go up to him frequently and gentle him with your hand; then walk around him again. Do not keep him in one position too long at a time; permit him to come to you and walk him around or about with you; then stand him at another place, and continue as before. Do not train him more than half an hour at a time. You should never attempt to train a horse to do more than one thing at a time. Learn him the one which you have commenced on well first; then in no case should you attempt to learn him another under a week or so, always using caution no matter what you wish him to do or learn. 


\section{A LIST OF MEDICINES}

\section{BELONGING TO THE HORSE,}

THEIR PROPERTIES AND USE.

\section{ANTIMONY.}

A compound of sulphor and antimony is a good alterative. It is given with sulphor and nitre in varying quantities.

\section{SPASMODICS.}

Of these opium stands first on our list, next peppermint, tincture of pimento, turpentine, camphor, assafotida, \&c.

\section{$-0$ \\ SPIRITS OF CAMPHOR.}

The spirits of camphor is made by taking 95 per cent. alcohol, put in as much gum camphor as it will dissolve. 
91

- VINEgar.

\section{VINEGAR.}

Vinegar is a very useful application for sprains bruises, \&c. Equal parts of boiling water and coll vinegar will form a good fomentation; extract of lead or bay salt may be added with some advantage.

\section{ALCOHOL-RECTIFIED SPIRITS.}

This is used in making many tinctures and other preparations; 3 or 4 ounces of which are largely diluted with water, and given to a horse that has become fatigued while on a journey, will cause him to rally and cheerfully pursue his course to the end of the day's travel.

\section{AQUA-FORTIS.}

This is a valuable external application for destroying fungus excrescences. A pledget of tar should be dipped in the acid, then firmly pressed on the cankerous surface. Every part with which the acid comes in contact will be deadened and slough off, when healthy granulations spring up. 


\section{SULPHURIC ACID.}

Sulphuric acid is a good application for the thrush and canker, and in fact the only thing that can be relied on. It is occasionally used with tar in the proportion of an ounce of acid to 1 pound of tar.

\section{ALOES.}

The Barbadoes aloes is the best for the horse. They are of a dark brown color; they are very useful for physic, and the dose is from $\frac{1}{2}$ to 1 ounce, which should be given immediately in cases where it is needed. They are also very useful in the form of a tincture, to make which 8 ounces of powdered aloes and 1 ounce of powdered myrrh, put into 2 quarts of alcohol dilu-. ted with an equal quantity of water. This mixture should be well shoken once a day for a fortnight, and be suffered to stand, in order that the undissolved portion may fall to the bottom. This constitutes an excellent application for wounds, whether recent or of long standing and indisposed to heal. It is not only a gentle stimulant but it forms a thin coat over the wound, and shiclds it from the action of the air. 


\section{ALUMi.}

Is occasionally used internally in cases of supurgation, in the form of alum whey:-two drachms of pulverized alum being putinto a pint of hot milk; yet there are much better astringents. Its principal use is external. A solution of 2 drachms to a pint of water makes alone, or with the addition of a small quantity of white vitriol, a very useful wash for cracked heels, grease and those forms of swelled legs, attended with moisture through the skin.

\section{MUURIATIC ACID OR SPIRITS OF SALT.}

This acid is very strong and should be bottled and corked tight. As soon as it touches any muscular or living part, a change of color is perceived. It is good for corns, canker thrush, and for every case where caustic is needed, this acid is unrivalled.

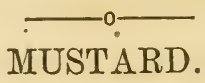

This will be found useful in inflammation of the chest or bowels. When using, it should be well rubbed on. 


\section{CANTHARIDES.}

Are the basis of the most approved and useful blister. In blistering, the hair should be cut or rather shaved off close, then rubbing in the ointment well for at least 15 minutes, repeating it every day until it does its work. After it has acted you may relieve the torture of the animal by the application of olive oil or lard. In deep seated sprains or inflammations, the blister should not be discontinued too hurriedly. An infusion of 2 ounces of the flies in a pirut of oil of turpentine for several days is used as a liquid. blister, and when sufficiently reduced with common oil, is called a sweating oil, and gradually abates or removes old or deep inflammation or cause of lameness.

\section{$\longrightarrow$ \\ CHARCOAL.}

This is occasionally used with linseed meal, for poulticing offensive ulcers and cracked heels; it removes the unwholesome smell and purfies the parts so that they heal easily. 


\section{BALL OR PILLS.}

The usual and most convenient mode of administering medicines, is in the form of balls compounded with sweet oil. Balls should never weigh more than $1 \frac{1}{2}$ ounces, otherwise they will be so large as not to pass down the gullet. They should not be more than one inch in diameter, and three inches in length. The mode of delivering balls is not difficult to acquire. The horse should be backed in the stall, the tongue drawn out gently with the left hand on the off side of the mouth, not continuing to pull, but by pressing the finger against the lower jaw. The ball being now taken between the tips of the fingers of the right hand, is passed rapidly up the mouth as near the palate as possible, until it reaches the root of the tongue. It is then delivered with a slight jerk, the hand being immediately withdrawn. Its passage should be watched down the left side of the throat; if it does not pass down a slight tap under the jaw or chin, will generally cause the horse to swallow it, or a few gulps of water will convey in into the stomach. Very few balls should be kept made. 
CLYSTTERS.

\section{CLYSTERS.}

These are useful and too often neglected means of hastening the bowels to their speedy action, where diseases require it. The old ox bladder filled and tied on the wooden or elder pipe, answers every purpose for injecting the fluid into the intestines. For a moderate clyster take 2 ounces of soft or yellow soap, mix with 1 gallon of warm water; for a more active clyster take $\frac{1}{2}$ pound epsom salts, dissolve in the same quantity of water.

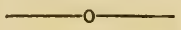

\section{LINSEED.}

An infusion of linseed is often used instead of water for the drink of a horse with a sore throat, catarrh, disease of the urinary organs, or of the bowels. Thin gruel is preferable, being as soothing and more nutritious. Linseed meal makes an excellent poultice for almost any purpose. 


\section{DIGITALIS.}

This should be powdered, put into a black bottle, corked tight, and kept in a dark place It is one of the most valuable medicines in vertinary practice, and on account of its action in diminishing the pulse and general irritability of the system, is very useful in inflammations, \&c. It is usually given in combination with emetic tartar and nitre. The average dose is 1 drachm of digitalis, $1 \frac{1}{2}$ drachms emetic tartar, and 3 drachms of nitre, repeated twice or three times a day. When the horse begins to amend the dose must be diminished one-half, and in a few days it may be omitted altogether, but the emetic tartar and the nitre should be continued during several days.

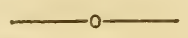

\section{PITCH.}

Is used in plasters. The best plaster for sand crack consists of 1 pound of pitch and 1 ounce of yellow beeswax melted together. 
MASHES.

\section{MASHES.}

Constitute a very important provender in sickness or health. A mash given occasionally to a horse that is fed on dry meat, prevents him from becoming dangerously costive. To the over-worked and tired horse, nothing is so refreshing as a warm mash, with his usual allowance of corn in it. Mashes are used for putting horses in good order for sale, giving him a round and plump appearance. They are made by pouring boiling water on bran, stirring it well cover over with a cloth, and let it remain until cool enough for the horse to eat; if in the heat of summer, a cold mash is preferable,-yet it should be made with hot water, and remain until it is cold.

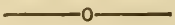

GINGER.

Is as valuable as a cordial as the gentian is as a tonic. These are both valuable in horse powders. 


\section{FOMENTATIONS.}

Are to open the pores of the skin and promote perspiration in the part, so as to abate local swellings, relieve pain and lessen inflammation. The effect depends upon the warmth of the water and not upon any herb that may have been boiled in it; they are best applied by means of flannel dipped in the hotwvater, or on which the water is poured, which should be as hot as the hand will bear. The fomentation should be continued for 15 or 20 minutes, but if kept on with for half an hour will be better. The parts fomentated should be wrapped or covered up warm. Great good has sometimes resulted from fomentations.

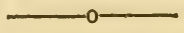

\section{GENTIAN.}

Stands at the head of vegetable tonics, an infusion of which is one of the best applications for putrid ulcers known. 


\section{OPITIM.}

Is the most valuable drug on the list as an anti-spasmodic; it is also a sedative and astringent. As au anti-spasmodic it enters into the colic drink; as a sedative it relaxes spasms of the muscular system. Opium should, however, be given with caution. In the early acute stage of fever it will be a bad practice to give it even in the smallest quantity. When the fever has passed it may be given with great benefit.

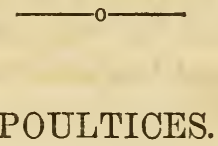

Few persons are aware of the value of these simple applications in abating inflammation, relieving pain, cleansing wounds, and disposing them to heal. In all inflammations of the foot they are very beneficial, by softening the horn hardened by the heat of the inflamed foot.Linseed meal forms the best general poultice. 


\section{DRINKS OR DRENCHES.}

A drink is not so portable as a ball; it is more troublesome to administer, and a portion of it is usually wasted. Medicines given as a drench will act upon the horse much quicker than when given in balls, but the great objection is in wasting a portion. Too much of the drink should not be forced into the horse's mouth at once, as it will be found very difficult to make him swallow large quantities; small portions should be given, which he should be made to swallow before any more is put into the mouth.

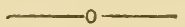

\section{TAR.}

Melted with an equal quantity of grease forms the usual stopping of the farrier. It is warm or slightly stimulant, and is therefore useful in dressing bruised or wounded feet; it prevents the penetration of dirt and water to the wounded part; it is also useful in chronic coughs. 


\section{LINIMENTS.}

Are designed to remove deep seated pain and inflammation, by gently stimulating the skin. The following is an excellent liniment for old swellings, sprains, or rheumatism: 2 ounces of hartshorn, 2 ounces camphorated spirits, 1 ounce oil of turpentine, and $\frac{1}{2}$ ounce of laudanum, mixed well together; or 1 ounce of camphor may be dissolved in 4 ounces of sweet oil, to which may be added 1 ounce of oil of turpentine. A little powdered cantharides or tincture of cantharides or ground mustard, will render either of these more powerful, or convert it into a liquid blister.

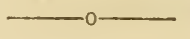

\section{SULPHUR.}

Is the basis of the most effectual application for mange. It is an excellent alterative, combined usually with antimony and nitre, particularly for mange, surfeit, grease, hidebound or want of condition, and it is a useful ingredient in the cough and fever ball. 


\section{COMMON SALT.}

Is very useful in a clyster. A solution of it has been given as an aperient drink, sprinkled over hay or in mash, it is very palatable to sick horses; few things will so soon recall the appetite as a drink composed of 6 or 8 ounces of salt in solution. Horses in health, it promotes the digestion of the food. There are few better lotions for inflamed eyes than a solution of $\frac{1}{2}$ ounce of salt, in 4 pints of water. An ounce of salt to 8 pints of water is a good embrocation for sore shoulders and back.

\section{$\longrightarrow$ \\ TURPENTINE.}

The common liquid turpentine has been described as one of the best diuretics; for the removal of cholic it stands unrivalled; with cantharides it is the basis of the. sweating blister for old sprains and swellings: 


\section{CHLORIDE OF LIME.}

This is very good for removing the smell of fistula, withers, poll evil and ill conditioned wounds and ulcerations. Chloride diluted with twenty times its quantity of water, and used as a wash for the wounds, will remove any infection that may lurk about them. One pint of the chloride, mixed with 3 gallons of water and brushed over the walls, manger and rack of the foulest stable, will completely remove all infections.

\section{GINGER ROOT.}

This is an excellent stimulant. It is useful in loss of appetite and flatulent colic, while it rouses the intestinal canal to its proper action. The ginger and gentian powdered is also very much used. Brown sugar is useful in the loss of appetite. 


\section{ZINC OR CALAMINE POWDER.}

This made into an ointment is valuable for healing. Take five ounces of lard, one ounce of rosin, melt them together and when these begin to get cool, stir in 2 ounces of calamine, finely powdered. If the wound is not healthy, a small quantity of common turpentine may be addecl. This salve justly deserves the name of healing ointment. The calamine is sometimes sprinkled with advantage on cracked heels.

\section{$\longrightarrow 0-$ \\ THOMPSON'S NO. 6.}

This is a good carminative for relieving colic, arresting mortification, and for sprains, rheumatism, pains, \&c. As a general stimulant it may be taken in teaspoonful doses in water and repeated as the case demands. Take $\frac{1}{2}$ gallon of fourth proof brandy, $\frac{1}{2}$ pound pulverized gum myrrh and $\frac{1}{2}$ ounce of African pepper, mix and macerate for ten days, when it will be ready for use. 


\section{LIST OF \\ DOMESTIC MEDICINES \\ RECEIPTS, \&C.}


CEMENT TO MEND CHINA AND CLASS. 111

\section{CEMENT TO MEND GLASS AND CHINA.}

Take 2 pounds good gum shellac, 2 ounces pulverized borax; put into an earthen crock, filled balf full of water; boil until all is dissolved, then take out a portion and roll into sticks while hot, on a table or smooth board.

\section{Directions For Use.}

Heat the edges of the ware over a fire or hot store, then heat the cement in the same manner; put the cement on the edges of the ware regularly, heat it again along the edges and place together as quick as possible, holding them firm until the cement cools, being careful to put the preces together as they came off, so as it will fit nicely. If done properly it will hold so firm that the ware will break some other place before where it has been monded.

\section{$\longrightarrow$ \\ LUNAR CAUSTIC.}

Is very useful in curing bites of rabid dogs, . . and for removing ulcerations of any kind. 


\section{.AMERICAN HEIEBORE.}

\section{Medical Properties and Use.}

This has been tried by many physicians and has proved a valuable remedy in chronic rheumatism and gout. It is certainly a powerful emetic when given in large doses, and the effect continues a long time. In over doses it effects the functions of the brain and nerrous system, in a powerful manner producing giddiness, prostration of strength, \&c. It has arrested the paroxysm of gout and giren relief in some unyielding cases of chronic rheumatism. It requires to be given with great caution and under vigilant restrictions. The mode of administration is in the form of a tincture. A saturated tincture is made in wine and 3 parts of this is mixed with 1 of the wine of opium; of this mixture from 15 to 20 drops. In some cases however, 1 drachm of the mixture will be required to give relief, which quantity generally vomits and always gives relief. The proper method of preparing this tincture is to macerate 8 ounces of the sliced root in $2 \frac{1}{2}$ pints of span- 
ish white wine, let it stand for 15 days and filter. Before given, it must be mixed with onefourth its quantity of the wine of opium; from 15 to 60 drops is a dose. In some cases less than the nauseating point will cure the disease, if not it must be carried to that point.

\section{EMETIC FOR POISON.}

If poison should be administered or swallowed accidentally, take two tablespoonsful of ground mustard, mixed with warm water, which will operate as an instantaneous emetic.

\section{$\longrightarrow$ \\ INDIAN TURNIP. \\ Medical Properties and use.}

The Indian turnip, when partially dried and grated and mixed with honey, is good for the coughs of old persons, when there is no ferer. It also enters into many of the cough syrups. 


\section{SENECA. SNAKEROOT.}

In chronic rheumatism it has been of great service by its universal stimulant and diuretic effects. If however an ounce of the root be boiled in a pint of water to a strong tea, and all be taken at opce, a violent vomiting, purging and diuresis occurs. The disease has been known to yield to one dose, but this is a desperate one, and should not be ventured upon by a person much debilitated; take a wine glass full 3 times until the water is evacuated in uterine complaints,-especially in painful menstruation is the seneca a good remedy. Begin one day before the return of the catatmenia and take it in such portions as the stomach will bear, every two hours until the flow commences. For this put 1 ounce of the root in a pint of water, give a small wine glass full every one, two or three hours. 
CEMENT FOR GRAFTING.

\section{CEMENT FOR GRAFTING.}

Take 1 pound of beeswax, 1 pound of rosin, 1 pound of tallow; put all into a pan and heat until the ingredients are melted, after cooling it will be ready for use. When using put a coat of the cement over the grafted part, thick enough to prevent the rain and air from penetrating.

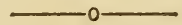

GUAIACUM, AMMONIATED TINCTURE.

Take 4 ounces powdered gum guaiacum, $1 \frac{1}{2}$ pints spirits of ammonia, put them together and let the mixture stand for fourteen days, when it will be ready for use. Shake the bottle occasionally. This is a celebrated remedy in the treatment of chronic rheumatism. The dose is from one to two teaspoonsful three times a day, given in milk or some mucilaginous tea. The stomach must be well cleaned before the tincture is used, and the diet light. 
116 COMPOUND TINCTULE OF GENTIAN.

\section{COMPOUND TINCTURE OF GENTIAN.}

Take of gentian root bruised 2 ounces, orange peel do. 2 ounces, cardamom seed do. $\frac{1}{2}$ ounce, proof whiskey 1 quart; add the other ingredients to the whiskey, and skake the bottle once a day for fourteen days, when it will be ready for use. This is much used in dyspepsia and debilitated states of the digestive organs. The stomach should be cleaned before it is given. It is not admissable where there is fever. Dose from one to two teaspoonsful in water, to be repeated before breakfast, dinner and supper.

\section{OINTMENT FOR MILCH SCALD ON THE FACES OF INFANTS.}

Take 6 drachms of beefs marrow, 2 drachms oil of sweet almonds, 1 drachm red peruvian bark, powdered, mix and melt over a slow fire. Apply every day, washing it off every morning with mild soap. 
SIMPLE TINCTURE OF RHUBARB.

\section{SIMPLE TINCTURE OF RHUBARB.}

Take of best Turkey rhubarb 3 ounces and pulverize, good whiskey 1 quart, add the rhubarb to the whiskey and shake it every day for a week, then let it stand ten days and filter through paper, or let it stand without filtering. From a tea spoonful to a large table spoonful is a dose according to the age of the person and nature of the case. It is a good purgative in costive habits. Take it at bed time in sweetened water.

\section{$\longrightarrow$ \\ SIMPLE SYRUP OF RHUBARB.}

Take of best Turkey rhubarb 2 ounces, water 1 pint, macerate the rhubarb in the water warm for twenty-four hours; strain off, add 2 pounds of refined white sugar and simmer until they are well mixed, add 2 tablespoonsful of whiskey, stop it tight in a bottle for use. This is a good medicine for infants in teaspoonful doses. 


\section{AMERICAN COLUMBO:}

\section{Medical Propertics and Use.}

This is a mild tonic, calculated to meet the indications alike with the other bitters of its class. It is a very good and pleasant tonic in $i_{\text {ndigestion and dyspepsia, improving the appe- }}$ tite and digestion. It is given in infusion and in substance-1 ounce of the pulverized root infused in a pint of boiling water. A small wine glass full of the infusion may be taken once in 2 hours, or from thirty to sixty grains of the pulverized substance, in sweetened water, from 3 to 5 times a day; but the most common way of using the columbo is in combination with other tonics, such as gentian, orange peel, and columbo, of each 1 ounce powdered, then add to them 1 quart of whiskey, of which bitters a table spoonful may be taken in water three times a day, as a tonic in cases of debility. 


\section{BLACK ALDER.}

The berries of this plant are sometimes used, but the bark is the proper medicinal part of the shrub. It is best adapted to the cure of flabby, ill-conditioned ulcers and mortifications, in which a strong decoction is freely used with great benefit. It should be given internally several times a day, as well as applied as a wash and poultice to the parts. A saturated tincture, both of the bark and berries is used internally. 


\section{THE PRICKLEY ASH.}

\section{Its Medical Properiies and Use.}

The prickley ash has a good reputation in the United States as a remedy in chronic rheumatism. In that disease its operation seems analagous to that of mazorion and guaiacum, which it nearly resembles in its sensible properties. Many physicians place so much confidence in it that it is generally kept by the apothecaries. It is most frequently given in decoction-an ounce being boiled in a quart of water and taken in small quantities, frequently repeated. Dr. George Hayward. of Boston, took it in his own case of chronic rheumatism with evidently good effect; he took a pint of the decoction a day, diluted with water so as to weaken its pungency. The powdered bark may be taken in doses of from 10 to 20 grains, and frequently repeated. Dr. Bigelow says it is also given with good effect in cases of old indolent sores; it is given internally and applied to the sore in the form of a wash. Doctors Barton and Thatcher both speak highly of this medicine. 


\section{AMERICAN GENTRAURY. \\ Its Medical Properties and Use.}

- Every part of this plant is a pure and very strong bitter. It is used in form of tea or tincture and is good for ague and fever. It was used in the yellow fever at Philadelphia with good effect. It may be given even when the fever is on, in such quantities as the stomach will bear. It is not apt to nauseate and is an excellent tonic for the stomach, which improves the appetite and promotes digestion. It is highly recommended by Drs. Barton, Chapman and - Elliott, all of whom are physicians of high respectability.

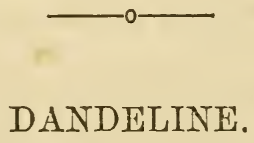

Has been much employed in Germany and the United States, and is certainly a valuable 
remedy in chronic diseases of the liver and the digestive organs generally. It is also a good remedy in diseases of the spleen. It is beneficial in consumption and as a general alterative when combined with sarsaparilla, and invaluable in scrofula. One ounce of the fresh root, or $\frac{1}{2}$ ounce of the dried, and the same quantity of sarsaparilla put into a pitcher and a pint of boiling water poured on it at night, to be used at pleasure next day, so that all is taken before bed time, or as much more as the stomach will bear. This repeated for a month, produces a fine effect on the system, when the blood needs purifying or in cases of chronic affections of the liver.

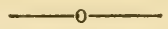

\section{BLOOD ROOT OR PERCOON ROOT.}

Medical Properties and Use.

The blood root is an active emetic and cathartic, which acts finely on the liver. It has been given in pneumonia, catarrh, whooping cough, 
croup, consumption, rheumatism, jaundice and dropsy of the chest. For rheumatism, it may be given in 2 or 3 grain pills, 3 or 4 times a day. It is an effectual remedy for the yellow water in horses: 3 or 4 ounces of the fresh root may be bruised and a pint of water added, the juice of which should be squeezed out for a drench; 1 or 2 doses will cure. It purges the horse freely. The tincture is often used: 2 ounces of the root to a quart of spirits makes the tincture, $\frac{1}{2}$ an ounce of which is a dose for an adult.

\section{$\longrightarrow$ \\ BONESET OR THOROUGHWORT.}

Medical Properties and Use.

Thoroughwort is tonic, diaphoretic, and in \$ large doses emetic and purgative. It is good in intermittent fevers to break the chill, if given in large doses in the form of warm tea as the chill comes on; in less doses a little warm it will sweat the patient freely; in large draughts taken 
cold it acts as a tonic and prevents the return of the chill. It is good in pleurisy as a sweat or in heavy colds; it is also good when made into a syrup for bad coughs, and in some forms of consumption, where the patient is weak and the skin hot and dry. It grows in almost every part of the United States, but mostly in the Western and Southern divisions, and should be gathered in September. Every part of the plant is medicinal, but the leaves and flowers are best. It should always be given in the form of a tea.

\section{BITTER ROOT OR SILKWEED.}

\section{Medical Properties and Use.}

The root is the part used in the form of bitters in asthma and cartarrh, also coughs and dyspepsia and in rheumatism. It may be taken

- in the form of bitters in quantities sufficient to purge gently and freely, or in powder in 20 grain doses, 3 times a day, or it may be given in strong infusion, 1 ounce of the root to a pint of water and drink in such doses as the stomach will bear. 


\section{PLEURISY ROOT.}

Medical Properties and Use.

It has long been employed by the regular medical faculty as a valuable medicine in pleurisy, catarrh, pneumonia, consumption and other diseases of the breast, and is evidently useful in all these cases. It is good in acute rheumatism and dyspepsia. It may be given in the form of a strong tea, or in powder; if in powder from 20 to 60 grains may be given several times a day, in sweetened water.

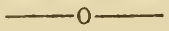

\section{EXTEMPORE GASEOUS CHALYBEATE WATER.}

Take of pure sulphate of iron 2 drachms, white sugar 3 drachms, pulverize, mix and divide into 12 powders. Then take of super carbonate of soda 2 drachms, white sugar three drachms, mix and divide into 12 powders. Mis one of each of the powders separately in half 8 
GENTIAN:

tumblerful of water, pour together and drink while effervescing. This is a pleasant drink and a good tonic for a weak stomach.

\section{GENTIAN.}

Medical Properties and Use.

Gentian posesses in a high degree the tonic properties which characterize the simple bitters. It excites the appetite, invigorates the powers of digestion. It may be used in all cases of disease depending upon pure debility of the digestive organs, or requiring a general tonic impression; as dyspepsia, gout, difficult menstruations, hysteria, scrofula, intermittent fever, diarrhœa, and worms. It is given in the form of infusion or tincture. The dose in infusion is a wine glassful 3 or 4 times a day. Infuse $\frac{1}{2}$ ounce of the powdered root in a pint of water. A tea spoonful of the tincture may be given as often in a little water. 
RATTLEWEED ROOT.

\section{RATTLEWEED ROOT.}

This unites with a tonic power the property of stimulating the secretions, particularly those of the skin, kidneys and mucus membrane of the lungs. Its medical properties are found in its salutary effects upon the nervous system, in neuralgia of the heart, in sciatica, and in other forms of rheumatism. It is equal if not superior to the colchicum in rheumatism, and far superigr to it in neuralgia of any description. I have used it extensively in those cases, and with the happiest effects. I cured myself of a severe sciatica in twenty-four hours with it, but the dose was too large, producing violent sickness, great prostration, nausea, vomiting and profuse perspiration. I took 3 or 4 drachms of the saturated tincture at one dose; but it effects the cure completely when properly prepared. It acts upon the stomach and bowels powerfully. and its full effects are not obtained until it purges freely. The following is the best formuls for its preparation.

$\frac{1}{2}$ pound powdered root,

1 pint alcohol. 
Mix and macerate for 20 days and filter. One tea spoonful should be taken 3 times a day, in sweetened water, which may be increased or diminished so as to produce 3 or 4 operations on the bowels in 24 hours. I have seen some persons that it would not purge. It sometimes produces rertigo before it begins to operate, but these symptoms will all subside after the purging commences, yet it will cure if it does not purge. Several cases of Vitus' Dance are recorded by Dr. Jesse Young, in which it performed cures after other remedies had failed.It is usually administered in decoction by those living in the country. One ounce of the powdered root is boiled in a pint of water for a few minutes, and a small wine glassful given from 3 to 5 times a day according to its effects.

\section{PIPSISSEWAY OR WINTER GREEN.}

This is an evergreen found in pine woods and in light shady soils in all parts of the United States, which blossoms in mid summer. IF he whole plant has rather a pungent and bit'ier taste. 


\section{Medical Properties and Use.}

It is aiuretic and tonic and is useful in all cruptive forms of diseases, especially in scrofula and cancer. A strong decoction may be made of the leaves and twigs, and a gill taken 3 times a day. Many cures of old ulcers, sore throats and like affections have been ascribed to the use of the pipsisseway. A decoction made of the leaves and given in small portions is excellent for colic in children. For grown persons it should be put in good rye whiskey, which, if made strong will scldom fail to cure the severest cases of colic and cramps. The pipsisseway put into whiskey and distilled the same as Wickey's cholera medicine is much better. Dose for an adult is from 1 to 3 tablespoonsful, for children from 10 drops to a teaspoonful.

\section{$-0 \div$ \\ TO THE CONSUMEP.}

If you want to save moncy never buy your castor oil by the bottle, but buy a pint of oil of some honest druggist, and you will then be able to perceive the difference. If put up in bottles 
it will cost you from 50 to $62 \frac{1}{2}$ cents; by the pint it may cost you 31 cents per pint. This is a great saving, as the article is always needed in a family. Never buy any other medicine or any thing that goes by measurement in small quantities, and especially such articles as come into every day use. Paying from 40 to 100 per cent. more for domestic articles will amount to a considerable sum in 5 or 10 jears. Some persons may say: "I am too poor and cannot spare the money." That kind of argument will not hold good. By saving 50 or 100 per cent. is the means to make you able. Try the experiment and you will soon be convinced; money is worth but 6 per cent.

\section{FOR PICKLING PEARS.}

- Take 1 pound of sugar to one quart of vinegar; 6 pounds of pears, peeled and quartered; $\frac{1}{2}$ ounce of cinnamon bark, broken in small pieces; $\frac{1}{2}$ ounce of cloves. Dissolve the sugar in the vinegar, then put the pears, cinnamon and cloves into a pot or crock, pour over the vinegar and 
FOR PICKLLYG PEARS.

boil all ingether until the pears become soft, and you have a pickel far superior to any preserves. This is worth giving a trial. Should the pears be too sweet, add a little vinegar at any time, . heating after the addition.

\section{ON THE PRESERVATION OF HEALTH.}

As this work is designed for the benefit of families as well as other purposes, it is hoped that a chapter on the preservation of the health of young girls will not be out of place. What we design to say in this chapter, will be applicable to the girl of ten years and upwards. It is the duty of the mother or guardian so to direct the conduct of the daughter that she may. enjoy the blessings of life, and become a useful member of society. But in order to lay the foundation of future usefulness, the health. should be well guarded in early life. Much of course depends upon a good constitution, and 
132 ON THE PRESERVATION OF HEALTH.

strict attention should be paid to its development and preservation. The child at an early age should be guarded against all that would - tend to weaken or derange this desirable attribute of the human system.

Exposure is one of the principal sources of injury to the constitution, and therefore the clothing should always be adapted to the season of the year, and the temperature of the air, whether children are at home or abroad. Girls are generally clothed sufficiently warm while at home, but when they are going from home, they change their warm apparel for thiner and cooler garments. They are often allowed to expose themselves to the chilling blasts of winter, with their arms naked, their breasts and shoulders cxposed, and their feet clad with thin stockings and shoes, in the place of those just laid aside, which were warm and comfortable.This is a practice that cannot be too much deprecated, being one of the great evils of dress and fashion, upon whose altar thousands have been sacrificed. How many do we find in these days with enlarged tonsils and broken croaking voices, the fruits of exposure and nothing else? 
The practice of tight lacing is another fruitful cause of destruction of health and brokendown constitutions. Young girls should not lace at all -an easy smooth jacket to make the dress fit smoothly is all they should wear. Are we asked why lacing is injurious? We answer, first, the ribs are soft and very elastic and the cartilages that join them to the breast bone are softer than the ribs. If then a jacket or corset be laced around the ribs or chest, so as to prevent a free and full play of the ribs at every inspiration, in the same proportion is the cavity of the chest diminished, and consequently the lungs are deprived of a certain amount of atmospheric air, in proportion to the contraction of the ribs, produced by the laced jacket or corset. Thus the order of nature is deranged and the system is deprived of that due proportion of oxygen which is necessary to health, the vitality of blood and the vigor and proper proportions of the system. One of the consequences of tight lacing therefore is, that the lungs are prevented from discharging a due portion of carbonic acid gas from the blood, and receiving in lieu therefor of due proportion of oxygen from the atmos- 
134 ON THE PRESERVATION OF HEALTH.

phere. Hence the person looks pale, the lips assume a blue or purplish color, the breathing is labored, the breast heaves and the circulation is prevented from going on as freely as it should. The small air vessels of the lungs are partially obliterated, they become diseased in their action and tubercles form in them or the lungs; these remain to become in a few years the seeds of an incurable consumption.

Again: The free action of the heat is prevented by tight lacing and the consequence is it labors like a dying man, but in vain-it cannot get relieved from its fetters. The blood is prevented from flowing with that freedom and ease which are essential to the well bcing of the system, and the violent exertions which the heart must make in order to carry on the circulation, become the cause of disease in that organ, which perhaps can never be cured. Another evil of lacing: The stomach is always included in the deadly grasp of the corset. The lower floating ribs are forced to take the place the stomach should occupy in part; the skirts are compelled to grow tou narrow, the liver is also pressed too closely and the stomach is bound as with a cord. 
The gastric juice is partly prevented from secreting and that which is secreted is unhealthy, the ducts of the liver and pancreatic gland are prevented from performing their healthy functions and consequently the food is not taken in due quantity to nourish the system, and what is taken is not properly digested, for the want of a free and healthy action of the digestive functions. Dyspepsia is the result, - a feeble and finally a destroyed constitution. For all the powers of nature must act freely and naturally, or a sound constitution and good health can never be enjoyed.

Nothing is so fascinating to an intellectual. young man as a well cultivated mind, a rosy cheek, an intellectual eye, and a corresponding expesssion of countenance; these you cannot have if you suppress any of the healthy functions of the system. Exercise is another essential item to promote the health of girls, and this they should be allowed to take freely. At an early age, let them run and play, jump the rope, throw the hoop, leap and skip; for free exercise gives freedom to the muscles and joints and strengthens the nerves, all of which are 
necessary for the building up of a good constitution. Girls should be allowed to sleep onethird of their time or eight hours in twenty-four, and when younger-they should sleep more. The young of all the animal creation require more sleep than those that are fully grown: girls, therefore, should retire early that they may obtain sleep enough; rise early and enjoy the benefit of the morning air, which is bracing to their systems. After children are ten years old, they should not sleep more than two in a bed, and there should not be more than two beds in a room, unless the room be very large and well ventilated. Girls should rise early and air and set their rooms in order; they should use free ablution of cold water over their breasts and arms, especially as far as they are in the habit of exposing them to the air, as this will prevent their taking cold as easily as they otherwise would. The diet of children should be plain and simple, as their digestive powers are not as strong as those of grown persons. The quantity should always be proportioned to the age and strength of the child. Much mischief is done by letting children eat too much. They 
should be allowed full time to eat and be taught to chew their victuals well. They should be taught to eat any thing that is common, so that they may appear easy at table at all times, and make their friends so likewise. Frequent bathing is of great service to youth; it invigorates the constitution and gives a fine complexion. The bath may be changed according to the season; it may be cold, tepid or salt. When the cold bath is used, either fresh or salt, the skin should be well rubbed with a coarse towel, as well before they go into the bath, as after they come out. When children are healthy liquid food is as a general rule, better for them than solid food, because it supplies more blood, and this is needed to form and build up the solids, but they should be allowed some of both

Children should always take light. suppers and light breakfasts. Their dinner should be of more substantial food and taken freely. But they should never be allowed to eat in haste, as nothing aids the powers of digestion more than the perfect mastication of food. 
HEALTH.

\section{HEALTH.}

Its Value Conditions, Preservation and Res- toration.

Health consists in the vigorous and normal or constitutional action of all the physical organs and functions. Life consists in precisely the same action: in proportion to the vigor of this action is the amount of both health and life, but in proportion as the physical functions are enfeebled or diseased, is health enfeebled and life diminished. But in proportion as we improve our health do we thereby increase life itself. Viewed in any and every aspect, health is life and life is health. By as much therefore as life is valuable should health be preserred if good and restored if feeble.

Health is the great seasoner or relish of all our blessings; nor is it possible to enjoy the latter except by means of the former: without health what can wo be? What can we do?What can we enjoy? For other things being equal, our capabilities of accomplishing and 
enjoying are proportioned to our health and diminished by disease. If we possessed all the wealth, and all the honors, and all the blessings mortals can possess, we could enjoy them only in proportion as we had health, and their value would be diminished just in proportion to its decline. Suppose we were sick and our appetite thereby destroyed, the richest food and most delicious fruits, instead of rendering us happy would nauseate us. How different if we were healthy. How a good appetite, the produce of health, would enjoy them. Well might the glutted alderman offer a ragiged boy a guinea for his appetite for breakfast. The rich invalid is poor, but he who is healthy is rich, because his fund of life and his capacities for enjoyment are proportionally great. Reader, if brought to the brink of the grave, your last hour come, what would you give? What that you possessed - would you not give for another year of life and its pleasures? Astor's thirty millions would be cheap. To impair health in obtaining any amount of earthly goods is a dear exchange, since then to preserve or regain health is to preserve, prolong or regain life itself, and to impair 
the former is to destroy the latter and its pleasures, as well as hasten death; and since the value of life so infinitely surpasses that of all other earthly blessings, what consumate folly to trifle with health on any account. Then ho,w much more foolish and even wicked virtually to throw it away for nothing, in our eager pursuit of those trifling objects, wealth, honors, and the like, which mainly engrosses mankind? What, sacrifice life upon the altar of mammon? For be it remembered, that no human being can impair his health at any period of his life, without proportionally shortening his days; without being brought to a strict account at the close of life, and be compelled to end it as much sooner than he otherwise would, as he has injured his health during his whole lifetime. Let me urge upon you the infinite importance of preserving your health. This effectually done, millions of money bestowed on each reader could not equally . benefit you, because of the incomparable greater value of health than money. Let your own experience testify. Which of you has not, some time or some how, induced debility or pain in one portion of your system or anotber, which 
will cripple you for life. A foolish ambition breaks down the constitution of an incalculable number of our youths, unwilling to be outdone they will work at the top of their strength as long as they can stand, perhaps over heat themselves, or in a single day or week bring on some complaint which debilitates them for life, and carries them to a premature grave. An ambitious youth wishing to show his employers what a great day's work he could do, shovelled till he lamed his side, so that for fifteen years he has been a partial invalid, cannot do any kind of work, nor more than half the amount he formerly did, besides working in almost perpetual pain. Nor is this the half; whatever enfeebles the health enfeebles the mind by weakening and disordering the brain. So perfectly are body and brain inter related, that all the conditions of either react upon each other; whatever augments the health, strengthens the body and thereby invigorates both the brain and the mind. What is the true value of the mind? How much could you afford to give for double the amount you now possess? Neither money nor any thing else can measure its value. To improve our 
minds is the most effectual mode possible of augmenting all the capabilities, all the pleasure, all the virtue of this life, and ripening for another, and hence should be the paramount business of our whole lives. Health allows you to be always on hand for business, from which sickness takes you and compels you to entrust its management to others, always disastrous, or cuts off your wages if a laborer, creates large ductors, nurses and a host of other incidental bills, and occasions a great variety of pecuniary losses. So measurably if any member of your family is sick, especially a wife. How many, reader, if they and their families had always been well, would have been rich who are now poor? Considered which ever way you will, to preserve the health if it be good, and if poor to regain and then preserve, should be the paramount business of life, should take precedence over all others, and be our first great concern. Come then readers one and all and let us make it our permanent business to preserve and augment our health; let us allow ourselves to do nothing that shall impair it; let us make and take time to do every thing in our power to invigorate it. 


\section{HOW TO PROLONG LIFE.}

The following should be carefully perused especially by the young. Are there any among you my young friends, who desire to preserve your health and cheerfulness through life, and at length arrive at a good old age? If so listen to what I am about to tell you.

A considerable time ago I read in one of the newspapers of the day, that a man had died near London at the advanced age of 110 years, that he had never been ill, and that he had maintained through life, a cheerful, happy temperament. I wrote immediately to London to know if in the man's treatment of himself there had been any peculiarity which had rendered his' life lengthened and so happy, and the answer I received was as follows:

"He was unusually kind and obliging to every body; he quarreled with no one; he ate and merely that he might not suffer from hunger or thirst and never beyond what necessity required; from his earliest youth he never allowed himself to be unemployed; these were the only means he used." 
I took a note of this in a little book where I generally write all that I am anxious to remember, and very soon afterwards I observed in another. paper that a woman had died near Stockholm at 115 years of age; that she never was ill, and was always of a contented disposition. I immediately wrote to Stockholm to learn what means the old woman had used for preserving her health, and now read the answer:

"She always had a great love of cleanliness, and in the daily habit of washing her face, hands and feet in cold water, and as often as opportunity offered she bathed in the same.She never ate or drank any delicacies or sweetmeats, seldom coffee, seldom tea, and never wine."

Of these likewise I took a note in my little book. Sometime after this I read that near St. Petersburg, a man died who had enjoyed good health until he was 120 years old. Again I took my pen and wrote to St. Petersburg, and here is the answer:

"He was an early riser, and never slept beyond seven hours at a time; he never was idle; he employed himself chiefly in the open air, and particularly in his garden; whether he walked 
or sat in his chair he never permitted himself. to sit awry or in a bent posture, but was always perfectly straight. The luxurious and effeminate habits of citizens he held in contempt."

After having read all this from my little book I said to myself: "you will be a foolish man indeed not to profit by the example and experience of these old people." I then wrote out all that I had been able to discover about these happy old people upon a card, which I suspended over my writing desk, so that I might always have it before my eyes to remind me what to do, and from what I should refrain. Every morning and evening $I$ read over the contents of my card and obliged myself to conform to its rules.

And now my dear young readers, I can assure you on the word of an honest man, that I am much happier and in better health than I used to be. Formerly I had the headache every day and now I suffer scarcely once in three or four months. Before I began these rules I hardly dare to venture out in the rain or snow without catching cold. In former times a walk of half an hoưr's length fatigued and exhausted me,now I walk miles without weariness. Imagine then 
the happiness I experience, for there are few feelings so cheering to the spirits as those of constant good health and vigor. But, alas! there is something in which I cannot imitate these happy old people, and that is I have not been accustomed to all this from my youth. Oh! that I were young again that I might imitate them in all things; that I might be happy and longlived as they were.

Little children who read this; you are the fortunate ones who are able to adopt in perfection this kind of life. What then prevents your living henceforward as healthful and happyly as the old woman of Stockholm or âs long and useful as the old men of London and St. Petersburg. 


\section{LIQUID OPODELDOC.}

Take $\frac{1}{2}$ pint 95 per cent. alcohol, 1 ounce camphor, $\frac{1}{2}$ pint turpentine; dissolve the camphor in the alcohol; then add the turpentine. For rheumatism, head ache, sore throat, old strains, swellings, cramps, numbness, stiffness, weakness, pains in the joints, corns, slight burns frost bitten feet, \&c.

\section{Directions FOR USE.}

Rub it well on the part affected with your hand or a piece of muslin, night and morning, and if convenient, at noon. In obstinate cases avoid as much as possible exposure to a damp atmosphere, to the extremes of heat and cold. keep the feet dry and comfortable, and be temperate in eating and drinking. For corns, lay a piece of flannel on them and moisten occasionally with the opodeldoc, avoid tight shoes. Travellers and families ought always to keep a bottle by them; it only requires a trial to prove its efficacy; keep the bottle closely stopped. In some cases of rheumatism and other affections, if a piece of flannel be worn over the part, relief will be obtained sooner. 
148 DR. WICKEY'S CHOLERA MEDICINE.

\section{Dr. WICKEY'S CHOLERA MEDICINE.}

Take 2 ounces Formentilla,

$\begin{array}{llll}\text { " } & 2 & \text { " } & \text { Devil Bit, } \\ \text { " } & 2 & \text { " } & \text { Bimbornella, } \\ \text { " } & 2 & \text { " } & \text { Bistorda, } \\ \text { " } & 2 & \text { " } & \text { Angelica, } \\ \text { " } & 2 & \text { " } & \text { Gentiana, } \\ \text { " } & 2 & \text { " } & \text { Zedary, } \\ \text { " } & 2 & \text { " } & \text { Valerian, } \\ \text { " } & 2 & \text { " } & \text { Elecampane, } \\ \text { " } & 2 & \text { " } & \text { Calamos, } \\ \text { " } & 2 & \text { " } & \text { Rue or other bitter herb. }\end{array}$

Pulverize these as fine as possible, put them into one gallon of French brandy of the best quality, or best fourth-proof old rye whiskey; brandy is best-put the whole into a bottle on jar-a bottle is best if one can be had large enough at the top, which must be closed; then place the bottle or jar in the sand, which should be at least two inches deep at the bottom of the kettle or crock; fill in sand to come above the drugs when settled, and put under it a slow fire, 
so as to keep it warm but not to boil. Let it digest for fourteen days and filter the whole of it through fine flannel several times, so as to separate the drugs well; then put in each gallon 2 ounces spirits of camphor and 2 ounces spirits saffron, when it will be ready for use.

\section{DIREOTIONS FOR USE.}

For preventing cholera: first take one tablespoonful in the morning, fasting on cold water, one at noon, and one at night. Second, for an attack or symptoms take from 2 to 3 tablespoonsful every 5, 10 or 15 minutes, as the case may require, until relieved, when the doses may be lessened, or not so often. Let the patient go to bed and keep warm and quiet as possible until relieved. Third, for the third stage or relapse, vomiting and pain in the stomach, take from 2 to 4 tablespoonsful every 5 or 10 minutes, as the case may be, until relieved or thrown into a sweat; cover up warm, and if cold apply plenty of hot bricks or bottles with hot water in, to the feet, hands, body, \&c. mustard plaster on the stomach, rubbing with the hand, some stim- 
150 DR. WICKEY'S CHOLERA MEDICINE.

ulent, as not a moment's time should be lost when the cold chill comes on. Fourth stage or relapse, attended with cold sweats and rice water discharges, take large doses every 3 or 5 minutes; continue until the patient becomes warm ard easier. No time should be lost at this stage of the disease. Apply hot bricks, Dot,les, \&c. as before directed; when relieved the soces may be less and not so often-say from $\frac{1}{2}$. g.our to 6 hours; continue 3 or 4 days as the case nay rcquire, and do not fail to keep the patient मаrm, \&c.

For bilious or cramp colic, cholera morbus, 7 ux, bilious fever, \&c. administer doses as above. set the patient go to bed and keep as quiet 2,S possible until relieved. In severe cases of cholera morbus, a mustard plaster should be placed over the stomach, which must be kept on as long as it can be borne. Travellers and families should not be without this medicine, as it Is considered by all who have used it to be the safest and surest remedy for the above disease sver introduced. Take a friend's advice and 1ever be without this remedy, as it was never nown to fail in curing what it is recommended 
DR. WICKEY'S CHOLERA MEDICINE.

to do. Give it a fair trial, and its efficacy will soon be seen. By strictly obeying the directions it is perfectly safe and harmless; it is also good in sick stomachs, \&c.

This medicine, when persevered in according to directions, will effectually cure cholera in all its stages, and all that it is recommended to do, which can be attested by certificates from many "persons. By adding the tincture of cayenne you will find this medicine effectual in cramp colic; add the tincture until as strong as it can be taken.

To be more plain and simple,-in making of the cholera medicine, if in the summer you can set the bottle or jar in the sun, which should be when the sun is very warm, letting it remain some 3 or 4 weeks-the longer you distil, the better the medicine. If in the winter season, you can place your crock on the top of the stove, keeping the fire regular, so as not to boil-if you distil until reduced one-third, it will bo much stronger and better. 
152 CERTAIN REMEDY FOR RHEUMATISM.

CERTAIN REMEDY FOR RHEUMATISM.

Take. of sarsaparilla root, coltsfoot root, or wild ginger root, sassafras root, dogwood root, yellow poplar root, prickly ash root, spicewood root, one handful of each, when dried, as much as you can hold in one hand; cut the bark off of the roots and pulverize as fine as you can, except the sarsaparilla, which must be cut in very small pieces; then put the whole in one gallon of best fourth-proof old rye whiskey, and let it stand for 1 or 2 weeks; but should you wish to use immediately, set the vessel containing the ingredients on the stove, and keep just warm for 2 or 3 days, when it will be fit for use.

\section{DIRECTIONS FOR UsE.}

Take from 1'to 3 tablespoonsful 3 times a day, one hour before meals. It may be taken 5 or 6 times a day provided it does not affect the nerves too much. It is perfectly safe and has cured more cases of rheumatism than any other remedy introduced. 
I will cite one or two cases where it effected complete cures: Mr. Joshua Deer, who had been in a most helpless condition for a long time, and had tried many other remedies in vain, was cured in five days after he commenced using it, so as to be able to take a ride on horseback, which can be certified by a number of persons living in the neighborhood. Any one doubting the above, can have it proven to their satisfaction by addressing Ezra Deer, or Henry Gross, who was cured by it in less time.

Let it be understood that there never was a preparation that would cure all cases: no, not one-fourth, therefore I have given a number of preparations, so that if one fail, others may prove efficacious, though the above remedy occupies the head of the list in our own estimation. Never give up any one remedy until you have given it a fair trial. "He that holds out faithfully shall be saved."

This medicine can be distilled the same as the cholera medicine, bottled up and kept for years. Mr. Joshua Deer, was cured with the distilled. Henry Gross and others used it in liquor. You must keep from labor and expo- 
154 - CERTAIN REMEDY FOR RHEUMATISM.

sure, while using the above and be careful not to eat any thing greasy, or that which will not agree with you.

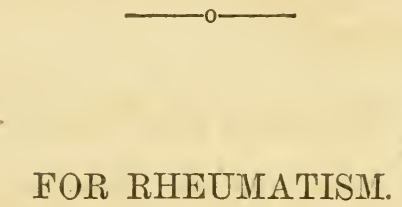

Take 1 ounce of saltpetre, 1 quart of ale-if ale cannot be had take whiskey or water-dissolve the saltpetre in the ale.

\section{Directions FOR UsE.}

Take 1 wine glassful before breakfast, 1 before dinner, 1 before going to bed, and continue until relieved. Should the second quart do no good, stop taking it. You must keep from labor and exposure while using the above. "Mr. Dill was cured by this remedy, who had suffered for more than a year constantly. 
FOR RHEUMATISM.

\section{FOR RHEUMATISM.}

- Take 1 ounce of sulphur, $1 \frac{1}{4}$ ounces of saltpetre, $\frac{1}{2}$ ounce of gum guscomb, 2 nutmegs, the whole to be finely pulverized, to which add 12 ounces of molasses.

\section{DiReCTIONS FOR USE.}

Take 1 tea spoonful every night before going to bed, but if it should act too free on the bowels, the quantity must be diminished.

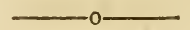

\section{LINTMENT FOR RHEUMATISM.}

Take 1 ounce of spirits of camphor, 1 ounce turpentine, 1 ounce sweet oil, 1 drachm oil of juniper, 1 drachm carbonate of hartshorn, mix these perfectly, and apply three times a day, rubbing it in by the stove or fire with the palm of the hand for 15 minutes. 


\section{LINIMENT FOR RHEUMATISM}

Take 2 ounces of saltpetre, 2 ounces spirits of hartshorn, 8 ounces of sweet oil. Pulverize the saltpetre as fine as possible, and mix with the spirits of hartshorn, letting it dissolve, then add the sweet oil. Bathe and rub in with the palm of the hand for 15 minutes, at the fire or stove, wrap with flannel if possible. If not strong enough you may add hartshorn, if too strong ald sweet oil. This is considered the best liniment ever introduced for the purpose. Use freely.

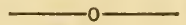

\section{LINIMENT FOR RHEUMATISM OR NEU- RALGIA.}

Take 8 cayenne pepper pods, and 1 pint of whiskey, boil over a fire until it is reduced to one-half the quantity, when it will be ready for use. Bathe the parts affected with the liniment three times a day. This liniment has often relieved where other remedies have failed. 
NERVE AND BONE LINIMENT.

\section{NERVE AND BONE LINIMENT.}

For Swellings, Bruises, Chapped Hands, Frosted Feet, Rheumatism, Cuts, Burns, Mosquito Bites, Stings, Pains in the Limbs, Back, Chest; \&c. Take 1 ounce spirits of hartshorn, 1 ounce spirits camphor, 1 ounce saltpetre, 1 tea spoonful sweet oil, 2 tea spoonsful laudanum; put all into a bottle, shake and mix well and it is ready for use. Bathe in at a fire 3 table spoonsful 3 times a day, rubbing with the hand for 15 minutes. Put the liniment into a bottle, and keep it corked tight. Never pour out more than one table spoonful at a time, being careful to keep the bottle corked tight. This liniment is far superior to any other in use, and you can make as much for 10 cents as you generally buy for 50 cents. Try the experiment and see for yourself.

The spirits of camphor is made by mixing $1 \frac{1}{2}$ ounces of gum camphor with $\frac{1}{2}$ pint of 95 per cent. alcohol. Put into a bottle and let them dissolve, shake occasionally, after which it will be ready for use. 
158 NERVE AND BONE LINIMENT.

The spirits of saltpetre is made by taking 2 ounces pulverized saltpetre put into a bottle, then add 2 ounces spirits of hartshorn, and let it remain half a day, shaking frequently, then add scant $\frac{1}{2}$ pint 95 per cent. alcohol, shake and let it dissolve, when it will be fit for use. For rheumatism add more hartshorn, and bathe the parts affected well.

\section{OINTMENT FOR GOUT AND RHEUMA- TISM.}

The chloride of gold made into an ointment - with lard is said to speedily relieve the pains of the gout or rheumatism. It stains the skin purple, which can be easily remored by washing it with urine. 


\section{FOR RHEUMATISM. \\ FOR RHEUMATISA.}

Take 2 balsam apples, put into $\frac{1}{2}$ gallon of good fourth proof whiskey in a jug and let it stand for a week or ten days, shaking occasionally. Dose, one wine glassful three times a day. Keep from exposure while using and eat nothing greasy or that disagrees with the stomach. This has cured where other remedies have failed, and should the first $\frac{1}{2}$ gallon not entirely cure, use the second immediately.

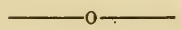

EFFECTUAL CURE FOR RHEUMATISM.

The following receipt, given by an Englishman to a respectable tradesman of Limerick, (Ireland,) who had for a considerable time labored under the most violent rheumatic pains in all his limbs and joints, having been used by him as directed but 5 or 6 times, as he states, eradicated the disease completely. Anxious that so effectual a remedy should be made publicly known we publish the recipe:

Take 1 ounce of sulphur, $1 \frac{1}{4}$ ounces of salt- 
160 EFFECTUAL CURE FOR RILEUMATISM.

petre, $1 \frac{1}{2}$ ounces gum gus̉comb, 2 nutmegs; the whole to be finely powdered in a mortar and 12 ounces of molasses. A tea spoonful to be taken every night on going to bed; should it operate too much on the bowels, a smaller quantity is to be taken.

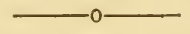

\section{PLASTER FOR RHEUMATISM.}

Or Pains in the Back, \&c. It is said to be a certain cure. Take 1 pound of rosin and melt it over a slow fire, then add $\frac{1}{2}$ pint of tar pouring in slowly, stirring all the time; when it is well mixed pour all into cold water, and work it well with your hands. As soon as it is cool and stiff enough, spread it on a linen rag and apply it to the affected part. The plaster should be a little larger than the pain extends-if you put the plaster on sheep skin it will be better. This is sure to give relief. 
TO MAKE HONEY WITHOUT BEES.

\section{TO MAKE HONEY WITHOUT BEES.}

Take 8 pounds best brown sugar, $1 \frac{1}{2}$ pounds rendered honey, 1 ounce cream of tartar, 4 drops essence of wintergreen, 2 drops essence of peppermint, 2 ounces best molasses, 3 parts of a pint pure cold water, dissolve the cream of tartar, then put all in a tin or bell metal vessel, let boil gently 6 or 8 minutes, stirring and mixing occasionally; then beat up the white of 2 eggs into a foam, and stir them in, and when nearly cool stir in 2 pounds more of bees honey; skim off whatever may rise to the top. If you want it nice and clean, strain it through a coarse cloth as soon as you have the eggs stirred in.If you strain it put in the $2 \mathrm{lbs}$. of honey after it is strained. This makes an excellent honey. The addition of the eggs is simply to give it the appearance of having combs in it, but can be left out if you wish. The same boney may be used for the second making. 


\section{JUDKIN'S OINTMENT.}

Take 1 pound of red lead, $\frac{3}{4}$ pound rosin, 1 pint linseed oil, 3 table spoonsful lamp black, 2 ounces British oil, $\frac{1}{2}$ ounce sugar of lead finely pulverized. Boil this over a slow fire one hour, then add 1 pint more of linseed oil, and boil another hour, when done add $\frac{1}{2}$ pint of turpentine while cooling off, stir and mix well, do not put the turpentine in when first taken off the fire. Let it cool 5 minutes, then pour in the turpentine slowly, stirring well. Should it catch on fire while pouring in the turpentine, put a lid or cover over the vessel immediately to smother the fire. There is no danger in making if careful, as it will be easily smothered. Pour out into a new earthen crock, let cool off, and when cool put into a jar or tin box. There is nothing better than this preparation for wounds, fresh or old boils, and cannot be surpassed for scalds, burns, \&c. 


\section{DirectToNs For UsE.}

Spread a thin coat of the ointment on a.piece of linen rag large enough to cover the scald or burn, which should be renewed twice a day.Scrape the old ointment off, and the rag may be used again with another coat of fresh ointment. For boils cut a hole in the rag so as to give it room to open and discharge its contents; renew the ointment three times a day. This is considered one of the best ointments of the age. Give it a trial and its effects will soon be felt.

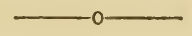

\section{REMEDY FOR THE BITE OF A SNAKE.}

Take the spirits of camphor made of whiskey and apply it to the bite, turning the bottle which contains it over the bite and let it remain on until all the poison is drawn out. The bottle used should have a large mouth so that it may cover the wound entirely. Drink freely of the whiskey until you begin to feel its effects. This done in time has never failed. 
FOR THE PILES.

\section{FOR THE PILES.}

Take the kernel of three peach seeds, mash them well, then add hog's lard or fresh butter, not salted, enough to form a salve and rub this between two butter plates until it becomes of a bluish color, grease with it and take enough rhubarb to keep the bowels open.

\section{$\longrightarrow$ \\ CERTAIN CURE FOR CANCER.}

Take 1 pint of strong ley and boil down till it forms a salve, then apply every 15 minutes until seven plasters have been applied, and as soon as it begins to bleed stop the applications, then work the core out and grease with hog's lard to kill it; heal with ointment or some good salve. When the ley has been boiled down, should the substance that remains become hard, work it into a salve. This is also good for the cure of fistula or poll evil in horses. 
FOR WHITE STELLINGS.

\section{FOR WHITE SWELLINGS.}

Take 1 handful of mullin leaves and $\frac{1}{2}$ pint of old rye whiskey; boil these together and strain, then add 1 gill of turpentine and 2 gills of spirits of camphor. Bathe well until all the swelling and soreness has left, wrap with flannel which should be dampened with the lotion; this is a certain remedy.

\section{TO KEEP CIDER SWEET.}

Make the cider as late in the fall as possible from solid apples, without using any water, put away immediately from the press, and lay it in some place where it may remain quiet, let the place be as cool as possible. Fill the barrel up full, take the bung out and leave it out for four days, filling it up occasionally as it settles or works out. Should the cider stop working under 4 days, rack it off carefully from the dregs, which should be done as soon as the cider stops 
working, then put your cider into a clean sweet barrel-it should be a barrel that has had whiskey or brandy in it-if not, rinse with water until perfectly clean, then swectened by putting in a small quantity of whiskey. If this cannot be done soak your barrels well so that they may be sweet and clean. After having racked your cider off from the dregs carefully, put in the whites of $6 \mathrm{eggs}$, battered light, and a scant $\frac{1}{2}$ pint of mustard seed. Bung up and in 5 or 6 weeks rack it off again carefully from the dregs. Cleanse the barrel well and put in the same barrel- $\frac{1}{2}$ gallon of old rye whiskey will add considerably to its flavor. If your cider is very sour, add from 3 to 5 lbs. white sugar; to insure its preservation it should be strained through a cloth from the press. By being careful-cider put up in this way will keep for 5 years.

\section{FOR BOILED CIDER.}

Make the cider late in the fall, using none but sound apples, not even those with small specks in, without any water. Take it right 
from the press and put it in a copper lettle; boil it one hour from the time it commences; skim it off as the skum arises as clean as you can; then pour into a clean, sweet whiskey barrel, put into a bag scant $\frac{1}{2}$ pint of mustard seed; let the bag down through the bung hole by a string, making the string fast to the barrel so as it can be drawn out again conveniently. It may be. flavored with ground cinnamon or cloves if you fancy the taste. Cider put up in this way will keep a long time and makes an excellent drink, by adding $\frac{1}{2}$ gallon of old rye whiskey it may be kept a number of years. Cider, either from the press or boiled, put into bottles or jugs, corked up tight and sealed over with sealingwax; it can be kept many years, and makes a delicious drink.

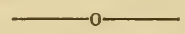 \\ CHERRY BRANDY.}

Press out the juice and add 1 gallon of water to 12 gallons of the juice; then dissolve in the juice 1 pound of white sugar to the gallon; boil slowly in a copper kettle, and skim off what 
rises to the top. Do not boil too long or it will get thick; when the skum stops rising freely pour it into some ressel to cool. Do not allow it to stand in the kettle to cool. When it has become cool put into whatever vessel you wish to keep it in, and add as much old rye whiskey as may suit your taste, say from 1 to 3 gallons. The better the whiskey is the better your brandy will be. Black heart cherries are the best if they can be had. This makes a much better drink than port wine.

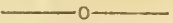

\section{BLACK OR DEWBERRY CORDIAL.}

For diarhœa or summer complaint. This is made by adding 1 pound of white sugar to 3 pounds of black or dewberries, allowing them to stand for twelve hours, then pressing out the juice and strain well, adding 1 third part good french brandy and 1 tea spoonful of finely pulverized allspice in every part of the cordial, which is ready for use at once. This cordial cannot be surpassed for children and weak stomachs, \&c. 


\section{BLACK OR DEWBERRY WINE.}

An excellent wine and a valuable metlicine for home use. To make a wine equal to port wine, take ripe blackberries, or dewberries are best; press out the juice, let it stand thirty-six hours to ferment, skim off whatever rises to the top, then to every gallon of the juice add one quart of water and 3 pounds of white sugar. Let this stand in open vessels for 24 hours, skim and strain it, then barrel it up until March, when it should be racked off carefully from the dregs, and bottled up for use.

\section{$-0$ \\ GAS BEER.}

For 8 gallon vessel-take three pints of fresh yeast, 3 pints of New Orleans molasses, put into your keg, then add 3 gallons of fresh water, bung up, and shake to mix well. Then take a tin bucket and put in one tea spoonful of ground cinnamon, 1 of ground cloves, 3 table spoonsful of ground allspice, 1 of ginger, 3 pints of molasses, then pour on it hot water and mix well; 
let this stand some 10 or 15 minutes, then pour it into the keg and fill up with fresh water, bung. up tight; put something orer the bung to keep it from working out-use a strong keg for this purpose. This makes an excellent cooling drink in summer. Lay your keg in the sun several hours or until it commences to work. In cold weather lay your keg close to the firein fifteen or twenty hours it will be fit for use.

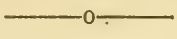

\section{SILVER TOP DRINK.}

Take 1 quart of water, 3 pounds of sugar, 1 tea spoonful of lemon oil, 1 table spoonful of flour, with the white of 5 eggs well beat up, mix the above well together, then divide the syrup and add 4 ounces of carbonate acid in the other, and bottle for use. Pour about a gill out of one bottle into a tumbler and the same quantity out of the other bottle into another glass, add a little water if you choose, pour the two together and drink while effervescing. 


\section{BLACK INK.}

\section{BLACK INK.}

Take 4 ounces of the extract of log wood, $\frac{1}{4}$ ounce of bycromate of pot ash, 1 pint boiling water, stir well until all is dissolved-if the ink is not black enough, add a little more of bycromate of pot ash. This preparation will also answer for coloring goods, \&c.

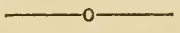

\section{RED INK.}

Take of spirits of hartshorn 1 pint, pure carmine $\frac{1}{2}$ drachm, put into a bottle and shake well -and it is fit for use.

\section{INDELTIBLE INK.}

Take of lunar caustic 100 grains, gum arabic 100 grains, make both fine and pour water enough over to dissolve it, put into a phial and stop tightly. 
To make the preparation to be used before writing on the linen, take 2 drachms of salts of tartar; 2 drachms gum arabic, dissolve these in 1 ounce of rain water. Before using the ink, wet whatever article you wish to mark with this last preparation and dry with a smooth iron, then wash the gum out and you have the name indellibly fixed.

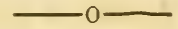

\section{ANOTHER BLACK INK.}

Take 1 pound logwood, 1 gallon soft water, boil it 1 hour and add 25 grains of bycromate of pot ash, 12 grains of prusiate of pot ash, stir a few minutes over the fire, take it off, and when settled strain it.

\section{$-0$ \\ WASHING FLUID.}

Take 1 gallon of soft soap, 4 ounces of sal soda, $\frac{1}{2}$ gallon soft water, and $\frac{1}{2}$ gill of spirits of turpentine, place them all into a pot over a fire and allow the mixture to boil a few minutes, it 
is then ready for use and can be kept in an earthen or stone vessel. In using this fluid the clothes intended to be washed should be soaked in water 10 or 12 hours, say over night, and then to a 10 or 12 gallon boiler or kettle full of clothes, covered with water, add 1 pint of fluid, boil briskly for fifteen minutes, and then ring them out in fresh water. It will be found that little or no rubbing will be necessary.This preparation will save a great deal of hard rubbing and labor-it is truly worth trying.

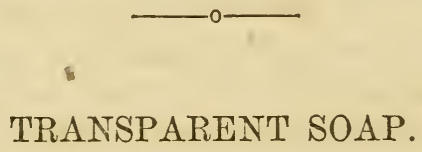

Take 3 pounds of best rosin soap, 1 quart of best alcohol, 1 ounce of venice turpentine, 1 ounce of oil of sassafras, or you may use bergamount or the oil of lemon, or cinnamon, either of which will answer. Cut the soap into thin shavings, put into a pan the alcohol and soap, melt over a slow fire so as just to keep from boiling; when all is dissolved let it boil a min- 
ute or two, you must be careful not to let the blaze of the fire get to it or it will catch on fire; it is best to put it on a stove where there will be no danger, keep stirring slowly until all is melted, then add your venice turpentine, stirring and mixing for a minute or so, then take your pan off the fire and put in your oil of sassafras immediately, or whatever oil you intend msing, the oil of sassafras is however the best. This soap cannot be surpassed for shaving, washing, and is excellent for sore or rough hands. Try it and you will be surprised-the rosin soap used must be clear.

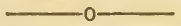

PROF. BIDDLE'S CELEBRATED PREPARATION FOR THE HAIR AND HEAD.

To make 1 quart, take nearly one half a pint of cold pressed castor oil and fill it nearly full of 95 per cent. alcohol, then add $\frac{1}{2}$ ounce of spirits of hartshorn, $\frac{1}{2}$ ounce of tincture of cantharicles, 40 drops oil of bergamot, which gives it an elegant perfume-shake well and it is ready for use. 
PREPARATION FOR THE HAIR AND HEAD. 175

\section{DiRECTTONS TOR USE.}

Wash your head first with whiskey, then apply the hair oil freely, pour it on the head gently and rub with the hand or stiff brush. For children only use the hair oil. To remove the dandruff, comb the head well with a fine comb, do this every time you use the preparation. This oil should be applied twice a week, which will loosen the dandruff so that it may be easily removed. A great and valuable discovery for the hair and head, two or three applications of which will remove every particle of dandruff, purify the skin and prevent the hair from coming out, giving new life and vigor to every hair on the head, and changing light or sandy hair to a beautiful dark lustre; also curing dizzy or nervous headache. No one should be without this valuable preparation, especially those who are subject to dandruff eruptions of the skin, falling off of the hair, dizzy or nervous headache. If it should make the head tender, only use half the tinctare of cantharides. The alcohol must be strictly 95 per cent.-you can add hartshorn if not strong enough, also bergamot for per- 
176 TO RESTORE TIIE IIAIR IN BALDNESS.

fume to suit. It is good for tetter on the head. Every ingredient can be had at almost any of the drug stores.

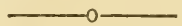

\section{TO RESTORE THE HAIR IN BALDNESS.}

Take of cold pressed castor oil 2 ounces, tincture of cantharides $\frac{1}{2}$ ounce, acetic acid $\frac{1}{2}$ ounce, strong water of amonia $1 \frac{1}{2}$ ounces, oil of nutmegs $\frac{1}{2}$ drachm, oil of lavender $\frac{1}{2}$ drachm, put this in a bottle, make into a lotion, when it will be ready for use.

\section{DIRECTIONS FOR USE.}

The head should be perfectly cleaned of all dirt and dandruff, with castile soap and warm water, and the lotion applied freely and rubbed in with a stiff hair brush once a day; in a week or two its good effects will be manifested. This is the best preparation for baldness yet introduced-give it a fair trial and you will not be disappointed. The drugs of this preparation can be had at any of the drug stores. 


\section{TOOTHACHE BALSAM.}

Take of creosote 1 drachm, oil of cloves 1 drachm, tincture of camphor 2 drachms, oil of petroleum 2 drachms, mix them thoroughly and cork tight for úse. A few drops of this mixture on cotton and applied to the nerve of the tooth will relieve the pain.

\section{$\longrightarrow$ \\ TOOTH POWDER.}

Take of supercarbonate of soda 1 ounce, pulverized orris root $\frac{1}{2}$ an ounce, cream of tartar $\frac{1}{2}$ ounce, oil of roses 10 drops, mix them properly. This may be used with the finger, rag or soft tooth brush.

\section{$\longrightarrow$ \\ ANOTHER TOOTH POWDER.}

Carbonate of magnesia any quantity, perfumed with the oil of cinnamon or neroli. This is the best tooth powder for children-the teeth should always be cleaned after eating, if you wish to keep the breath sweet. 


\section{COLOGNE WATER No. 1.}

Take of oil of bergamot 1 ounce, oil of lavender $\frac{1}{2}$ ounce, oil of neroli 1 drachm, oil of roses 15 drops, oil of cloves 30 drops, new milk 1 pint, pure alcohol 1 gallon, digest 1 day and filter through close flannel several times.

\section{$\longrightarrow$ \\ COLOGNE WA'TER No. 2.}

Take of oil of bergamot 1 ounce, oil of lemon 1 ounce, oil of lavender 3 ounces, tincture of muck 1 drachm, pure alcohol 7 pints, rose water 1 pint, gum camphor 20 grains, mix and digest 1 day and filter-cork up tight for use.

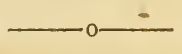

COLOGNE WATER No. 3.

Take oil of roses 5 drops, oil of bergamot 1 ounce, oil of lemon 1 ounce, oil of lavender $2 \frac{1}{2}$ 
ounces, oil of rosemary $\frac{1}{2}$ ounce, oil of cinnamon 10 drops, pure alcohol 7 pints, new milk 1 pint. Let the mixture stand one day and filter. All preparations of cologne should be kept closely stopped, otherwise they will loose their fine flavor.

\section{TOOTHACHE DROPS.}

Take of 95 per cent. alcohol 1 pint, oil of origanum 2 ounces, gum camphor 2 ounces, tartaric acid $\frac{1}{2}$ ounce. Digest 1 day and mix well, when it will be ready for use-cork up tight.A few drops of this mixture on cotton applied to the nerve, and the gums well rubbed with it will soon relieve the pain. This is harmless and pleasant. If you cannot get any cotton to the nerve, bathe the tooth and gums well with it.

\section{FOR DYSPEPSIA}

Take of $1 \frac{1}{2}$ pounds of white mustard seed from 1 tea.spoonful to 1 table spoonful, between meals-the whole seeds in cold water. 


\section{TO PRESERVE BUTTER No. 1.}

Take saltpetre and loaf sugar of an equal proportion and make a liquid. After packing the butter in a jar or sweet keg, pour over enough of the liquid to cover the butter an inch or two. If you should wish to re-pack the butter, pour off the liquid, which if sweet, may be used again when you have done packing.

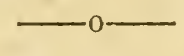

\section{TO PRESERVE BUTTER No. 2.}

Reduce separately to a fine powder, in a dry mortar, 2 pounds of the best common salt, 1 pound of saltpetre and 1 pound of loaf sugar; sift one of them over the other on a sheet of paper, then mix them well together and they are ready for use. 1 ounce of the preparation is enough to a pound of butter, and if well worked in will preserve it sweet for three years. This is worth giving a trial. 
TO PICKEL CUCUMBERS.

\section{$\bullet$ \\ TO PICKEL CUCUMBERS.}

Let your cucumbers be small, fresh gathered and free from spots; then make a pickel of salt and water, strong enough to bear up an egg; boil the pickel in a copper kettle if convenient; and skim it well; then pour it upon the cucumbers and tie them down for 24 hours, strain out through a colander and dry off well with a cloth.

Take the best wine or cider vinegar, cloves, mace, nutmegs, pepper and race ginger, boil them together and put the cucumbers in with a little salt, as soon as they begin to turn their color, put them into jars, crocks or tight barrels; when cold tie on a bladder or leather. This is excellent and worthy attention.

\section{SOFT GINGER BREAD.}

Four cups of molasses, 2 of butter, 2 of milk, eight eggs, two tea spoonsful of pearlash, ginger, and sufficient flour to make it stiff as pound cake. 
TO PRESERVE PEACHES.

\section{TO PRESERVE PEACHES.}

Take ripe free stone peaches-pare, stone and quarter them; to six pounds of the cut peaches allow three pounds of the best brown sugar; stew the sugar and peaches together, and set them away in a covered vessel; next morning put them into a preserving kettle and boil it slowly about an hour and three quarters, skimming it well.

\section{$\longrightarrow$ \\ TO PRESERVE PLUMBS, \&c.}

A pound of sugar to a pound of fruit; the sugar should be melted over a fire, moderate enough not to scorch it when melted. It should be skimmed clean and the fruit dropped in to simmer until it is soft. Put them in jars and cover carefully from the air. Glass is much better than earthen for preserves-they are not so apt to ferment. 
TO TAKE GREASE OUT OF CLOTH, \&C.

\section{SOAP TO TAKE GREASE OUT OF CLOTH, SATINS, SILKS, \&c.}

Take 4 pounds of white bar soap, $1 \frac{1}{2}$ pints 95

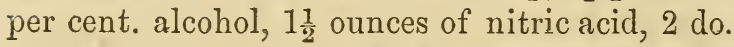
of saltpetre, 2 ounces soda, $\frac{3}{4}$ ounce camphor; cut the bar soap into thin shavings, put all the above ingredients in a crock, then boil over a slow fire, with very little blaze; pulverize your camphor as fine as possible and when all is properly dissolved, which will take 1 hour or so then take the pot off the fire and when cooled add $1 \frac{1}{2}$ ounces spirits of amonia, pour in slowly stirring all the time; should it catch on fire smother it with a cover or by throwing a cloth over the pot. Stir while boiling, and scent with $\frac{1}{2}$ ounce of oil of cinnamon. This will remove grease spots from cloth, silks, \&c., by taking a tooth brush-dip into water and make a lather with the soap, rub the grease spot well with the brush and lather, then wash it out twice in cold water, rinsing and squeezing the soap out as clean as possible-let it be clean water each time. This will take grease, paint, tar, oil, \&c., 
184 SOAP FOR GREASE, TAR, PAINT, \&C.

out of any kind of goods when properly appliad. By pouring it in a flat pan you can cut your soap into cakes of any size.

\section{SOAP FOR GREASE, TAR, PAINT, \&c.}

Take 1 quart 95 per cent. alcohol, $2 \frac{3}{4}$ pounds best home made soap; cut the soap into thin shavings, then put the soap and alcohol into a pan or ressel over a slow fire, and let all dissolve before it boils; when dissolved boil a few minutes, then pour the soap into a pan, and when cooled off cut into cakes. This preparation is excellent for washing dirty clothes and will not require near the labor that the common soap does. For cloth, silks, \&c., you may take less soap. It may be used in the same manner directed for the other soap.

\section{REMEDY FOR ITCH No. 1:}

- Take broad dock roots and lard sufficient to form a mixture, boil it until it forms a salve.- 
Bury the salve in the ground for 24 hours, then grease 2 or 3 times every evening before going to bed, dry in by the stove and shift the clothes. It never fails. Take sulphor of brimstone several days before applying the salve. This plant is not the burdock nor the narrowdock, which it resembles, except that the leaves of the broad dock are broader and the stocks do not grow near so high.

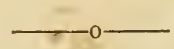

\section{REMEDY FOR ITCH No. 2.}

Take 4 ounces of venice turpentine, 4 ounces of red precipitate, 1 pound of unwashed butter. The turpentine must be washed 9 times in fresh spring water, then mix all the ingredients thoroughly. Apply several times of an evening before going to bed and dry in at the stove, after which put on clean clothes. Avoid getting wet while using this salve. Take sulphor and cream of tartar 2 or 3 days before applying. 


\section{REMEDY FOR ITCH No. 3.}

Take narrow dock and grate it, then add sweet milk or cream and fry them together and grease with it 3 or 4 times every evening, drying in at the stove, then dress with clean clothes. Take $\frac{1}{2}$ tea spoonful of sulphor twice a day several days before and after. This is a certain cure.

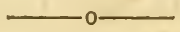

\section{PILLS BY DR. W. B. YOUNG.}

Take calomel, jalāp, aloes and rhubarb, equal portions, mix all together and add a little water at a time, and mix until you cannot see the calomel grains, roll in powdered helebore or epicac. Dose from 1 to 3 pills once a day in the evening. Roll the mixture out in rolls and cut up to make the regular sizes. These are an excellent domestio pill. 


\section{FRENCH PATENT OIL VARNISH.}

For Boots, Shoes, Harness and Carriages:Take 1 gallon alcohol, $1 \frac{1}{4}$ pounds gum shellac, 8 ounces of white turpentine, 4 ounces of rosin, 4 ounces of venice turpentine, 4 ounces oil of lavender, 1 ounce lamp black to color with; put the gum shellac and alcohol into a jug and shake let it stand a day or two to dissolve, then add the other ingredients and shake well until all is dissolved, when it is ready for use. In applying this polish use a sponge or brush, lightly and briskly, and it will make a beautiful polish. It will render leather water proof, but if used regularly a small quantity of oil should be applied occasionally.

\section{$-0$ \\ COX'S HIVE SYRUP.}

Take of bruised squills 10 drachms, seneca snake root 10 drachms; add the squills and snake root to 1 pint of water that has been first boiled, settled and poured off and simmer slowly until you have but half a pint of water, then strain it off and add clarified sugar 1 pound, 
- and simmer until all are well mixed, then add tartar emetic 22 grains, salts of tartar 22 grains, stir and mis properly while the fluid is warm, stop it up tight for use. This syrup is good in coughs, croup or bad colds in children, in 10 or 15 drop doses-no family should do without it one day. If you do not wish to be troubled making it, buy some and always keep it in your house. It is a sure and safe remedy for croup, in which little larger doses should be administered often until it vomits pretty freely-continue with the syrup until the tightness is broken, then use occasionally, not enough to romit so often. By keeping this remedy at hand you may. save some one of your family, and a large amount of trouble and expense. In croup put a mustard plaster on the breast and throat immediately, as no time is to be lost. Mustard plaster is made with ground mustard and wheat flour equal parts; mix them together and wet with warm vinegar, greasing the throat and breast with turpentine or good liniment; putting flannel around the neck is very good.Young parents should be on their guard when not acqminted with the disease. 


\section{DOMESTIC COUGH SYRUP.}

Take of cumfrey root one ounce, elecampane root 1 ounce, nettle root 1 ounce, hoarhound leaves 1 ounce, spikenard root $\frac{1}{2}$ ounce, pulverize all fine and boil them in a quart of water down to a pint, strain the liquor off and when settled pour off again; add to it 1 pint of strained honey, and simmer down slowly to a pint and a half; add to it scant $\frac{1}{2}$ ounce juice of indian turnip; take a green turnip and beat and squeeze the juice out, add to the syrup when milk warm; if put in while hot it will loose its medical properties. A table spoonful or less may be taken from 4 to 6 times a day, in cases of bad cough, it is healing and strengthening to the lungs; it may be made with or without the indian turnip juice. The indian turnip is an excellent of itself. 
190 GREAT SALVE FOR WOUNDS, \&C.

\section{GREAT SALVE FOR WOUNDS, \&c.}

Take 1 pound sheep tallow, 1 pound beeswax, $\frac{1}{2}$ pound rosin elder inside bark, 1 pound balm of gillead leaves or flowers, put into a pan and fry over a slow fire to a salve, spread thin on a linen rag and apply 2 or 3 times a day.

\section{SODA POWDERS.}

To make these powders put 1 tea spoonful of carbonate of soda into a glass nearly half full of water, and $\frac{1}{2}$ tea spoonful of tartaric acid in the other, and add enough sugar and lemon syrup or lemon juice to suit the taste; stir and dissolve the powders and sugar, then pour one into the other and drink while effervescing. This is a very pleasant and cooling drink. 


\section{PATENT BLACK JAPAN.}

For iron or wood carriages, \&c. Take 1 gallon of turpentine, $2 \frac{1}{4}$ pounds asphaltum, put them into an iron pot over a charcoal fire and let remain until dissolved, then strain it-if it becomes too thick when cold add spirits of turpentine. For wood or canvass add while hot, to every gallon 1 pint of copal varnish and $\frac{1}{2}$ pint of linseed oil. This is a good and cheap paint or varnish, used by a great many coachmakers, blacksmiths, \&c.

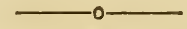

\section{TO MAKE SOFT SOAP.}

Take 10 pounds of common yellow or rosin soap, such as is purchased here for 4 or 6 cents per pound, 6 pounds sal-soda, 10 gallons soft or rain water; cut the soap into small thin pieces and put the whole over a fire, bring the water nearly to a boiling point and allow it to remain at that temperature until the soap is thoroughly dissolved; it may then be taken off. If the soap made with these ingredients is found to be too strong add cold water until it becomes of the proper consistency and strength. 
FURNITURE POLISH.

\section{FURNITURE POLISH.}

Take $\frac{1}{4}$ pound beeswax, separate into shatings, put in a pan and add $\frac{1}{2}$ gallon of spirits of turpentine and 1 pint linseed oil; let it remain for 12 hours, then stir it well with a stick into a liquid; while stirring add $\frac{1}{4}$ pound shellac varnish and 1 ounce alkinet root. Put this mixture into a gallon jar and stand it before a fire or in an oven for a week, just to keep it warm, shaking it up 3 or 4 times a day, then strain it through a hair seive or fine flannel. In using pour a tea spoonful on a wad of baize or flannel, and go lightly over the face or other parts of the mahogany furniture, then apply a similar dry wad briskly and in three minutes it will produce a dark brilliant polish, unequalled and of great value. The shellac varnish is made by taking $\frac{1}{4}$ pound good gum shellac and pouring alcohol enough orer to dissolve it, say as much as to cover the shellac. 


\section{ESSENCE OF LEMON.}

Take 1 pint alcohol, $\frac{1}{2}$ ounce of oil of lemon, color with tincture of tamarisk. To make these essences for family use you should take 95 per cent. alcohol and the quantity of oil named in the reciept, which will save you three hundred per cent. paying you for your labor. If you wish to make a pint, get a glass bottle that will hold a little more than a pint and put your alcohol and oil in, shake and mix them well, then color to suit.

To make 1 gallon of the essences for sale, take 1 gallon of common alcohol and 2 ounces of the oil-color as in the others.

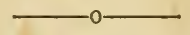

\section{ESSENCE OF PEPPERMNT.}

Take 1 pint alcohol, $\frac{1}{2}$ ounce of oil of peppermint, and if you wish it colored add in small quantities the tincture of tamarisk, stirring it, until you have the color to suit your taste. This is excellent for cramp colic in man or horse. 


\section{EYE WATER.}

Take 40 grains sulphate of zinc to $\frac{1}{2}$ pint of warm soft water, shake until well dissolved and cork up tightly. In using pour out about 1 tea spoonful into a cup and bathe the eyes with it. Never use by dipping your finger into the bottle, but pour a small quantity out into a vessel of some kind. This is the best eye water yet introduced and will be certain to relieve the inflamed eye. Try it and its efficacy will soon be manifested. Always bathe the eye of an erening, just before going to bed-if it is used. during the day you should keep out of the air. If too strong add a little water. The cost of this preparation is but $6 \frac{1}{4}$ cents, and cannot be surpassed.

\section{$\longrightarrow$ \\ ESSENEE OF CINNAMON.}

Take 1 pint of alcohol, $\frac{1}{2}$ ounce of oil of cinnamon, color with the tincture of red sanders, and mix as above. This is excellent in diarrhœe, summer complaints or looseness of the bowels. 
CERTAIN CURE FOR FELON.

\section{CERTAIN CURE FOR FELON.}

- We have known instances of the most intense suffering, neither rest by day or sleep at night, in which this process has effected cures. As soon as it becomes apparent that a felon is making its appearance, which is known by a constant soreness and pain proceeding from the bone, take a strong cord of any kind and wrap it about the afflicted part, as tightly as can be borne; keep it in this condition until the pain can be endured no longer. Now loose the cords and soon as the pain, caused by the cording subsides, tighten it again. Continue this for several days or until. the felon is completey blackened and killed.We have known several persons who have been afficted with felons to try this remedy with success-in fact we have never known it to fail. The cording stops the circulation and then the sore has nothing to feed upon, when it soon dies of starvation. We have faith in this remedy, even after a felon has made considerable progress. If the felon has commenced at the bone 
the sooner you have it cut the better; there is no application that will burst or open the skin that is next to the bone, it should be cut if the above remedy fails.-Clipper. 


\section{RECEIPT FOR HOGS.}

That have lost their appetite. Put urine in the slop, or when you can conveniently, urinate in the trough as you pass along. This is excellent, but a small quantity of ashes put in their slop cannot be surpassed for restoring the appetite, and also very good for the kidneys, worms, \&c. Give it a trial and be convinced of its efficacy.

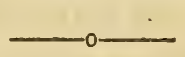

\section{GREASE FOR CARRIAGES, \&C.}

Take 1 pound of beeswax, $\frac{1}{2}$ pint of lamp black, mix well while hot, and when cooling off, add oil until it becomes of a proper consistency. In the winter season add more oil. This makes a lasting grease, which cannot be surpassed for carriages, \&c. 


\section{FOR PLAGUE BLISTER.}

Take sassafras leaves and dip them in warm water, then take castile soap and make a thick lather, and apply with a soft brush as far as the sore or inflammation extends, then apply the sassafras leaves, warm 3 or 4 thick, tie it up loosely, renew every 8 hours. This cannot be surpassed for inflammation of this nature. Give it a trial and its effects will soon be felt. Use none but castile soap.

The following certificate attests the value of this simple cure:-

$$
\begin{array}{r}
\text { Middletown Frederick Co., Má. } \\
\text { June 5th, 1852. }\}
\end{array}
$$

To all whom it may concern, greeting:-

I hereby certify, that some time in March, 1847, my wife was afflicted with a pain and swelling in her arm, which proved extremely painful, and appeared to be contracting the arm, leaving a red or purple streak as far as the swelling extended. As some three or four of my children were then lying sick with scarlet fever, also a negro girl, several physicians were sent for to attend them, who were consulted in relation to my wife. Some pronounced it the hysterics, others attempted to effect a cure, but all in vain; at length it was pronounced a pest or plague blister and very dangerous. The person who informed me what it was, recommended me to Mr. J. D. Kougle for a cure. Mr. Koogle came and applied poultices, which in an bour or two 
after the first application reliered her so much as to enable her to sleer, which she had not done for ten or twelve days. Previous to this the physicians recommended every thing that had a tendency to induce sleep without arail. Nothing could ease ner pain so as to enable her to sleep. She continued the poultices recommended by Mr. Koogle until finally relieved, though they left the hand and part of the arm perfectly hollow-nothing but skin, bone and sinew-yet the parts are now entirely healed and as full as usual, without any other application.

Yours, \&c.

JACOB T. C. MILLER.

\section{RECEIPT FOR HUMORS OR BREAKING OUT ON CHILDREN.}

Take wheat flour and put into a hot stove roast it to a brown color, stir and mix it while browning. In using sprinkle on the sore-it scarcely ever fails to heal after all other remedies have failed. . The sores should not be dried up too suddenly, and particularly when it is a general breaking out over the face, hands, \&c. 
200 CURE FOR TIIE BITE OF A SNALE.

CERTAIN CURE FOR BITE OF A SNAKE.

Drink as much whiskey as you can. It will do no harm and is a certain cure-use it immediately after the bite.

CURE FOR THE BITE OF A MAD DOG.

Take of elecampane root $1 \frac{1}{2}$ ounces, cut it fine or pulverize if you can, then boil it in one pint of new milk down to a quarter of a pint. Take this in the morning fasting, and eat no food till 4 o'clock in the afternoon. It should be taken every other morning-the two last doses must weigh 2 ounces each. This may be used several times a day.

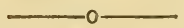

* CLAY POULTICE FOR MAN OR HORSE

Take of yellow clay any quantity, and add vinegar enough to form a poultice, apply it cold. To a sprained joint it gives very speedy relief, often cures in one night. This cannot be surpassed for a fresh sprain on horses. 


\section{DOMESTIC TONIC.}

Yellow poplar bark, dogwood bark, wild cherry bark, 1 ounce of each; pulverize fine, and add to them 1 quart of whiskey, shake the bottle and let it stand one week. A table spoonful in water three times a day is a dose in cases of debility after fevers.

\section{OINTMENT FOR SCROFULUS ULCERS.}

Take of basilicon ointment 1 ounce, venice turpentine $\frac{1}{2} \mathrm{oz}$, pulverized verdigris 2 drachms, beef gall $\frac{1}{2}$ ounce, mix them perfectly over a slow flre. Dress the sores twice a day-do not wet them but wipe them clean with a soft rag.

\section{$-0-$ \\ GREEN OINTMENT.}

Take basilicon ointment $\frac{1}{2}$ pound, finely pulvized verdigris $\frac{1}{2}$ ounce; melt the basilicon slowly and add the verdigris, stirring until it is well mixed. This is a good dressing for old sores and ring worms on the head or face. 


\section{TINCUTRE OF PEACH KERNELS.}

Take $\frac{1}{2}$ pint of peach kernels, bruise the and add one quart of whiskey. Take a table spoonful three times a day. This often cures gravel in the form of sand or fine gravel in the bladder. We have known the patient to pass off gravel in large quantities while using this remedy.

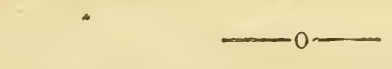

\section{FOR TRANSPLANTING TREES.}

That are flagging or drooping, or looking as if they were going to say good bye. First reduce the top litter, or if needed a good deal, it may be that there is more top to exhaust than root to supply; then loosen the soil and water if dry, and lastly mulch the ground as far as the roots extend. This you may do by covering it with three or four inches of straw. Litter tan bark or something of that sort to keep the roots cool and moist, so as to cause them into 
new growth. Watering a transplanted tree every day, letting the surface dry hard with the sun and wind, is too much like basting a joint of meat before the kitchen fire to be looked upon as decent treatment, for any thing living when you water do it after the sun sets. If you find your fruit trees barren from too great running to wood, (about the first of June is the time) clip or pinch off the ends of the side shoots, so as to expend its substance in making buds instead of wasting all the sap in over growth.

\section{$\longrightarrow$ \\ HOW'TO KEEP APPLES.}

Spread on the floor oats to the depth of about two inches; the oats should be good and properly cured, and then place your apples side by side on the oats until they are covered over with them. Then cover your apples again, and continue laying a course of apples and oats until you have finished your crop. If they are properly put up they will keep better in this way than any other way. Farmer try it and convince yourself. 


\section{DOMESTIC YEAST.}

Boil 1 pound of good flour, $\frac{1}{4}$ pound of brown sugar and a little salt with two gallons of water for one hour. When milk warm bottle it and cork close; it will be fit for use in 24 hours; 1 pound yeast will make 18 pounds of bread.

\section{COMPOST TO PREVENT CROWS AND INSECTS FROM TAKING CORN.}

Take from 1 to 2 pounds sulphor brimstone mixed with plaster and ashes, and a handful scattered on to the corn as it peeps out of the ground will be sufficient to protect an acre from their ravages. Brimstone is a good manure on all soil that does not abound in it. 
HOW TO DESTROY IICE OR VERMTN.

\section{HOW TO DESTROY LICE OR VERMIN ON CHICKENS.}

Place among the sand and dust that the hens nust themselves in $\frac{1}{2}$ pound black sulphor and also sprinkle some lime in and mix. This will keep them off and give them a glossy appearance. If infested with these insects dampen the skin under the feathers with a little water, then sprinkle a little black sulphor on the skin, and in 12 hours they will all disappear. Also, previous to setting a hen, if the nest be slightly - sprinkled with the sulphor there, is no danger of the hen becoming annoyed by them.

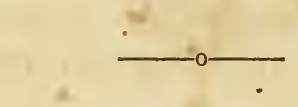

\section{WORTH KNOWING.}

One pound of green coperas, costing 6 cents, dissolved in 1 quart of water, and poured down a privey, will effectually destroy the foulest smells; for water closets aboard ships and steamboats, or for rats, mice, \&c., keep it dissolved 
near the place and in a few days it will all disappear. About hotels and other public places, there is nothing so nice to cleanse places as simple green coperas dissolved under the bed in any thing that will hold water, and thas render a hospital and other places for the sick free from unpleasant smells. For butchers' stalls, fish markets, slaughter houses, sinks and wherever there are offensive and putrid gasses, dissolve coperas and sprinkle it about, and in a few days the smell will pass away. 


\section{APPENDIX.

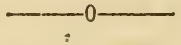

INFORMATION HOW

\section{TO TREAT DANGEROUS DISEASES.}

There are several diseases which are very dangerous and run their course in a very short time, and prove fatal if they are not properly treated or arrested before they become firmly seated. I would here urge upon every. owner of horses, (and in fact every disease which this work treats on,) to pay strict attention to it. In many diseases, what you can 10 must be done at once or not at all-the old saying is 'a stitch in time sares nine,' and there is a great deal of truth in this, in many diseases.

I would here urge upon you the importance of glystering in certain diseases. In the Wind Colic and also in the Spasmodic Colic, as soon as you ascertain what the disease is and not before. The truth of the mratter is that no man has any right to give any medicine until he is certain what the disease is. Give the medicine 
and course of treatment prescribed in the disease . then quickly follow with injections. If you have neglected to prepare yourself for glystering, back-rake with your hand-this is done by greasing the hand and arm with lard or oil and introduce it as far as you can. The glystering or back-raking never does any harm but always assists in relieving. Every owner of horses should prepare himself with sereral large beef or hog bladders, a few elders with the pith punched or burnt out, and by so doing you are prepared at any time to give an injection. This may be done by cutting a notch around the one end of the elder, then fill your bladder with soap suds or oil, next tie the bladder on the end of the elder you have notched, firmly, and introduce the elder into the fundament, and then you can force the suds.into the fundament easily by pressing on the bladder. You should in all cases where there is great danger of loosing your horse, give injections and continue to repeat them until they operate. There are many cases in colics that the horse is bound or corked, this can be perceived by the horse trying frequently or straining to dung; when this does 
occur it is very dangerous and you must in these cases give large doses of aloes and glyster freely, repeating until you get it to operate. If you fail to get an operation you will lonse your horse. Preparation for glystering: Take warm water and make a suds with soap, add thereto epsom salts, and in some cases you may add $\frac{1}{2}$ oz. aloes. Fish oil is a very good article of itself; from a pint to a quart for one injection. I have known 1 pint of fish oil to be given as a drench in colic, and has relieved where all other remedies have failed.

I will here state that there are more horses killed by medicine improperly given than ever was cured. For this reason, the great majority of owners of horses and in fact a great many farriers who pretend to know, do not know what the disease is, and next is a dose of medicine and perhaps in less than half an hour the horse drops down dead, and why, because in many cases the medicine given for the disease, is the dose that puisons or kills dim, from the fact that he was mistaken in the disease, or given medicine for one disease when it was auther. Therefore, I here again assert that 
no man has any right to give medicine until he fully ascertains what the disease is. This he can easily get at if he will pay some attention to the symptoms which are so plainly described in this work. As soon as your horse commences to complain, watch him closely and you will find him to point out to you plainly what the disease is, and you will find the horse to point it out to a hair's breadth as I have described it to you.

Why is it that men will toil and labor hard through the summer's heat, and expose themselves to the extreme cold in winter, and at the end of the year perhaps, will lose more in horse flesh than they have made. Millions of dollars are lost yearly in horses and a great part of it for the want of carefulness and paying some attention to the diseases of the horse, which costs no man any hard labor or exposure. Let me urge upon you the importance of realing this work over again and again, paying attention to it as you perugse it over, and you will find it gives you such information as each and every - person should have for his own interest. I will here state that an ounce of preventative is a 
great deal better than a pound of cure. Many diseases might be prevented by being cautions in their treatment to horses and keeping them in a healthy condition. This should be done by using the celebrated horse powders on page 60 , twice a year, fall and spring. Say you feed from 1 to $1 \frac{1}{2}$ pounds to each horse, each time, fall and spring. If you adopt this once you will never depart from it afterward, as you will find it to be a preventative of diseases and will find so much 'improvement in your stock that you will not depart from it. Every man that has a horse should habit himself to sprinkle a little salt on the feed every time he feeds his horse. The salt is nourishing and is just as much needed in the horse's food every meal as it is needed on the food that a man eats.

The Inflammation of the Lungs is another dangerous disease. It is becoming to be a common disease among horses, and carries off its thousands, simply because it is at first a snealing disease; the farmer and owner thinks very little of it when it first makes its appearance, and the truth is there are very few persons who know anything about the disease, and if it is suf- 
fered to run over the third day, you might as well take the horse out where you want him to die; yet, with all its dangèr and certainty of death if neglected, there is not a clisease which is plainer in its symptoms or is pointed out plainer by the horse than in this disease. It is impossible to be mistaken in this disease if you but pay the least attention to it, and is easily conquered if taken in time. In this clisease the fuxglove, tartar emetic and nitre sliould be used twice or thrice a day, as directed in Inflammation of the Lungrs.

Bots is another which is rery dangerous when they take hold. Feed the Celebrated Horse Powders, as directed and use plenty of salt and you will not have one case in a thousand of Bots.

If you want the best Lotion in the world for fresh or old wounds on horses, turn to page 70 , there you will find it, Tincture of Aloes and Mylur; if you want to cure the Ringbone or Spavin, turn to page 71, and you will find it; if you want to cure the Blood or Bog Spavin, turn to page 68; if you want a Lotion for to cure the Scratches in a few days, turn to page 64 ; if you 
want a Lotion for Sprains, Bruises, Swellings, \&c., turn to page 63; if you want a certain remerly for Sweaney, turn to page 74 ; if you want to see the List of Medicines used in the disnases of horses, you will find them from pages 93 to 108, giving their medical properties and uses.

- I will here name a few Domestic Medicines, Receipts, \&c., and would urge every.person and family to make use of them and keep them on hand, as they have proven to be very valuable and will do what they are recommended to do. Dr. Wickey's Cholera Medicine cannot be surpassed for cholera, cholera morbus, diarrhoea, summer complaint, looseness of the bowels, sickness of the stomach, cramp colic, flux, \&c. This Medicine is easily prepared and will keep for many years if made out of good brandy. There is not any Medicine now in use that will give the same amount of satisfaction as this, and it is perfectly safe and harmless, as it is purely vegetable, see page 148.

Prof. Biddle's preparation for the hair and head will positively cure the tetter or any itching or humor of the skin, will prevent the hair 
from falling off, and has restored more hair than any other hair restorative ever introduced, see page 174 .

If you want sweet cider the year round, turn to page 165 and follow directions, and you will have it; if you want honey without bees, turn to page 161 and you can have it; if you have the rheumatism and want to be cured, turn to pages 152, 153, 154 and 155; if you want a liniment that cannot be surpassed and is easily made, turn to page 157 and you will see how to make it. You should add double the quantity of laudanum and use the spirits of saltpetrewhich is made by pouring alcohol over the saltpetre, the same as the camphor.

If you want to read an interesting subject, turn to page 131 and read the whole subject and you will have it in truth; if you want the best medicine in the world for colic, turn to pages 128 and 129 . I will here state that the Pipsissiway is the best for colic, it has a whitish stripe running through the centre of the leaf. The Wintergreen has not this whitish stripe through the centre; both of them keep green the year round. The Wintergreen is con- 
sidered very excellent for colds and coughs, it is used as a tea for coughs. If you want an eye water that will relieve inflamed eyes, turn to page 191; this is truly valuable and is a harmless application, yet easily made, costing but $6 \frac{1}{4}$ cents.

I have here named some of the leading articles, which will prove to be very valuable to all that have occasion to make use of them. Try them and you will be convinced.

\section{$\longrightarrow 0-$ \\ SCARLET FEVER.}

I will here give to the reader the symptoms of Scarlet Fever. This disease has slain its thousands where the monster disease, Cholera has slain its hundreds, and it becomes every parent to feel it his duty to be careful when the disease is in the neighborhood. It is evident that the disease is contageous, in this form it can be taken by inhaling the breath from one that has it, and it is satisfactorily proven that it can be carried in woollen goods from one family to another. 
Srmproxr-This disease commences with chilliness, dullness of the head and prostration of strength, according to the violence of the attack. There is sometimes nausea and vomiting, and the surface soon becomes florid and hot.

The throat is generally inflamed and the same appearance extends to the tongue, which is sometimes of a very deep scarlet, tinged with blue. If the symptoms are increased, it is called Scarlet Fever in a malignant form, the symptoms are very violent and the patient becomes pale and faint, the heart palpitates, the Fever continues to rise higher and higher, there is great danger.

The pulse now rises to one hundred and fifteen or twenty strokes in a minute. The pulse and the eruption will gire the form and character of the disease. The eruption generally commences with red patches, which spread and unite till they cover the whole body. The eruption appears first on the face and neck, then on the legs, and the redness is greatest about the loins and bending of the joints, and on the hands and ends of the fingers. There is however not a perfect regularity in the erup- 
tion of Scarlet Fever, either in appearance or duration. In ordinary cases the eruption remains out about four days, when the grain of the skin begins to peel off and in a few days more it disappears. As the disease progresses, the tonsils becomes specked with ash colored spots and Ulceration follows. In favorable cases their slugs come off in eight or ten days.

If the Patient does not die by the ninth day, the will generally get well uncler proper management, though it may be three weeks, in some cases before he recovers. When this disease terminates favorably, all the symptoms generally yield, beginning about the fourth day after the eruption appears. The patient is more liable to relapse in this disease than any other, and caution should be used to prevent a relapse. Parents would do well to watch its first appearance and keep their children from its influence as much as possible utsing preventatives, such as keeping a tar plaster around the neck, keeping gum camphor, a little asafœetida and a small piece of garlic around thethis should be put into a small muslin bag and hung around the neck. Let the children eat 
small preces of garlic during the day. These are considered preventatives by the Medical Faculty.

Treatmert-Give mild purgatives, such as Oil, to keep the bowels open. Drink plentifully of balm tea, if this cannot be had, use Sage, Hysop, Saffron Blossom, or Dittany. This will bring out the eruption and keep it out full. If this can be accomplished, the danger will be very much lessened. This fact should be kept in view in all eruptive diseases. Keep a Tar Plaster around the neck; add to the tar a small portion of Spirits of Turpentine, keep this on - for some time, renewing, adding turpentine enough to cause the skin to red. If the patient be not very careful when he gets out, he will take cold, and the glands of the neck will swell and supperate and the ear will run, and if great attention be not paid, deafness will probably be the result.

They must be kept clean and Laudanum and Sreet Oil put into them every day till they get well. 
6 REASONS For PLANTING AN ORCHARD. First, would you leave an inheritance to your children, plant an orchard. No other investment of money and labor will in the long run pay so well. Second, would you make home pleasant, the abode of the social virtues, plant an orchard. Nothing better promotes among neighbors a feeling of kindness and good wili, than a treat of good fruit often repeated.

Third, Would you remove from your child-. ren the strongest temptation to steal, plant an orchard. If children cannot obtain fruit at home, they are very apt to steal it, and when they have learned to steal fruit, they are in a fair way to steal horses, \&c.

Fourth, Would you cultivate a constant feeling of thankfulness towards the Giver of all good, plant an orchard. By having constantly before you one of the greatest blessings given to men, you must be hardened indeed if you are not influenced by a spirit of humility and thankfulness.

Fifth, Would you have your" children love their home, respect their parents while living and venerate their memory when dead, in all their wanderings, look back upon the home of 
youth as a sacred spot, as oasis in the great wilderness of the world, then plant an orchard.

Sixth, In short, if you wish to arail yourself of the blessings of a bountiful Providence, which are within your reach, you must plant an orchard. And when you do it, see that you plant good fruit, don't plant Crab Apple Trees, nor Wild Plums, nor Indian Peaches, the best are the cheapest. Seriously, we have often wondered why our farmers clid not devote more attention to the cultivation of fruit; it certainly would prove profitable and pleasant. An orchard of an acre or so of choice fruit, properly taken care of could not be the least profitable portion of a farm. Upwards of a hunchred bushels of fruit can be gathered annually, and without much trouble from merely a small garden patch. One great point to commence with is to procure good sorts, for it requires no more labor to attend a tree that will bear apples worth seventy-five cents and a dollar a bushel than one producing those not worth more than two shillings. Let our farmers think of these things. But, the inquiry is frequently made how shall we manage our trees, to produce fine flavored fruit in a short time. 
First, select good, rich soil, such as will produce 70 bush. indian corn per acre, if not such it should be made such by mauuring. You cannot expect a tree to flourish and produce good fruit when there is no strength or food to supply it with proper nourishment. It is too much like building a house without a foundation, or sitting down to dine at an empty dish, there being nothing to support the growth of the tree, no food to supply it with proper nourishment, finally, it dies for the want of nourishment, if not, the fruit which it bears, if any, is small and knotty, having scarcely any taste or flavor. If you want nice, large, fine flavored fruit, prepare your soil before planting your trees and keep it prepared by manuring occasionally. It is unreasonable to expect to raise fruit from a tree when it is half or three quarters starved out, all for the want of rourishment. You may here make inquiry how to prepare your soil. This may be done by putting a heavy dressing of manure on it, then obtain sufficient depth of soil, so as to enable the roots to extend themselves freely and hold moisture without dying out in protracted drought. This may be done with a common plow, letting it run 8 or 10 
inches deep, then by means of a good subsoil plow, running it in the same furrow, you will obtain a depth" of 15 or 18 inches. This process should be continued until you have all plowed that depth. When you have this accomplished, run your harrow over several times leveling and pulverizing it finely. When you have all this completed your soil will be prepared for planting your trees. If you cannot possibly prepare your soil in this way, you should by all means dig very large holes, say six or eight feet in diameter and a foot and a half deep, working the manure through the soil as you dig it up. This may seem to the farmer as requiring too much labor, but will richly pay him for it in the end. Plant your trees in this soil firmly, leaving the soil a little lower about the body of the tree, so as it may hold the water, if - filled up about the level of the soil, the water will run away from the roots and your. tree may die for the want of moisture. Every tree should have a stake driven in the ground to fasten or stay the tree, so as to prevent the storms from bending and switching it about. If this is not done your trees will be injured, 
and will not thrive. There are a great many farmers complaining that they cannot raise any fruit. Truly, how can they expect to raise fruit when they will crowd their trees into small holes, and the soil so hard that you can scarcely drive a stake into it with a sledge, and above all the land starred out, the grass and weeds suffered to grow up at such a rate that you are not able to see the body of the tree. Young trees should be nursed and cultivated, keeping the soil mellow by repeated stirring and preventing the growth of any vegtable for several feet from the tree. A hoed crop is next best to clear mellow ground. A sowed crop, grass or weeds is ruinous to young trees. After you have your treas well set, you should by all means wash them down once or twice a year with soap and water. Say about one quart of soap to two quarts of water-wash from the large brauches to the bottom-this will destroy the insects that may be put into the body and limbs of the tree. Many drooping trees have been made healthy by using this wash. If you wish to preserve your peach trees, it is necessary for you to apply this to them twice a year, also frequently pouring reasonably hot soap 
suds to the body and root of the tree; this will kill and destroy the worm which so frequently destroys your trees. The lie which is left at the bottom of the kettle from boiling hot soap is very good and should always be used to wash your trees. If you wish to preserve your peach trees, you should by all means search the roots and body of the tree, and where you find any gum caused by the worm, remore it by means of a knife, carefully cutting away where any gum is found, and as far as there seems to be a hollow uncler the bark, then wash the whole stem well, suffering it to run to the roots: It is stated by a worthy gentleman, that by planting tansey around the tree, the worm will not trouble the nots. This is simple enough and worthy of a trial. It is hoped that these important truths will cause the Farmer and others to put them in practice, and it most undoubtedly will be the means of raising improred fruit and will be richly paid for all his labour.

\section{CATCH AN OWL.}

Those who are troubled with owls, let them set a steel trap on the top of a pole near the hen roost, and you will be certain to catch him. 


\title{
A SUPPLEMENT
}

TO THE

\section{FARMER'S OWN BOOK:}

A TREATISE ON THE

\section{Diseases of Horned Cattle,}

\author{
WITH $\Delta \mathrm{N}$
}

\section{EXPLANATION OF THEIR SYMPTOMS,}

\author{
AND THE
}

COURSE OF TREATIENT TO BE PURSUED.

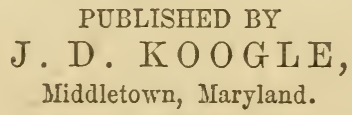

1858. 


\section{P R E F A C E.}

The beneficence of an all wise Providence in organizing man, so as to secure him dominion over animals of inferior physical construction, impose on him obligations to exercise that eminent advantage in a spirit of mercy and in mitigation of the pains and clisorder of the brute creation! Impose upon him as a gentleman, as an intelligent Farmer, or as a man of humanity; should deem it essential to make himself familiar with the nature and injuries of the suffering brute. To say nothing of the duty, which common intelligence and humanity enjoins upon every one to prepare himself with proper information, remedies and common medicines, which will enable him to extend immediate relief to the speechless, suffering animals. No man should hesitate, to provide himself with a book which will teach him plainly in what way to give relief to the poor speechless brute. 
IIORNED CATTLE.

\section{THE AGE.}

The age of neat anttle is very difficult to get at, until they reach the age of three years; after this, we get at the age by the horns. The surface of the horn continues very smooth, until the expiration of the second year of the animals life, when a wrinkle or circle of thicker horn begins to be formed around the base. This is truly completed in twelve months and another ring then begius to appear, so that if the perfect rings or circles are counted, and two added to them, the age of the beast is supposed to be ascertained. These rings, however, are not always clear and distinct, and it is very easy to remove one or two of them with a rasp, at least to the unpracticed eye, when the animal begins to be remarkably old. In addition to this, a well known fact should be stated:That if a heifer takes the bull at about two years old, the first ring is formed a twelve month berore its usual time, and consequently she would always appear to be reckoning by her horns, a twelve month older than she really 
is. After all, the age as denoted by the horn can only be calculated in the Cow. These rings do not begin to appear in the $\mathrm{Ox}$ or Bull until the animal is five years old, and then they are frequently too confused to be accurately counted.

When in health, a softness of the skin, and a glossy appearance of the hair, not only indicates present health, but a disposition to thrive; while a hard dry skin clinging to the ribs, and a staring in every direction, show that there is something wrong in the constitution, and that it will be labor in rain to attempt to fatten suclf a beast, for your own interest, you should put jour beast in good condition, and keep it in condition.

\section{ON THE DISEASES OF HOPNED CATTLE.}

Inflammatox:-Inflammation is the most frequent diseased condition to which neat Cattle are subject. External imflammation is known by the part being swollen, tender and hotter, than in its natural state; in garget or durwnfall of the udder, which is an imflammation of one or more 
quarters of the bag; the affected parts are swollen, tender and hot. If this state of the bag is neglected, matter or pus will be formed, and make a troublesome job, this should not be neglected or defered; if it is properly treated, the swelling heat and tenderness will generally disappear.

\section{INTERNAL INELAMMATION.}

Internal Inflammation by other and often more inđistinct symptons. We can here seldom ascertain the heat or tenderness, or swelling of the part, and can usually only judge of the complaint, by the effects which it produces on the system. Every internal inflammation soon affects the whole system, accompanied with considerable fever, and that fever and degree of it is easily ascertained by the heat of the breath, and the mouth, and the base of the horn, by the redness of the eye, hardness of the pulse and the loss of appetite. When Inflammation seizes any important organ, as the brain, lungs, bowels, kidneys, udder, \&c., bleeding is to be immediately had recourse to, after bleeding, a purging drink is to 
be administered, sometimes it is necessary to insert a seton in the dew lap. For external im- flammation from severe bruises, wounds and other accidents, fomentations with warm or cold water. Poultices made of Linseed Oil, when they can be applied.

\section{BLEEDING, ITS UTILITY.}

Bleeding is a most useful and powerful reme$\mathrm{dy}$, in the cure of Inflammatory Complaints. It lessens the quantity of blood in the vessels, and diminishes nervous power. The following are the chief diseases, in which bleeding is required.

In all kinds of fever, itching and humors of the skin, enlarged glands, or kernels between the jaws, bruises, strains, catarrh or colds, \&c.

The jugular or neck vain, is that which is mostly opened; in many inflammatory complaints too much can hardly be taken, provided the bleeding be stopped as soon as the patient appears likely to faint or fall down. A strong healthy Beast will bear the loss of fire six quarts of blood without the least injury; large Cattle will 
bear seven or eight quarts with decided advantage.

\section{ON PHYSIC.}

The chief purgative Medicines for neat Cattle are Glauber Salts, Epsom Salts, Barbadoes aloes, Linseed Oil and Sulphur. In some extreme cases the Croton Nut, freshly prepared may be used with decided advantage. Aloes are getting into disuse, on account of it nauseating and exciting the Animal; if it does not operate immediately, half an ounce of aloes may be arlded to the salts with decided advantage. In particular diseases where there is considerable fever, or the attack of fever is apprehended, there is no purgative so beneficial as the Epsom Salts; in bad cases twenty four ounces may be given at a dose, and eight ounces of sulphur every six hours, until the purgative effect is produced. Linseed Oil is a good purgative, the dose is from a pint to a pint and a half. Common Salt is a very good purgative in mild cases, a pound dissolved in warm water is a dose; it should not be given when the animal labors with fever. 


\section{ON SETONING.}

The utility of setoning is to create excitement and unload the orerloaded vessels in neighboring inflamed parts. The mode of inserting a seton, it is commonly made of horse hair platted together, cord or tape alone or leather, it should be tolerable thick and ten or twelve inches in length. Before inserting the seton it should be dipped or saturated with Turpentine, tincture of Cantharides, or Helebore. The seton now prepared; an assistant is to hold the animal, while the seton needle with the cord affixed to it is plunged into the upper edge of the brisket or dew lap, and brought out again towards its lower edge. The space between the two openings should be from four to eight inches; the seton is to be secured by fastening a small piece of wood, or tying a large knot at either end of the cord; matter will begin to run the second day, and after that the cord should be drawn backwards and forwards two or tliree times a day, in order to irritate the parts, by this means increase the discharge. Where a considerable ef- 
fect is intended to be produced, the black helebore is the best, this will very quickly cause considerable swelling, as well as a discharge.

\section{COLDS AND COUGHS.}

Colds or Coughs are frequently much neglected, and very much injures the animal, let this hint suffice, as soon as you perceive the animal. to have thie cough, give a purging drink. Take epsom salts $1 \mathrm{lb}$., powdered caraway seeds $\frac{1}{2} \mathrm{oz}$., dissolve in a quart of warm gruel. After that use the cough and fever drink until relieved twice a day.

Cough and fever medicine.-Take emetic tartar, 1 oz., powdered digitalis $\frac{1}{2}$ drachm, saltpetre 3 drachms, mix and give in a quart of gruel; house the beast find keep it comortable, especially at night, do not expose to cold and wet weather.

If the above should not give relief: Take emetic tartar half drachm, nitre two drachms, powdered gentian root one drachm, powdered chamomile flowers one drachm and powder gin- 
ger half drachm. Pour upon them a pint of boiling ale, and give the infusion, when nearly cold ; give until relieved. Should not this entirely relieve-take liquorice root 2 oz; bruise and boil in a quart of water, until the fluid is reduced to a pint, then add two drachms powdered squills, honey 2 ounces; add to the above and give as directed in the above.

\section{INFLAMIIATION OF THE LUNGS.}

Inflammation of the Lungs is caused by perspiration, sudden and great changes of the weather, especially when accompained with wet and damp air at night, and particularly when driving a long journey.

Symptoms are dullness, shivèring cough, particularly soar, the ear, roots of the horns and legs are generaly cold; the breath and mouth is hot, the mouth generally open, and there is a ropy discharge from it; the beast will often lie down and can scarcely be induced to move, the flanks heave, the head is protruded, showing great difficulty in breathing. 
Remedy:-Copious bleeding is the first and great important remedy; bleed until the beast trembles, if you do not, you will loose your beast; next, place in your seton in the dewlap, fire the sides and blister, then follow with the Ferer medicine. Emetic tartar 1 drachm, digitalis $\frac{1}{2}$ drachm, nitre $\frac{1}{3}$ drachms; continue until relieved twice a day.

\section{DERANGEMENT OF THE LUNGS.}

When the milch Cow is attacked, there is a diminution of the milk, and it has a ropy appearance and a saltish taste after being separated from the cream. The animal has a heary - appearance; the eyes being dull, with a stiffened staggering gait; the appetite is impaired, the nostrils and skin is of a yellow color, the bowels are generally costive, by pressing on the edge of . the short ribs on the right side, the animal will shrink, indicating pain and tenderness. Remedy.-If any fever bleed, then follow with one or two drachms of calomel, 1 scruple of Opium, 2 drachms of ginger, give in gruel a few hours 
afterwards. Give 12 ounces epsom salis and half pint Linseed oil; the calomel and opium may be repeated twice a day, and the purgative also, until the bowels are sufficiently operated upon; the sides may also be blistered, and seton may also be inserted. If the animal should be left weak, use the following tonic drink:-Gentian root powder $\frac{1}{2} \mathrm{oz}$, ginger 1 drachm, epsom salts $2 \mathrm{oz}$, mix the whole with a pint of warm water gruel, and gire it morning and night.

\section{IMFLAMMATION OF THE BRAIN.}

Causes:-It proceeds most commonly from redundancy of blood, or overflowing of the blood, by means of hastening the fattening too rapidly, or by turning in a rich pasture.

Srmptoms:-In the early period of it, the beast - is dull and stupid, he stands with his head protruding, or pressed against something fur support, he refuses to eat, is unconscious of the surrounding objects, now and then suddenly drops as if he were shot, he starts up all at once, is fearless of any surrounding object, his, eyes will become 
red starting from their sockets, will stagger about, falling and rising again and run against everything in his way, he will stamp, tear up the ground with its horns, run at every one within its reach, bellowing until nature is quite exhausted; trembling will then come over him, he will grind his teeth and saliva will.pour from his mouth, every limb will be convulsed and he will presently fall and die.

REuEdy:-The chief or only cure is bleeding, let the blood flow rapidly until he falls from the loss of blood. Setons should be placed on each side of the poll, and blistered on the forehead, then follow with heavy doses of physic, when relieved feed cautiously for a few weeks.

\section{STAGGERS or SWIMMING IN THE HEAD.}

CAuse:-Starvation during the winter season, and being admitted into too fertile a pasture in the Spring, producing a redundancy of blood, which gives rise to the disease.

Srimptons:-Are heaviness, dullness, disposition to sleep, resting his head upon any conve- 
nient place, reals and staggers when he attempts to wall.

If this disease is not checked by bleeding, or purging, or proper management, it may terminate in inflammation of the brain or fever.

REMedr:-This must be remedied by bleeding, purging and giving the ferer medicineafter purging, give emetic tartar one drachm, digitalis $\frac{1}{2}$ drachm, nitre $\frac{1}{4}$ drachms twice a day until relieved, feed cautiously.

\section{INFLAMIMATION}

\section{OF THE BOWELS WITH COSTIVENESS.}

Inflammation of the bowels is by no means an uncommon disease among neat cattle, very often proves fatal. It is easily recognized by the peculiar symptoms.

CAUSE:-This disease mostly arises from exposure to cold, and especially when catțle go into rivers or ponds, after being heated and fatigued, chilling the blood. It is sometimes produced by too much dry or stimulating food.

Symptous:-The animal is continually lying 
pown, getting up again, strikes at his belly with his hind feet. The bowels obstinately constipated; dungs in small quantities, hard, covered with mucus at times, streaked with blood - the urine is generally voided with difficulty and heaving at the flanks, accompanied with fever, becomes fearfully weak and staggers as he walks, he leares his company, hides himself under hedges, \&c. Becomes deaf, he trembles all over, his skin is hot, back and loins tender, ears and horns hot, indicating the highest degree of general fever.

Reuedy:-The first thing to be done and that which admits of no delay, is to bleed profusely. Next, purge freely; continue the purging medicines until the bowels are freely opened, then lessen the doses so as to keep the bowels open. In severe cases you must give injections until the medicines operate freely. This is a very dangerous disease and the course pursued must be decisive, or the beast is lost! The only hope you have after bleeding, is in physicing; you should by all means clyster largely and in great quantities, the epsom salts and castor oil will do no harm; thin gruel is very good! Let these hints suffice. 


\section{DIARRHEA OR PURGING.}

Diarriea or Purgixg:-In the first place indicates some disordered state of the bowels, or the presence of some offending matter in them, and he will endeavor to remedy this; not by attempting to arrest the discharge too speedily! First, give a mild physic, then follow with the astringent.

Pemedr:-Take a strong decoction, white oak bark 3 ounces, laudanum $1 \frac{1}{2}$ oz., golden tincture $1 \mathrm{oz}$. Give it in thin gruel until relieved.

Dysentery, Slimy, Flux, or scouring rot is treated the same way. The symptoms of this are considerable tenderness on the spine a little beyond the shoulders, the dewlap hangs down, and has a flabby appearance; the dung runs off with a putrid and offensive smell, and as it falls upon the ground, rises up in bubbles, the hair appears pen feathered or starring; the eyes are generally inflamed, with heaving of the fianks, painful twitching of the belly, severe straining, griping, \&c. This disease treated the same as Diarrhea. 
Red Water. - This disease consists of a discharge of high colored urine, occasionally tinged with a bloody appearance, it is an affection of the kidneys; in some cases the discharge changes to a dark red, or blackish color. When the kidneys are effected, the beast evinces tenderness on pressing the loins.

Remedr:-Take oil of juniper $\frac{1}{2}$ oz., laudanum 1 oz., oil turpentine $1 \mathrm{oz}$, mix and give in a pint linseed tea, once or twice a day until relieved. The oil of juniper may be increased or diminished as the case may require it.

\section{GARGET, DOWNEALL IN THE UDDER, OP INFLAMED BAG.}

This is a disease of the utmost consequence to the owners of Cattle; young Cows in high condition are most liable to it, especially at the time of calving. This clisease makes its appearance in one or more quarters of the bag, which becomes swollen, hard, hotter than usual and painful when pressed. The milk is lessened and mingled with blood, pus and corruption, at 
times the flow of milk is totally stopped and sometimes the inflammation extends to the hip joint, hock and foot lock.

REMedr:-It will be necessary as soon as the downfall is discovered, and especially in an ag-. gravated case, to bring the animal out of the pasture and if deemed necessary, take from three to fire quaits of blood according to the size or strength, next give her a purging drink and bathe the udder well with elder ointment, or use mercurial garget ointment, which is made by taking soft Soap 1 lb. Mercurial Ointment 2 ounces, camphor rubbed down with a liftle spirits of wine 1 ounce, rub them well together. Should there be any ferer, give a few doses of fever medicine; this is a disease of great importance, as many Cows are ruined or lnst purely from neglect: The milk must be taken from the Cow perfectly clean, and this shonld be done several times during the day; and the Cow must be fed scantily and with no stimulating foor,

The teats sometimes get very sore, this is easily remedied by using the ointment for sore teats. Take elder ointment 6 ounces, Bees wax 2 ounces, Sugar of lead 1 ounce, Alum 1 ounce in 
fine powder, mix them well together, whilst cooling bathe the teats freely.

\section{TPEATMENT OF THE COW, BEFORE AND DURING CALVING.}

It is an old and true saying, and the truth of it is nowhere more evident than in treatment of the Milch Cow ; that the prevention of an evil is better than the cure. The Cow should be dried six or eight weeks before calving, for two reasons: First, the strength and constitution of the Cow require a little respite. Second, the mixture of the old milk and the new secretions, that nature prepares for the expected calf. During the early period of gestation, the animal may and should be tolerably well fed, for she has to provide milk for the Dairy, and nourishment for the fœtus. But when she is dried, her food should be considerably diminished:She should not be too fat, or full of blood at the time of calving, for that is the frequent cause of difficult, labor, garget fever and death.

There are few things in which the Farmer 
errs, more than in this: There is also an error in starving her before she calves, but, is much more danger in bringing her into too high condition. Some Cows are apt to slink their calves before their time; this generally happens about the middle of their pregnancy. She becomes fererish of her food, wandering in search of something which she seems to be longing for. She should be immediately remored from the other cows, bled and physiced; the best thing to be done is to fatten her for the butcher, for she will be very certain to do the same again. When the ninth month is nearly expired, she should be looked after; if in high condition, she should be physiced, and if necessary, bled, and if she is about to calve, she should be separated from the other cows, or brought into the cowhouse, and suffered to remain quiet, and undisturbed. But should she not be successful in calving within a reasonable time, she should have assistance.

Srmptoms.-Are uneasiness, slight lifting of the tail, lying down and getting up. The still earlier symptoms are enlargement of the udder, and redness of the space between the shape and the udiler. 
Treatuent:-When the labor has actually commenced, the membranes will more and more protrude until they break, and the fluid by which the calf was surrounded will escape. If her pains are strong, she should not be meddled with for a few hours. And if no portion of the Calf presents itself, the hand well greased should be introduced, in order to ascertain the situation, and position of the calf. The natural position is with the fore feet presenting, and the muzzel lying upon the fore leg. If this is found to be the case and it has advanced into the passage, sometime longer should be allowed to see what nature will do. However, as soon as you perceive the throes to begin to weaken, if no progress has been made, manual assistance must be rendered.

Here there are two objects to be accomplished; the saving of the lives of both the mother and the young one; all should be done gently.

\section{THE MODE OF ASSISTANCE.}

The hand should be well greased, then intro- 
duced, and the fore-legs of the calf laid hold of and drawn down, drawing gently at the moment of the mother's throes. Care should be taken that the head is accompanying them. The hand will sometimes be sufficient for this purpose. If the head cannot be moved by the hand, a cord must be procured with a slip knot at the end, which is to be moved carefully into the passage, and the mouth of the young animal being opened, fastened round his lower jaw, the end of this must be given to an assistant, who should pull gently but firmly at the moment of the throes, while the operator llaws out the feet.

Should not this succeed, take two other cords or rope, and fasten one around each leg-two assistants should pull at the feet.and another at the head; while one ascertains the progress that is made-too much force should not be used, as the calf may yet be saved. Remember the natural position of the calf, is the presenting of the muzzel lying upon the fore-legs. The most usual false position, is the presentation of the head, while the feet of the calf are doubled down under his belly. A cord must be passed as before, around the lower jaw, which is then to be 
pushed back into the womb. The operator now introduces his hand and feels the situation of the feet, then fix a cord around each pastern, or about the knee, and bring them into the passage. The head is next to be brought forward again by means of the cord; the cords being now pulled steadily together, it will generally be extracted. Should the calf be dead, and much swollen, the head may then be opened by means of a knife, so as to lessen the bulk. When the feet present and the head is doubled. under the rim of the passage. The cords should be placed round the feet, the hand passed into the womb, and the cord looped round the lower jaw. The calf pushed farther back into the womb, the head brought into the passage and the three ropes pulled together. The delivery effected as quickly as may be without the exertion of more force than is necessary.

The last false presentation is the breachthe tail appearing at the mouth of the shape. The hand is to be passed into the uterus, fasten the cords around each hock. The calf is then pushed as far back as possible into the womb, and the hocks are after brought into the pas- 
sage, the head placed in the proper position, and the ropes changed if necessary, and all three cords drawn gently, until the calf is extracted; considerable force is sometimes needed, but should all be done gently, with an increase of drawing, until the job is completed. By studying these cases, the operator will be able to accomplish his object. In all cases of false presentations, although great force must sometimes be used.

The uterus, or calf bed is sometimes protruded and inverted. The case is not desperate. The part must be cleansed from blood and dirt, and supported by a sheet, then the operator beginning at the very bottom of the womb, returning gradually, and with great care, and patience. The animal should be bled before this is attempted, and the application of cold water should be used for some time; this will contract the womb, and render its return more easy. A stick or couple should be passed through the lips of the shape; in order to prevent its return, and give the following medicines a few times: Tàke laudanum 1 oz., sweet spirits of nitre $2 \mathrm{oz}$., give in a pint of warm gruel. The protrusion 
or invertion of the gut, should be returned the same as in the womb, and a few sticks placed through the shape.

The Cow should in all. cases be suffered to lick or clean the calf, as nature has designed it. The cow and calf will be much happier if suffered to remain together for several hours, having free access to each other. The mother should not be exposed to severe weather, immediately. after calving. Should have a few wäm mashes.

\section{THE MILK FEVER.}

This is a disease which is prevalent amongst, Cows in high condition.

Srmptous:-Staggering gait, breathing irrerular, eyes full and glassy, the animal reels, is unconscious, the head turned on one side, the feeling partially lost, the legs sometimes becomes paralyzed.

REMEDY:-Take epsom salts 12 ounces, flour sulphur 4 ounces, ginger $\frac{1}{4} \mathrm{oz}$. spirits of nitrous ether $1 \mathrm{oz}$., dissolve in warm water-give one half of this twice a day, until the bowels are opened, continue until relieved. 


\section{DISEASES OF THE EYE.}

Diseases of the eye are generally inflammations, and caused by a bruise or blow inflicted carelessly.

ReMedF:-First bathe the eye well with cold water several times, say some ten or fifteen minutes at a time; Then use the following lotion. Take 40 grains sulphate of zinc, dissolve in $\frac{1}{2}$ pint soft warm water, and bathe the eyes until completely relieved.

\section{THE HOOVE OR BLOWEN FROM PASTURE.}

Causes:- The cause of Cattle becoming bloted, is from being turned into the pasture in the spring of the year, whilst the pasture is young and full of sap, the ox or cow eats greedily and rapidly, so much so that the stomach is unable to propel forward, the portions of food as it is received, and becomes overloaded and clogged, the food remaining in the stomach too long. Then comes the great danger; what you can do must be done at once, or not at all. The symp- 
toms are plain enough, the beast swells to an enormous extent, the breathing is very laborious, and the beast is threatened with suffication froפı the pressure of the stomach on the lungs. The animal is lost unless relief is soon obtained.

REMEDY:-Relief is sometimes obtained from motion and running the beast moderately; sometimes from placing tar, or a tar band into the mouth; sometimes from taking salt and black pepper and throwing it down the throat; somo persons have run a lancet, or pocket knife, into the animal, at the spot passing through the skin, and the wall of the belly, so as to enter the paunch; this should be done midway between the last rib and the haunch bone. Another excelent remedy is $\frac{1}{2}$ oz. Cloride of lime, put into a pint or quart of warm water, and put into the stomach, these generally give immediate relief. There are other remedies, which generally givo relief; such as Lime water-also $1 \frac{1}{2}$ ounces of Hartsbarn may be given, with $1 \frac{1}{2}$ pints of water, or 1 ounce Sulphuric Ether in 1 pint of water. The following is plain and simple, and gives re- lief in almost every case. This has been used extensively, and always given satisfaction. 
ReceIPt:-Take two tablespoonsful Rappee Snuff, 1 gill Vinegar, 1 gill Sweet Milk. Mix well and give as a-drench. This has been thoroughly tried and relieved nineteen cases out of twenty; it is simple and worthy of attention. No time should be lost in this disease; what you can do must be done at once, or not at all.

Preventatives:-Every Farmer should adopt the rule, to feed his cattle the following :

Every morning, take 1 pint air slacked lime, 1 pint ground alum salt-mix well and feed with offall. Every particle of the lime should be slacked. Adopt this rule and you will have little or no trouble with your cattle. Dose from 1 to 2 table-spoonsful every morning; in offall before turning into pasture. Another preventative:-Take ashes, air slacked lime, and ground alum salt, equal portions, and feed every morning, or if you have not the lime, the salt and ashes will do well.

\section{CHOKING.}

Cattle are extremely liable to become choked on turnips, roots, apples, potatoes. 
Rexedy:-Give $\frac{1}{2}$ pint of oil, which will lubricate the passage, then run gag, or tube, or rod, with a knob at the end, down the throat; this should be done carefully, so as not to injure the parts. Should you not give relieí by this means, find the position, or place where the apple, or turnip has lorlged. This may be done by pressing carefully along down the throat; place a block on the one side of the object, then strike a right smart blow with a mallet, or billet of wood, sufficient to crush the apple or object to pieces, which will instantly blowen out, and the animal relieved.

\section{POISONS.}

Little can be done in this, unless you have a pump, so as to extract the poison from the stomach, then follow with physics.

\section{EMBROCATION FOR BITE OF VIPER.}

Take hartshorn, spirits camphor, olive oil, equal quantities-mix and rub the wound, and neighboring parts well, morning and night. 
One pint whiskey, 1 ounce hartshorn, 1 oz. spirits camphor, $\frac{1}{2}$ pint warm water should be given to the animal.

\section{WOUNDS.}

The first thing is.to clean the wound from all dirt and gravel. A good fomentation with warm water will effect this. If the wound is much lacerated, or punctured, we must bring them neatly together. If any portions so torn as to prevent its from doing this completely, they should be removed with a knife, or sharp scissors; then the edges brought together by means of passing a needle and strong waxed twine deeply through them, making two, three or more stitches, half inch from each other. T'hen apply the tincture of myrrh and aloes, and bandage tolerably firm, not so much so as to prevent the circulation. If there should be proud flesh, the wound must be cleansed with a strong solution of blue vitriol, and then dressed with the tincture. All wounds should be first well cleansed, before applying anything on them. 


\section{ANGLE BERRIES OR WARTS.}

These are little warty tumors, growing on various parts of the skin, and sometimes on the teats.

REMEDr:-The eqasiest and shortest way to remove them, is to tie a piece of waxed silk firmly around the base of each, and to tighten them every day; by means of this, the tumor will drop off, and will rarely grow again. To make it certain, the parts should be touched with a hot iron or lunar caustic; the warts should be well scarred, and they will never appear again.

\section{THE FOUL IN THE FOOT.}

The first thing is to examine the wound carefully, and see how far it extends under the hoof or horn. The first step is to clean all the foul or proud flesh, by means of a knife, then apply lunar caustic, or muriatic acid, until the wound becomes healthy and dry. In extreme cases where there is swelling, apply a poultice night and morning, then apply the caustic, and keep 
dry and from all danger of getting dirt and gravel in. When the wound begins to look healthy, apply the tincture of Aloes and Myrrh, until perfectly relieved, and give a gentle purgative.

\section{TO DRY A COW OF HER MILK.}

The best time to dry cows is whilst feeding dry feed. A good dose of physic and after it has operated, follow with an astringent drink, will generally settle the business. Six drachms of alum dissolved in 1 pint water, is a dose. The cow should be milked clean when the astringent is giren; feed on dry food for a few days. Should the udder get very hard in a few days, milk clean and give another astringent drink, and the third may be given if necessary.

\section{THE MANGE.}

This is a troublesome disease among cattle, at times the itching torments the beast wonderfully; causing the cow to fall off in her milk, 
and generally gets thin in flesh, if suffered to remain any length of time. The most effectual application is an ointment, which, sulphur is the principal ingredient.

Mange Onntment:-Take flour of sulphur 1 lb., strong mercurial ointment 2 ounces, common turpentine $\frac{1}{2}$ pint; lard $1 \frac{1}{2} \mathrm{lb}$. Melt the turpentine and lard together well; stir in the sulphur when it begins to cool-when cool, rub the mercurial ointment on a marble slab, with the other ingredients, mix these together. This should be.well rubbed in with the hand daily, wherever there is mange. If in the winter, the animal should not be exposed to serere cold. Give a few doses of physic, with sulphur added to it. Warbles gad fly or ose fly, is quite an annnoyance to the animal. The $\mathrm{fly}^{\circ}$ generally alights on the back, deposits the egg under the skin, causing a tumour to rise the size of an hazel nut, some larger-it soon bursts, leaving a hole on the top, for the grub or worm, which now lives and feeds on the fatty matter.

ResedY:-Squeeze out the worm or grub, by pressing firmly, if this cannot be accomplished, open it with a lancet or knife, and put in a few 
drops spirits turpentine, a few times which will destroy the grub.

\section{RABIES OR HYDROPHOBIA.}

This is a dreadful Disease, produced by the bite of a rabid or mad dog. The symptoms of its approach are dullness, loss of appetite, the eyes protuding and red; is continually voiding urine or dunging, saliva drivels from his mouth: presently weakness of the loins, and staggering appear; sometimes they linger six or seven days, and die. "There is no cure.

Reuedy:-Destroy the animal as soon as possible. Care should be taken that the saliva is not received on a wound; any wound which it has fallen on, should be immediately well burned with lunar caustic. Should you see the rabid dog bite your animal, and find the spot, immediately burn the wound well with the lunar caustic, their is a possibility of their escape. The hair should be clipped of, and every scratch carfully touched with the caustic. 


\section{FOR YOUNG CALVES.}

Should the mother's milk not be sufficient to operate upon the bowels, or not at all, give 1 or 2 ounces Epsom salts; according to the size: dissolve in $\frac{1}{2}$ pint gruel, add a little ginger, and a few drops peppermint, or as you may give Castor oil; if it should be an obstinate case, give an injection, or two of salts dissolved in water, and a little castor oil, this will set all right.

\section{COW POWDERS.}

This is an excelent powder for general derangements of the System. Such as falling off of the milk, dullness, stupidness, stairing of the hair, \&c.

This powder is truly astonishing in its effects on cattle, giving new life and vigor to the animal. No owner of cattle should do without this powder, and should adopt the rule to feed all his cattle, some of the powder, once or twice a year, and especially before commencing to 
36 IIORNED CATTLE.

fatten them. This powder is equally as good for Sheep. Take

$\frac{1}{2}$ pound gentian root,

$\frac{1}{2}$ " flour of brimstone,

$\frac{1}{2}$ " fenugreek,

$\frac{1}{2}$ " rosin,

$\frac{1}{2}$ " copperas,

$\frac{1}{4}$ " cream of tartar,

$\frac{1}{2}$ " epsom salts,

$\frac{1}{2}$ " juniper berries,

$\frac{1}{2}$ " spice berries,

$\frac{1}{4}$ "6 salts nitre,

$\frac{1}{2}$ " ginger,

$\frac{1}{4}$ " caraway seed,

$\frac{1}{4}$ " aniseed,

2 oz. antimony,

2 oz. columbo,

1 oz. gum assafœetida,

2 oz. alum,

Pulverize these articles fine and mix well, and it is ready for use. Any of the above articles can be had at any Drug Store.

Directions for UsE:-Dose for a full grown animal, one table-spoonful once or twice a day, as the case may require. 
This powder cannot be excelled, it is an excellent medicine for all derangements of the system, it is perfectly harmless, and should be fed sometime in all chronic and lingering diseases, or at least until entirely relieved, and the system put in perfect health. No animal can thrive unless in health. Therefore every farmer should adopt the rule to feed all his stock, and especially those which he wishes to fatten with some of these powders; by so doing you will save feed and time. In fattening, feed on offal.

Directions:-For a full grown sheep, dose, 1 tea-spoonfull once or twice a day, as the necessity of the case may require. Feed on offel. 



\section{T N DEX}

\section{To \\ DISEASES OF HORSES.}

Bots or Grubs........................................ PAGE. 2526

Brood Mares......................................................... 57

Chest Founder........................................................... 39

Chronic Cough.................................................... 45

Ears ................................................................... 30

Enlargement of the Hock.............................................. 48

Epidemics............................................................... 44

Eyes.................................................................... 29

Flatulent Colic...................................................9 1011

Founder Acute..................................................52 5354

Grease ...........................................................50 51

Inflammation .................................................. $40 \quad 4142$

Bladder.....................................................15 16

Bowels.............................................222 2324

Feet..............................................52 5354

Kidneys ................................................ 17

Larnyx ................................................434 44

Lungs...........................................18 $1920 \quad 21$

Injury of the Eyes..................................................... 34

Lampass.............................................................. 35

Nembranes of the Nose.............................................27 28

Physicing ............................................................ 47

Poll Evil............................................................5 $677^{7} 8$

Process of Teething...........................................36 $37 \quad 38$

Rabies or Madness................................................. 33

Restiveness or taming Horses...................................55 56

Spasmodic Colic..................................................12 $13 \quad 14$

Sprain of Back Sinews................................................ 48

— of Coffin Joint.............................................. 49

Staggers.............................................................31 22

Thick or Broken Wind............................................. 46

Warts ................................................................. 58 


\section{N D E X}

TO

\section{RECEIPTS BELONGING TO THE HORSE.}

A Good Horse Powder..... ..................................... 68

Arabian Oil for Horses......................................... 61

Blistering........................................................... 69

Ointment............................................ 71

Celebrated Horse Powders........................................60 61

Cooling lotion for inflammation............................... 74

Cure for Ring Bone............................................. 71

Blood or Bog Sparin..................................... 68

Black Tongue.................................................. 63

Bots .....................................................62 90

Distemper....................................................... 66

Galds on Horses............................................ 61

Sweaney .............................................74 $75 \quad 76$

Urine Bound................................................. 65

Embrocation for the Throat .................................... 67

For the Blacksmith............................................... 89

Hoof Ointment..................................................... 66

How to throw a Horse................................. $77 \quad 78 \quad 79 \quad 80$

to break a kicking Horse...........................85 $86 \quad 87 \quad 88$

to make a Horse follow you............................... 91

to learn him to stand still.................................. 92

Infallible Lotion for Bruises, \&c................................ 63

Liniment for Sprains.......................................... 73

Lotion for Scratches or Grease................................. 64

Quiet or Tame Horses............................................ 64

Rules for a Horse that Shies.............................81 $82 \quad 83 \quad 84$

Spirits of Pimento................................................ 72

Tincture, Aloes and Myrrh..................................... 70

Iodine....................................................... 73

Opium ................................................... $7_{0}$

To make Elder Ointment........................................... 67

Treatment of Founcer............................................ 65 


\section{N D E X}

TO

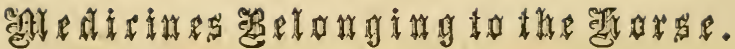

Alcohol.............................................................. 94

Aloes................................................................. 95

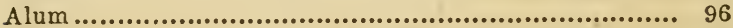

Antimony ....................................................... 93

Acqua-Fortis ................................................... 94

Balls or Pills........................................................ 98

Cantharides....................................................... 97

Charcoal................................................................. 97

Chloride of Lime................................................ 107

Clysters ......................................................... 99

Common Salt..................................................... 106

Digitalis.......................................................... 100

Drinks and Drenches............................................... 104

Fomentations..................................................... 102

Gentian .......................................................... 102

Ginger .......................................................... 101

Liniments...................................................... 105

Linseed.............................................................. 99

Mashes............................................................... 101

Muriatic Acid ...................................................... 96

Mustard ............................................................ 96

Opium ................................................................ 103

Pitch.................................................................. 100

Poultices.......................................................... 103

Spasmodics........................................................... 93

Spirits of Camphor............................................. 93

Sulphur ............................................................... 105

Sulphuric Acid.................................................. 95

Tar .............................................................. 104

Turpentine ........................................................... 106

Thompson's No. 6.................................................. 108

Vinegar................................................................. 94

Zine or Calamine Powder......................................... 108 



\section{INDEX}

\section{T0 \\ DOMESTIC MEDICINES.}

American Helebore.................................................. 112

Columbo................................................. 118

Gentuary.............................................. 121

Black Alder............................................................... 119

Blood or Percoon Root......................................... 122

Boneset or Thoroughwort....................................... 123

Bitter Root or Silkweed.......................................... 124

Boiled Cider........................................................... 166

Black Ink....................................................171 172

Black or Dewberry Wine....................................... 169

Black or Dewberry Cordial........................................ 168

Compost to prevent Crows from Corn.......................... 204

Clay Poultice for Man or Horse.................................. 200

Cure for bite of Mad Dog....................................... 200

- for Bite of Snake............................................... 200

for Bronchitis................................................ 196

for Cancer.......................................................... 164

for Felon,....................................................... 195

Cox's Hive Syrup.................................................... 187

Cologne Water.......................................................... 178

Cherry Brandy................................................... 167

Consumer............................................................ 129

Compound Tincture of Gentian................................. il

Cement for Grafting................................................. 115

Cement to Mend Glass............................................. 111

Dandeline...................................................... 121

Dr. Wickeys' Cholera Medicine.....................148 149150151

Domestic Tonic.................................................... 201

Domestic Yeast........................................................ 204

Dr. Young's Pills................................................. 186

Domestic Cough Syrup........................................... 189

Essence of Cinnamon.............................................. 194 
Eye Water....................................................... 194

Essence of Peppermint.............................................. 193

Essence of Lemon.......................................... 193

Extempore Gaseous Chalybeate Water.......................... 125

- Emetic for Poison................................................ 113

French Patent Oil Varnish...................................... 187

Furniture Polish.............................................. 192

Gas Beer........................................................ 169

Great Salve for Wounds, \&c................................... 190

Grease for Carriages, \&c...................................... 197

Guaiacum, Amoniated Tincture............................. 115

Gentian ......................................................... 126

Green Ointment............................................ 201

Ileal th, Its Value \&c........................................138 to 142

How to Prolong Life......................................143 to 146

How to Keep Apples............................................ 203

How to destroy Lice on Chickens............................... 205

Indian Turnip.................................................... 113

Indellible Ink................................................... 171

Judkins' Ointment............................................ 162

lieep Cider sweet................................................ 165

Liquid Opodeldoc.......................................... 147

Lunar Caustic................................................... 111

Make Honey. without Bees........................................ 161

Make Soft Soap................................................. 191

Ointment for Scrofulus Ulcers................................ 201.

Piles............................................................. 164

Prof. Biddle's Celebrated Preparation.......................174 175

Preserve Butter............................................... 180

Pickel Cucumbers............................................... 181

Preserve Peaches............................................. 182

Preserve Plumbs................................................ 182

Pleurisy Root.................................................. 125

Pickling Pears................................................... 130

Preservation of the Health................................131 to 137

Patent Black Japan............................................. 191

Plague Blister .................................................. 198

Remedies for Rheumatism................................152 to 160

Receipt for Humors on Children................................. 199

Receipt for Hogs.............................................. 197 
Rattleweed Root................................................ 127

Remedy for Bite of a Snake..................................... 163

Red Ink................................................. 171

Restore the Hair in Baldness.................................. 176

Remedy for Itch........................................185 186

Soap to Take Grease out of Cloth, \&c.......................183 184

Soft Ginger Bread.................................................. $181^{\prime}$

Silver Top Drink........................................... 170

Simple Syrup of Rhubarb.................................... 117

Tincture of Rhubarb................................... 117

Seneca Snake Root............................................... 114

Soda Powders................................................. 190

Transplanting T'rees............................................. 200

Tincture of Peach Kernels........................................ 202

The Prickley Ash.............................................. 120

Toothache Balsam................................................ 177

Drops................................................... 179

Tooth Powder................................................... 177

Transparent Soap.................................................. 173

White Strelling............................................. 165

Washing Fluid................................................ 172

Worth knowing.............................................. 205 



1,

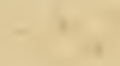

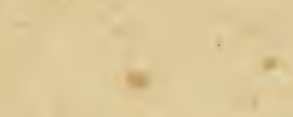
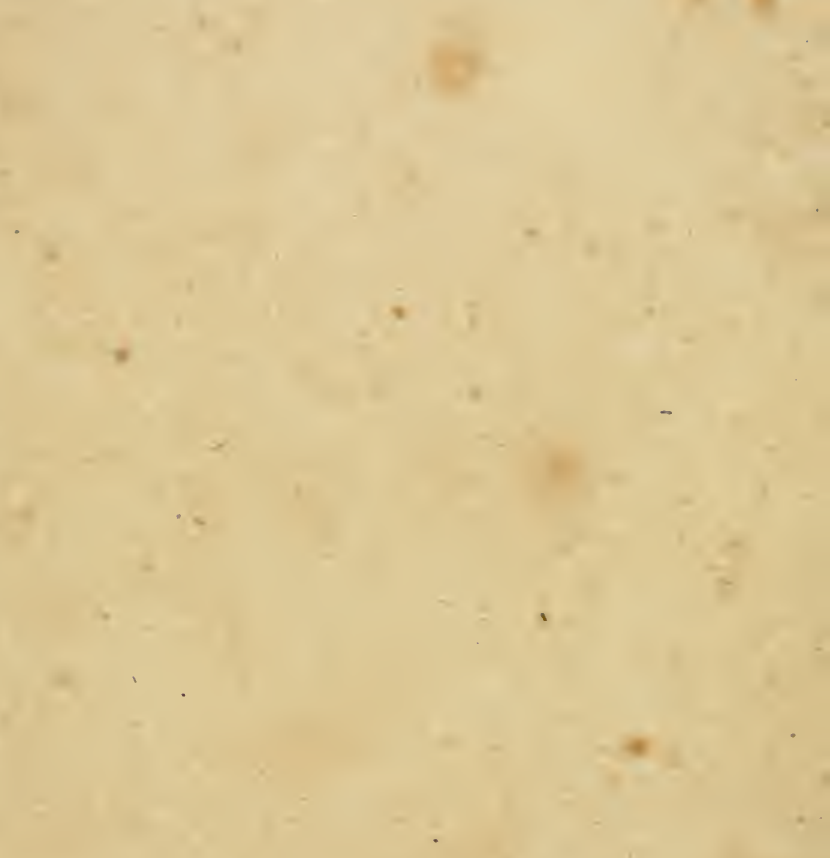

(1)

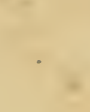





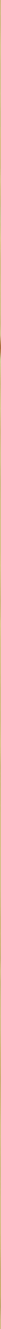




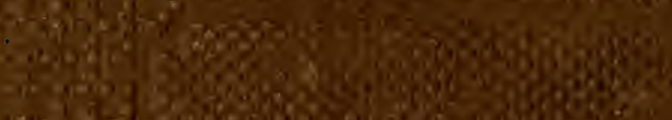

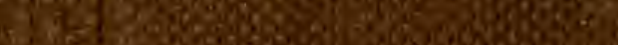

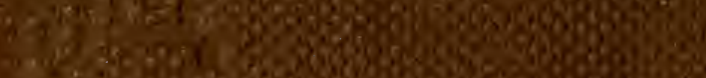

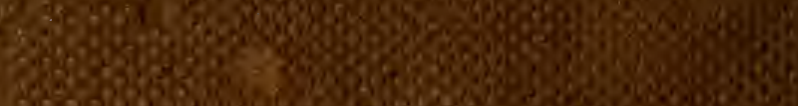

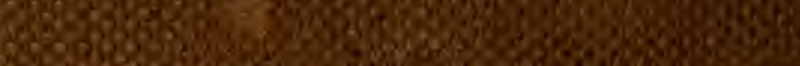

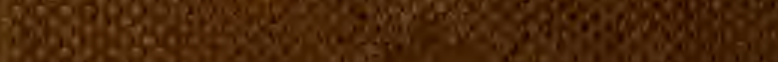

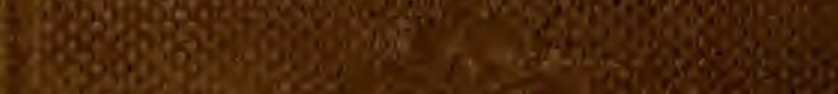

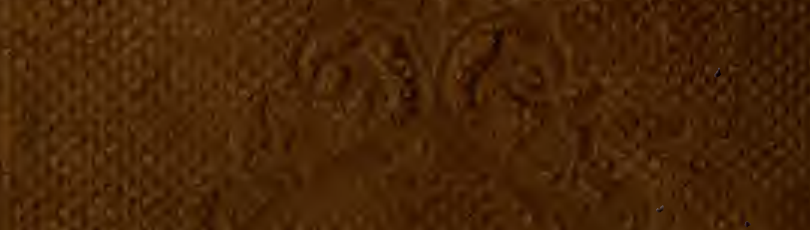

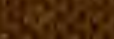

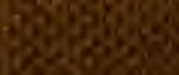

(4) 10

$$
\text { 16: } 19
$$

28. 13.

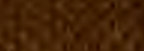

$1,1,1$,

ais

, 192

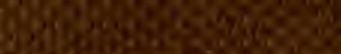

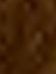

$$
\sqrt{4}
$$$$
\left(x^{1}, 2,2,2,2\right.
$$

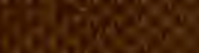

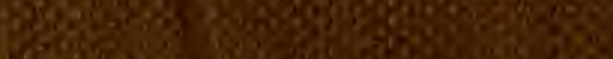

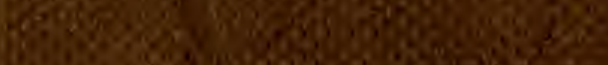

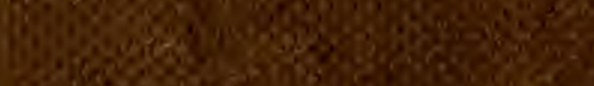

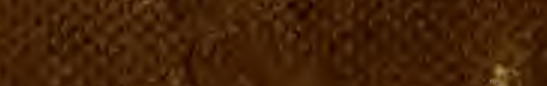

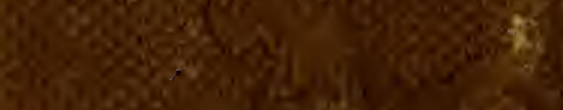

